University of Tennessee Health Science Center UTHSC Digital Commons

\title{
Uncovering p53 Mutations and Abnormal Gene Expression in Pediatric Adrenocortical Cancer
}

\author{
Alina Nico West \\ University of Tennessee Health Science Center
}

Follow this and additional works at: https://dc.uthsc.edu/dissertations

Part of the Medical Genetics Commons, and the Neoplasms Commons

\section{Recommended Citation}

West, Alina Nico, "Uncovering p53 Mutations and Abnormal Gene Expression in Pediatric Adrenocortical Cancer" (2007). Theses and Dissertations (ETD). Paper 293. http://dx.doi.org/10.21007/ etd.cghs.2007.0347.

This Dissertation is brought to you for free and open access by the College of Graduate Health Sciences at UTHSC Digital Commons. It has been accepted for inclusion in Theses and Dissertations (ETD) by an authorized administrator of UTHSC Digital Commons. For more information, please contact jwelch30@uthsc.edu. 


\title{
Uncovering p53 Mutations and Abnormal Gene Expression in Pediatric Adrenocortical Cancer
}

\author{
Abstract \\ Pediatric adrenocortical cancer is extremely rare and often fatal (approximately 0.3-0.4 cases per million \\ worldwide; $50 \% 5$-year survival). The incidence of pediatric adrenocortical cancer in southern Brazil is \\ 10-15 times higher than the worldwide incidence. Due to the rarity of adrenocortical cancer, especially in \\ children, underlying gene dysregulation and mechanisms of tumorigenesis of the adrenal gland are very \\ poorly described in the literature. However, it is well-known that the tumor suppressor p53, which is \\ mutated in over $50 \%$ of all human cancers, is commonly mutated in pediatric adrenocortical cancer. In \\ addition, evidence strongly suggests that if a child has adrenocortical cancer, it indicates a germline p53 \\ mutation exists. \\ In order to provide an understanding of the etiology and the biology of this disease, blood and tumor \\ samples from 35 pediatric adrenocortical tumor patients, including 24 from southern Brazil, were \\ screened for p53 mutations. Matched blood and tumor samples were obtained as available. Of the 35 \\ patient samples screened, 24 samples were entered into a novel gene expression study that exclusively \\ investigated gene dysregulation in pediatric adrenocortical cancer; the first study of its kind. Overall \\ findings from this study reveal the importance of screening for germline p53 mutations and provide \\ fundamental insight into pediatric adrenocortical cancer. \\ Document Type \\ Dissertation \\ Degree Name \\ Doctor of Philosophy (PhD) \\ Program \\ Interdisciplinary Sciences \\ Research Advisor \\ Gerard P. Zambetti, Ph.D. \\ Keywords \\ pediatric adrenocortical cancer, p53 mutations, gene expression

\section{Subject Categories} \\ Diseases | Medical Genetics | Medical Sciences | Medicine and Health Sciences | Neoplasms
}




\title{
UNCOVERING p53 MUTATIONS AND ABNORMAL GENE EXPRESSION IN PEDIATRIC ADRENOCORTICAL CANCER
}

\author{
A Dissertation \\ Presented for \\ The Graduate Studies Council \\ The University of Tennessee \\ Health Science Center
}

\author{
In Partial Fulfillment \\ Of the Requirements for the Degree \\ Doctor of Philosophy \\ From The University of Tennessee
}

By

Alina Nico West

December 2007 
Chapter 2 ( 2006 by The American Association for Cancer Research Chapter $3 @ 2007$ by The American Association for Cancer Research All other material $@ 2007$ by Alina Nico West 


\section{DEDICATION}

This dissertation is dedicated to my parents,

Ms. Cecelia Jacob and Mr. Robert West,

my sister, Ms. Rebecca West,

and my late grandmother, Mrs. Annie L. Johnson,

for their love and support. 


\section{ACKNOWLEDGEMENTS}

I would like to thank Dr. Gerard Zambetti for allowing me to work in his laboratory on an extraordinary research project under his mentorship. I am extremely grateful for all of the opportunities he has presented to me. I would like to thank the lab - Mr. Rob Jeffers, Mrs. JinLing Wang, Dr. Eun-Hee Shim and Dr. Sean Garrison - for all of their suggestions and advice and for making my research experience at St. Jude Children's Research Hospital so much more valuable.

I would like to thank the collaborators on the Pediatric Adrenocortical Tumor project: Drs. Raul Ribeiro, Carlos Rodriguez-Galindo, Bonald Figueiredo, Richard Kriwacki, Enzo Lalli, David Malkin, and Geoffrey Neale. I have held the communications with these individuals in extremely high regard during my graduate career because without such collaborations, this project would not have been possible.

All studies were supported by grants from the $\mathrm{NIH} / \mathrm{NCl} \mathrm{CA} 63230$ and CA71907 (Dr. Gerard Zambetti), Cancer Center CORE Grant CA21765, and by the American Lebanese Syrian Associated Charities (ALSAC). Studies presented in Chapter 2 were additionally supported by CA104568 (Dr. Richard Kriwacki).

Studies presented in Chapter 3 were additionally supported by Fondation pour la Recherche Médicale and L'Association pour la Recherche sur le Cancer (Dr. Enzo Lalli) and the National Cancer Institute of Canada with funds from the Canadian Cancer Society (Dr. David Malkin). 


\begin{abstract}
Pediatric adrenocortical cancer is extremely rare and often fatal (approximately 0.3-0.4 cases per million worldwide; $50 \%$ 5-year survival). The incidence of pediatric adrenocortical cancer in southern Brazil is 10-15 times higher than the worldwide incidence. Due to the rarity of adrenocortical cancer, especially in children, underlying gene dysregulation and mechanisms of tumorigenesis of the adrenal gland are very poorly described in the literature. However, it is well-known that the tumor suppressor p53, which is mutated in over $50 \%$ of all human cancers, is commonly mutated in pediatric adrenocortical cancer. In addition, evidence strongly suggests that if a child has adrenocortical cancer, it indicates a germline p53 mutation exists.

In order to provide an understanding of the etiology and the biology of this disease, blood and tumor samples from 35 pediatric adrenocortical tumor patients, including 24 from southern Brazil, were screened for p53 mutations. Matched blood and tumor samples were obtained as available. Of the 35 patient samples screened, 24 samples were entered into a novel gene expression study that exclusively investigated gene dysregulation in pediatric adrenocortical cancer; the first study of its kind. Overall findings from this study reveal the importance of screening for germline p53 mutations and provide fundamental insight into pediatric adrenocortical cancer.
\end{abstract}




\section{TABLE OF CONTENTS}

$\begin{array}{ll}\text { Chapter 1. Introduction } & 1\end{array}$

1.1 The Discovery of p53 1

1.2 The Tumor Suppressor p53 3

1.2.1 The Protein Structure of p53 3

1.2.1.1 The Transactivation Domain 4

1.2.1.2 The Proline-Rich Domain 4

1.2.1.3 The DNA-Binding Domain 5

1.2.1.4 The Tetramerization Domain 6

1.2.1.5 The C-Terminal Domain $\quad 7$

1.2.2 p53 Translocation 9

$\begin{array}{ll}\text { 1.2.3 Regulation and Activation of p53 } & 11\end{array}$

1.2.3.1 p53 Activation via Post-Translational Modifications 11

1.2.3.1.1 p53 Activation via PIKK Phosphorylation $\quad 11$

1.2.3.1.2 p53 Phosphorylation by Non-PIKK

Family Members $\quad 15$

1.2.3.1.3 p53 Activation via Acetylation $\quad 16$

1.2.3.1.4 p53 Activation via Sumoylation 17

1.2.3.1.5 Oncogenic Activation of p53 17

1.2.3.2 Negative Regulation of p53 20

1.2.4 p53 Responses to Cellular Stress 21

1.2.4.1 p53-Mediated Cell Cycle Arrest 22

1.2.4.2 p53-Mediated Apoptosis 23 
$\begin{array}{ll}1.3 \text { Li-Fraumeni Syndrome } & 27\end{array}$

1.3.1 Clinical Characteristics of LFS and LFLS 27

1.3.2 Germline p53 Mutations and LFS and LFLS 28

1.4 Pediatric Adrenocortical Cancer 30

1.4.1 Clinical Characteristics of Pediatric Adrenocortical Cancer $\quad 30$

1.4.2 Biology of Pediatric Adrenocortical Cancer 32

$\begin{array}{ll}\text { 1.4.3 Purpose } & 36\end{array}$

Chapter 2. Identification of a Novel Germline Variant Hot Spot Mutant p53-R175L in Pediatric Adrenocortical Carcinoma 37

$\begin{array}{ll}2.1 \text { Introduction } & 37\end{array}$

$\begin{array}{ll}2.2 \text { Materials and Methods } & 40\end{array}$

2.2.1 DNA Analysis $\quad 40$

2.2.2 Transactivation Assay 41

2.2.3 Apoptosis Assay 42

2.2.4 Colony Reduction Assay 43

2.2.5 Protein Analysis 43

2.2.6 Tissue Preparation and Immunohistochemistry 44

2.3 Results $\quad 45$

2.3.1 Identification of the Germline p53-R175L Mutation Associated with ACC $\quad 45$

2.3.2 Elevated Expression of Mutant p53-R175L in ACC 48

2.3.3 In Vitro Characterization of Mutant p53-R175L Function 48

$\begin{array}{ll}\text { 2.3.3.1 Transactivation } & 48\end{array}$

2.3.3.2 Growth Suppression $\quad 51$ 
Chapter 3. Gene Expression Profiling of Childhood Adrenocortical Tumors

3.1 Introduction

3.3.2 Gene Expression Profiling Distinguishes Adrenocortical Tumors from Normal Adrenal Tissue

3.3.3 Validation of the Gene Expression Dataset

3.3.4 Cell Origin of the Pediatric Adrenocortical Tumors

3.3.5 Comparison between Adult and Pediatric Adrenocortical Tumors

3.3.6 Differences between Pediatric Adrenocortical Carcinoma and Adenoma 
$\begin{array}{ll}4.1 \text { Introduction } & 91\end{array}$

4.2 The Impact and Future of p53 Mutation Screening on Genetic Counseling for Pediatric Adrenocortical Cancer Patients and Their Families

4.3 Future Importance of Gene Expression Profiling for Pediatric Adrenocortical Cancer Patients

List of References

Appendix A. Chapter 2 Supplemental Data

Appendix B. Chapter 3 Supplemental Data

Vita 


\section{LIST OF TABLES}

Table 3-1. Clinical Data of 24 Pediatric Adrenocortical Cancer Patients

Table 3-2. Dysregulated Genes in Pediatric ACT 77

Table B-1. qRT-PCR Primer Set Sequences and PCR Conditions 


\section{LIST OF FIGURES}

Figure 1-1. Functional and Structural Domains of the p53 Protein 3

Figure 1-2. ATM Activation of p53-Induced Cell Cycle Arrest 13

Figure 1-3. Rb-E2F-ARF and ARF-MDM-2-p53 Pathways 19

Figure 1-4. p53-Mediated Apoptosis 26

Figure 2-1. Pedigree of the p53-R175L Family 46

Figure 2-2. DNA Sequencing Analysis of the Germline p53-R175L Mutation Associated with Adrenocortical Carcinoma $\quad 47$

Figure 2-3. p53 Immunohistochemistry of R175L Tumor 49

Figure 2-4. Transactivation of the Wild-Type p53 Responsive Promoter-Luciferase Reporter by WTp53 and Mutant p53 Proteins

Figure 2-5. p53 Colony Reduction Assay 52

Figure 2-6. p53 Apoptosis Assay 54

Figure 2-7. Quantitation of p53 Apoptosis Assay 55

Figure 2-8. Structural View of R175L Mutation within p53 DNA Binding Domain (DBD) 57

Figure 3-1. Heat Map and Hierarchical Clustering Analysis Comparing Pediatric Adrenocortical Tumor and Normal Cortex

Figure 3-2. Dysregulation of IGF-II Gene Expression in Pediatric Adrenocortical Cancer

Figure 3-3. Dysregulation of HSD3B2 Gene Expression in Pediatric Adrenocortical Cancer

Figure 3-4. Comparisons of Pediatric ACT Gene Expression Profiles to Adult ACT and Fetal Adrenal Cortex Gene Expression Profiles 
Figure 3-5. Heat Map of Differentially Expressed Genes Comparing Pediatric Adrenocortical Carcinomas and Adenomas

Figure 3-6. Three-Dimensional Scaling of ACC and ACA Samples by Principle Component Analysis

Figure A-1. Transactivation of the Wild-Type p53 Responsive Promoter-Luciferase Reporter by WTp53 and Mutant p53 Proteins in 10(1) Cell Line

Figure A-2. p53 Colony Reduction Assay Using Increased Plasmid Dose

Figure A-3. Quantitation of p53 Apoptosis in H1299 Cell Line

Figure B-1. NOV Gene Dysregulation in Pediatric Adrenocortical Cancer

Figure B-2. Dysregulation of NR4A1 Gene Expression in Pediatric Adrenocortical Cancer

Figure B-3. NR4A2 Gene Dysregulation in Pediatric Adrenocortical Cancer 


\section{LIST OF ABBREVIATIONS}

A

a.a.

$\mathrm{Ab}$

ACA

ACC

ACT

Ad

AML

APAF-1

ARF

Arg

A-T

ATM

ATR

BAK

BAX

BCA

BCL2

BCL-XL

bFGF2

$\mathrm{BH} 3$

BLM

BRCA1

BRCA2

BWS

C- Terminus

CBP/p300

CD4+

CDC25A

CDK1

CDK9

CDKN1C

cDNA

CHK1

CHK2

CK1

CK2

CMV

CMV-Neo-Bam

CNS

CTD

Cys
Alanine

amino acid(s)

Antibody

Adrenal Cortical Adenoma

Adrenal Cortical Carcinoma

Adrenal Cortical Tumor(s)

Adenoma

Acute Myeloid Leukemia

Apoptotic Protease Activating Factor 1

Alternative Reading Frame

Arginine

Ataxia-Telagectasia

Ataxia-Telangectasia Mutated-1

ATM-Rad3-Related

BCL2 Antagonist Killer 1 BCL2-Associated X

Bichoninic Acid

B-Cell CLL/Lymphoma 2

BCL2-Related Protein, Long Isoform

Basic Fibroblast Growth Factor 2

BCL-2 homology domain-3

Bloom Syndrome

Breast Cancer 1 gene

Breast Cancer 2 gene

Beckwith Wiedemann Syndrome

Carboxy Terminus

CREB binding protein/ E1A protein 300

Cluster of Differentiation 4 positive

Cell Division Cycle 25 A

Cyclin-Dependent Kinase 1

Cyclin-Dependent Kinase 9

Cyclin-Dependent Kinase Inhibitor 1C complementary DNA Checkpoint Kinase 1 Checkpoint Kinase 2 Casein Kinase 1 Casein Kinase 2 Cytomegalovirus

Cytomegalovirus- Neomycin-Bam HI Central Nervous System Carboxy Terminal Domain

Cysteine 


\begin{tabular}{|c|c|}
\hline D & Aspartic Acid \\
\hline DBD & DNA binding domain \\
\hline DSB & Double strand breaks \\
\hline DDT & Dichloro-Diphenyl-Trichloroethane \\
\hline DHEA-S & Dihydroepiandrosterone sulfate \\
\hline DMEM & Dulbecco's Modified Eagle's Medium \\
\hline DNA-PK & DNA-activated protein kinase \\
\hline ER & Estrogen Receptor \\
\hline $\mathrm{F}$ & Phenylalanine \\
\hline FADD & Fas-Associated Death Domain \\
\hline FBS & Fetal Bovine Serum \\
\hline FDR & False Discovery Rate \\
\hline FGFR1 & Fibroblast Growth Factor Rec \\
\hline FGFR4 & Fibroblast Growth Factor Recepto \\
\hline G & Gly \\
\hline g & \\
\hline GADD45 & Growth Arrest- and DNA Damage-Inducib \\
\hline GFP & Green Fluorescent P \\
\hline $\mathrm{H} 2 \mathrm{O} 2$ & Hydrogen Perox \\
\hline HAT & Histone Acetyl Transfer \\
\hline HDM2 & Human Double Minute 2 \\
\hline His & Histi \\
\hline HLA-DPA1 & Human Leukocyte Antigen DP Alpha 1 \\
\hline HLA-DPB1 & Human Leukocyte Antigen DP Be \\
\hline HLA-DRA1 & Human Leukocyte Antigen DR Alpha 1 \\
\hline HLA-DRB1 & Human Leukocyte Antigen DR Beta 1 \\
\hline HPV & Human Papilloma Virus \\
\hline HRP & Horseradish Peroxid \\
\hline HSD3B2 & 3-beta Hydroxysteroid Dehydrogenase, Ty \\
\hline hsp & heat sho \\
\hline I & Isoleu \\
\hline IGF1R & Insulin Growth Factor Receptor \\
\hline IGF2R & Insulin Growth Factor Recepto \\
\hline IGF-II & Insulin Growth Factor II \\
\hline INHA & Inhibin A \\
\hline IPACTRB & International Pediatric Adrenal Cortical Tumor Registry and \\
\hline IRB & Institutional Review Bc \\
\hline K & \\
\hline KCNQ1 & Potassium Channel, Voltage-Gated, KQT-Like Subfamily, Mem \\
\hline $\mathrm{kDa}$ & kiloDá \\
\hline L & Leuc \\
\hline LFLS & Li-Fraumeni-Like Synd \\
\hline LFS & Li-Fraumeni Syndrom \\
\hline $\mathrm{LOH}$ & Loss of Heteroz \\
\hline LSAB & Labeled StrepAvidin-E \\
\hline M & \\
\hline
\end{tabular}


MCL1

MDM-2

MDMX

MEF

Met

MethA

$\mathrm{MHC}$

$\mathrm{ml}$

$\mathrm{mm}$

$\mathrm{mM}$

MOMP

$\mathrm{N}$

NCBI

NES

NGFIB

NLS

NO

NOR

NOV

NR4A1

NR4A2

NR5A1

$\mathrm{N}-$ Terminus

NURR1

$\mathrm{P}$

p21

p53

p53AIP

pAb

PBL

PBS

PgR

PIKK

PMAIP

PRD

Pro

$\mathrm{Pu}$

PUMA

PXXP

Py

qRT-PCR

$\mathrm{R}$

$S$

SDS-PAGE

SF1

$\mathrm{SH} 3$
Myeloid Cell Leukemia 1

Murine Double Minute-2

Murine Double Minute X Mouse Embryonic Fibroblast Methionine

Methylcholanthrene

Major Histocompatibility Class

milliliter

millimeter milliMolar

Mitochondrial Outer Membrane Permeability Asparagine National Center for Biotechnology Information

Nuclear Export Signal Nerve Growth Factor IB Nuclear Localization Signal

Nitric Oxide

Normal

Nephroblastoma Overexpressed Nuclear Receptor Subfamily 4, Group A, Member 1 Nuclear Receptor Subfamily 4, Group A, Member 2 Nuclear Receptor Subfamily 5, Group A, Member 1

Amino Terminus

Nuclear Receptor-Related 1

Proline

protein 21

Tumor Suppressor protein 53 p53 apoptosis-inducing gene phosphoantibody

Peripheral Blood Lymphocytes

Phosphate Buffered Saline

Progesterone Receptor phosphoinositide-3 like kinase kinases Phorbol-12-Myristate-13-Acetate-Induced-Protein

Proline-Rich Domain

Proline

Purine

p53 Upregulated Modulator of Apoptosis

Proline- $X$ amino acid-X amino acid-Proline

Pyrimidine

quantitative Real-Time Polymerase Chain Reaction

Arginine

Serine

Sodium Dodecyl Sulfate- Polyacrylamide Gel Electrophoresis

Steroidogenic Factor 1

Src Homology 3 
SJCRH

SUMO-1

SV40

TAD

TAF

TNFR

TP53

TRADD

U

Unk

UV

$\mathrm{V}$

W

WTp53

$\mathrm{Zn}^{2+}$

$\Delta \Delta \mathrm{cT}$

$\mu \mathrm{g}$
St. Jude Children's Research Hospital Small Ubiquitin-like Modifier 1

Simian Virus 40

Transactivation Domain

TATA Binding Protein Associated Factor Tumor Necrosis Factor Receptor Tumor Suppressor p53 gene Tumor Necrosis Factor Receptor 1-Associated Death Domain protein unit(s) Unknown Ultraviolet Valine Tryptophan Wild Type p53

Zinc

delta delta Cycle Threshold microgram 


\section{CHAPTER 1: INTRODUCTION}

\subsection{The Discovery of p53}

A tumor suppressor is defined as the wild-type form of a gene that plays a crucial regulatory role in cellular growth, proliferation, and differentiation and whose loss of function results in oncogenic processes. These processes encompass the overall positive regulation of cellular proliferation through several factors called proto-oncogenes that include signal transducers, transcription factors, and growth factors and their receptors. When proto-oncogenes succumb to alterations such as mutation and overexpression, which compromise their normal regulatory function on cellular proliferation resulting in dysregulated growth and transformation, they are called oncogenes. Tumor suppressors are recognized through their negative actions on oncogenic transformations in order to maintain normal cellular function and chromosomal stability (1).

The TP53 gene encodes the tumor suppressor protein $\mathrm{p} 53$, discovered in 1979 by three groups. David Linzer and Arnold Levine demonstrated that a 54kDa protein co-precipitated with large $\mathrm{T}$ antigen in whole cell lysates of simian virus 40 (SV40)-infected murine cell lines (2). Around the same time, it was shown by David Lane and Lionel Crawford that a $53 \mathrm{kDa}$ protein immunoprecipitated with large T antigen in cellular extracts from a murine SV40transformed cell line (3). In 1979, DeLeo, et al. coined the term "p53" and detected the $53 \mathrm{kDa}$ protein using antisera produced in mice that developed sarcomas after chemical induction by the polycyclic hydrocarbon and carcinogen, 
methylcholanthrene (MethA) (4). The protein p53 was described by all three groups as a tumor antigen due to its detection in either chemically or virallyinduced tumors (2-4). Shortly following these murine tumor studies, p53 was detected in human tumor cell lines (5).

Until the early 1990's, the function of p53 was unknown. Some reports implied p53 functioned as a potential oncoprotein because it induced cellular transformation. In a study by Eliyahu et al., rat embryonic fibroblasts were transiently co-transfected with a plasmid (pMSVp53G) containing a p53 cDNA and the human HA-RAS gene in order to examine the oncogenic effects of p53 on primary cells (6). Indeed, it was shown that p53 and HA-RAS were able to promote cellular transformation. The result was similar to studies in which cotransfection of primary cells with the MYC and HA-RAS oncogenes result in cellular transformation (7). However, it was discovered a few years later that the p53 cDNA used to construct the pMSVp53G plasmid contained a mutation at codon 135 resulting in a valine to alanine amino acid substitution $(\mathrm{V} 135 \mathrm{~A})(8,9)$. It was also established that cell lines from fibrosarcomas arising in mice treated with MethA had the V135A mutation, which participates with RAS in oncogenic transformation (10). Almost a decade following its discovery, these findings led to the conclusion that p53 was a tumor suppressor $(8,9,11,12)$. 


\subsection{The Tumor Suppressor p53}

\subsubsection{The Protein Structure of p53}

The human p53 protein is 393 amino acids long and is divided into five functional domains: the transactivation, proline-rich, DNA-binding, tetramerization, and basic domains. In addition, there are five structurally conserved regions located between the transactivation and DNA-binding domains (Fig. 1-1) (13-16).

The TP53 gene is evolutionarily conserved in rodents, fish, primates, vertebrates, and mammals (13). Mutations that arise within the five conserved regions of the TP53 gene are representative of high "evolutionary constraint" (17). Overall structural functions of the p53 domains include maintaining stability

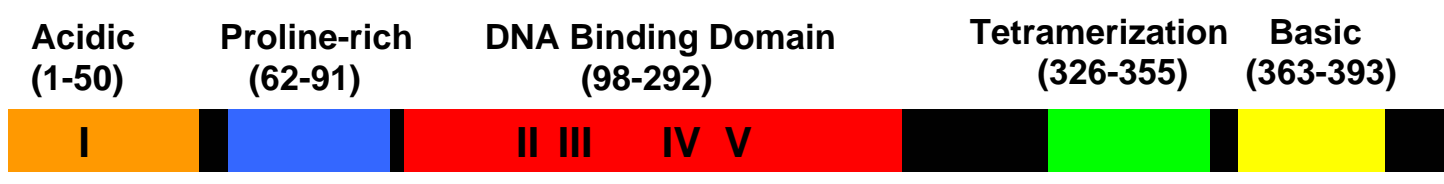

N

C

Figure 1-1. Functional and Structural Domains of the p53 Protein. The p53 protein contains five functional domains: acidic or transactivation (amino acids 150; shown in orange), proline-rich (amino acids 62-91; shown in blue), DNAbinding domain (amino acids 98-292; shown in red), tetramerization domain (amino acids 326-355; shown in green), and the basic C-terminal domain (amino acids 363-393; shown in yellow). The protein is also comprised of five structurally conserved domains: I (amino acids 13-23), II (amino acids 117-142), III (amino acids 171-181), IV (amino acids 234-258), and V (amino acids 270-286). 
of the p53 protein and establishing DNA contact of p53 downstream targets in response to cellular stress (16).

\subsubsection{The Transactivation Domain}

The N-terminal transactivation domain (TAD) is represented by amino acid residues $1-42$. Only one of the five structurally conserved domains of p53 is located in the TAD between amino acid residues 13 and 23. Specific residues in the conserved region of the TAD are post-translationally modified for p53 gene regulation and include contact sites between residues 18 and 26 for its negative regulator, Murine Double Minute-2 (MDM2). In addition, the p53 transactivation domain interacts with proteins such as histone acetyl transferases, which foster transcriptional activation of p53 [reviewed by $(14,16,18)]$.

\subsubsection{The Proline-Rich Domain}

The proline-rich domain (PRD) lies adjacent to the transactivation domain between amino acid residues 62 and 91. It contains five PXXP motifs which serve as the consensus sequence for binding Src-homology $3(\mathrm{SH} 3)$ domains. In addition, the proline-rich domain contains 15 proline residues. It was demonstrated that if PRD amino acid residues 62-91 are deleted, p53 cannot efficiently suppress cellular growth via apoptosis (19), even though the protein retains the ability to transactivate p53 target genes, including p2 $21^{\text {WAF } 1 / C I P 1}$, MDM2, and BAX (20). A PRD knockout mouse model ( $\left.p 53^{\triangle P / \Delta P}\right)$ was generated in order to examine the physiological importance of the proline-rich domain. Both 
$p 53^{\triangle P / \Delta P}$ and wild-type p53 MEFs that overexpress the E1A oncogene are susceptible to apoptosis after ionizing radiation treatment $(21,22)$. However, p53 $\triangle P / \Delta P$ MEFs were unresponsive to adriamycin-induced cell cycle arrest. This data suggests that the PRD may contribute to p53 induction of cell cycle arrest and apoptosis under specific conditions. Most importantly, when the $p 53^{\triangle P / \Delta P}$ genotype was tested as a suppressor of E1A and Ras-induced tumors, it was unable to suppress tumor growth in nude mice; further demonstrating the importance of the proline-rich domain on p53 induction of apoptosis versus cell cycle arrest during oncogenic stress (22).

$M d m 2^{+/-}$mice were crossed with $p 53^{\Delta P / \Delta P}$ mice and then intercrossed to yield $p 53^{\triangle P / \Delta P} / \mathrm{Mdm}^{-1}$, however, this phenotype was embryonic lethal. In contrast, $p 53^{\Delta P / \Delta P}$ rescued $M d m X$ embryonic lethality in $\mathrm{MdmX}^{-/ /} / p 53^{\Delta P / \Delta P}$ mice, suggesting the proline-rich domain modulates MdmX activity on p53, but does not modulate the effects of Mdm2 and therefore cannot rescue the embryonic lethal $\mathrm{Mdm}^{-/}$phenotype (22).

\subsubsection{The DNA-Binding Domain}

The p53 DNA-binding domain (DBD) is located within amino acids $98-292$ (exons 4-9 of the TP53 gene). The DBD participates in DNA sequence-specific binding of p53 transcriptional targets $(14,16)$. The DBD consists of two structures: a $\beta$-sandwich scaffold comprised of two anti-parallel $\beta$-sheets made up of four and five $\beta$-strands, and a DNA binding surface. The DNA binding surface is comprised of a loop-sheet-helix motif and two loops, L2 and L3, bound 
by a $\mathrm{Zn}^{2+}$ atom $(23,24)$. Loss of the $\mathrm{Zn}^{2+}$ atom results in abrogation of DNA binding activity but, according to structural studies, the DNA binding domain remains folded and stable (24). The general consensus sequence for p53 transcriptional targets is 5' PuPuPuC(A/T)(T/A)GPyPyPy-3' in 2 tandem repeats separated by $0-13$ nucleotides $(23,25)$. Currently, there are 1,501 human transcripts representing genes that are responsive to human p53, with 361 containing a p53 consensus sequence in their regulatory regions $(26,27)$.

A p53 mutant lacking the DBD and the TAD is functional in transforming cells and forming oligomers with full-length wild-type p53, but is unable to transactivate target genes (28). Mice expressing mutant p53 in which exons 2-6 are deleted develop spontaneous lymphomas around the age of 9 months (29, 30). In addition, the DBD is one of the most mutated regions of the TP53 gene. To date, approximately $80 \%$ of human p53 germline mutations occur in the DBD, demonstrating the functional importance of this domain (31).

\subsubsection{The Tetramerization Domain}

The tetramerization domain (a.a. 326-355) is located proximal to the Cterminus of the p53 protein. Originally, p53 was described as forming a tetramer when analyzing the binding site of SV40 on p53 $(32,33)$. Shortly thereafter, human and murine p53 were reported to form oligomers, including tetramers (34, 35). In the monomer of $p 53$, the tetramerization domain consists of a $\beta$-strand (a.a. 326 to 333) linked to an a-helix (a.a. 335-355) by the G334 residue. Hydrogen bonding occurs within the hydrophobic core between the $\beta$-strand 
(F328, L330, I332) and the a-helix (F338, F341, and N345). Salt bridge formation occurs between the D352 residue of one monomer and the R337 of another monomer. p53 dimerization occurs via $\beta$-strand interaction that forms an antiparallel $\beta$-sheet and an eight hydrogen bond backbone, and $\alpha$-helix interaction that places the $\alpha$-helices antiparallel to one another. Tetramerization requires $\alpha$-helix interaction between two dimers at amino acid residues M340, L344, A347, L348, and L350, placing the $\beta$-sheets outside of the tetrameric structure. Structural data was confirmed by mutating amino acid residues in the tetramerization domain, especially those located in the hydrophobic core to alanine in order to demonstrate their importance in formation of tetramers. Mutated residues included: F328, L330, I332, R337, F338, M340, F341, L344, and L348 (36-39). The hydrophobic core of the tetramerization domain, especially the G334 residue, is conserved throughout evolution, reiterating the importance of these residues for tetramer formation and stabilization (40). In addition to tetramer formation, a nuclear export signal lies between amino acid residues 340 and 351 (41). p53 tetramerization is required for DNA binding and mutations within this region have been found in human cancers $(38,42,43)$.

\subsubsection{The C-Terminal Domain}

The C-terminal negative regulatory domain (CTD) is comprised of basic amino acid residues required for the regulation and function of p53 (14). The Cterminal domain undergoes several post-translational modifications, including acetylation and sumoylation in response to cellular stresses, such as DNA 
damage. $\mathrm{K} 373,381$, and 382 are acetylated by the p300/CBP acetyltransferase in response to DNA damage caused by ionizing radiation (44). K382 is also acetylated by p300 in response to UV radiation (45). The p53 C-terminal domain promotes the reannealing of single strand DNA and RNA and binds to DNA containing insertion/deletion mismatches in response to DNA strand breaks (46).

The negative regulatory region of the p53 C-terminus consists of a DNAbinding domain (amino acid residues 363-393) that nonspecifically binds DNA, contributing to p53 latency (14). There are two models of p53 latency: allosteric and competitive binding. The allosteric model proposes that the C-terminal domain inhibits the core domain via conformational changes. The competitive binding model proposes that when competitor DNA, i.e., long single-stranded DNA, nonspecifically binds to the CTD, binding of p53 core domain to its consensus sites on target DNA is inhibited. Post-translational and structural modifications to the $\mathrm{C}$-terminus alter protein conformation in order to activate p53-mediated transcription $(47,48)$. Deletion of residues required for non-specific DNA binding by the CTD activates p53 sequence-specific binding, allowing p53 DBD to bind target DNA. Short single strand oligonucleotides also stimulate p53 binding to consensus sites $(49,50)$. Phosphorylation of S392 by casein kinase II and $\mathrm{S} 378$ by protein kinase $\mathrm{C}$ activate sequence-specific binding in the core domain (51). PAb421, which masks residues 370-378, inhibits CTD nonspecific DNA binding $(52,53)$. This data overall suggests that either inactivation or deletion of the C-terminal domain activates the core domain for site-specific DNA binding by the p53 protein. The mechanism of p53 latency and C-terminal 
domain competition with the core domain for DNA binding is still in debate. Nuclear magnetic resonance (NMR) spectra and mobility shift assays suggest that p53 conformation of wild-type p53 and truncated p53 lacking the C-terminus is identical (54). Because of the structural similarities between wild-type p53 and p53 lacking the C-terminal domain, it has been suggested that steric hinderance by excess large DNA bound to the $\mathrm{C}$-terminus is inhibitory to core domain binding of target DNA and may serve as a mechanism for p53 latency $(53,54)$. Indeed, steric hinderance by non-specific DNA binding might serve as the mechanism for the C-terminal domain inhibitory effect on the core domain. NMR spectra show that K373, 381, and 382, which are acetylated residues, exhibit large chemical shifts upon DNA binding, suggesting that these residues possibly bind non-specific DNA. It was also suggested that upon acetylation of these residues, non-specific DNA binding is inhibited (37).

\subsection{2 p53 Translocation}

p53 nucleocytoplasmic translocation is regulated by its association with nuclear import and export machinery, post-translational modifications, and its negative regulator, MDM2. p53 has three nuclear localization signals (NLS) located in the C-terminus of the TP53 gene: Bipartite NLS1 (a.a. 305-322), corresponding to the general consensus of a bipartite NLS which consists of two basic lysine and arginine clusters separated by 10 to 12 amino acids, NLS2 (a.a. 369-375) and NLS3 (a.a. 379-384). p53 has two nuclear export signals (NES): 
NES1 (a.a. 11-27) in the N-terminal TAD and NES2 (a.a. 340 and 351) in the Cterminal tetramerization domain $(14,41)$.

Under normal conditions, p53 translocation between the nucleus and the cytoplasm allows maintainance of chromosomal stability. It was demonstrated in normal fibroblasts that p53 is localized in the cytoplasm until the cell enters the G1/S transition of the cell cycle, when it is shuttled to the nucleus and is retained there until S phase begins. p53 is also translocated to the nucleus during cellular stress responses, i.e. following DNA damage (55-57).

p53 nuclear import is mediated via binding of an NLS receptor complex (containing importin- $\alpha$ and $-\beta$ heterodimers) to p53 NLS sequences in the Cterminus and is energetically driven by RanGTP. Importin binding is inhibited by p53 tetramerization, phosphorylation of C-terminal amino acid residue S315, cytoplasmic tether binding, and missense mutations at amino acid residues K305, R306, and R283 $(55,56)$.

p53 is normally maintained at low basal levels in the cytoplasm via ubiquitination and subsequent nuclear export by its negative regulator, MDM2. It has been proposed that MDM2 first binds the $\mathrm{N}$-and C-terminal NES of p53, targeting it for ubiquitination and subsequent translocation from the nucleus to the cytoplasm. Once p53 is ubiquitinated, monomers are shuttled to the cytoplasm via CRM-1/exportin-mediated MDM2 translocation. Amino and carboxy terminal nuclear export signals are masked via protein alterations, i.e. conformational changes and post-translational modifications, in order to retain p53 in the nucleus. Specifically, the C-terminal NES is partially masked by 
tetramer formation and during the DNA damage response p53 is phosphorylated on serines 15 and 20 , masking the $\mathrm{N}$-terminal NES, thereby preventing MDM2 binding on amino acid residues 22 and 23 . However, ubiquitination of p53 lysine residues in the $\mathrm{N}$ - and $\mathrm{C}$-termini unmasks the nuclear export signals, allowing nucleocytoplasmic shuttling of p53 $(55,58)$.

\subsubsection{Regulation and Activation of p53}

\subsubsection{1 p53 Activation via Post-Translational Modifications}

Because p53 plays a pivotal role in maintaining genomic stability, it is a highly regulated tumor suppressor. Stress signals are transmitted to p53 via posttranslational modifications, such as phosphorylation, acetylation, and sumoylation, all leading to p53 activation. In addition, it is negatively regulated in an autofeedback loop by MDM2.

1.2.3.1.1 p53 Activation via PIKK Phosphorylation DNA damage is one of the genotoxic stresses a cell can encounter to cause chromosomal instability. Once DNA damage lesions are made, cellular mechanisms are in place to either repair the DNA or destroy the cell. Three of the most studied DNA damage sensors are the phosphoinositide-3-like kinase family members (PIKKs): DNAactivated protein kinase (DNA-PK), Ataxia-Telangectasia Mutated-1 (ATM) kinase, and ATM-Rad3-Related (ATR) kinase, all of which phosphorylate p53 (59). 
ATM kinase recognizes serine and threonine residues that are followed by a glutamine residue. Ionizing radiation, which causes DNA double strand breaks (DSBs), signals the ATM response. ATM is then activated via autophosphorylation. Following its autophosphorylation, ATM activates several downstream effector genes which respond to DNA DSBs. Specifically, ATM either directly phosphorylates p53 on S15 or phosphorylates an effector kinase, checkpoint kinase 2 (CHK2), on T68. CHK2 phosphorylation leads to either phosphorylation of the phosphatase CDC25A on $\mathrm{S} 123$ or phosphorylation of p53 on S20. CDC25A dephosphorylates cyclin dependent kinase 1 (CDK1) and cyclin dependent kinase 2 (CDK2), allowing the cell to progress from $G 1$ to $S$ phase of the cell cycle. However, CHK2 phosphorylation of CDC25A leads to its proteasomal degradation whereas CHK2 phosphorylation of p53 on S20 blocks the MDM2-p53 interaction, resulting in p53 stabilization and nuclear accumulation. ATM phosphorylates MDM2, additionally preventing its interaction with p53, assuring p53 stabilization. Once p53 is stabilized, it is able to activate downstream targets including $\mathrm{p} 21^{\text {WAF } 1 / \mathrm{CIP} 1}$, preventing $\mathrm{G} 1$ to S-phase progression (Fig. 1-2) (60).

ATM also phosphorylates checkpoint kinase 1 (CHK1) on S345, blocking G2 to M-phase progression. CHK1 phosphorylates CDC25C, a phosphatase that dephosphorylates CDK1, allowing the cell to enter M-phase. However, unlike CHK2, CHK1 does not phosphorylate p53 (60). 


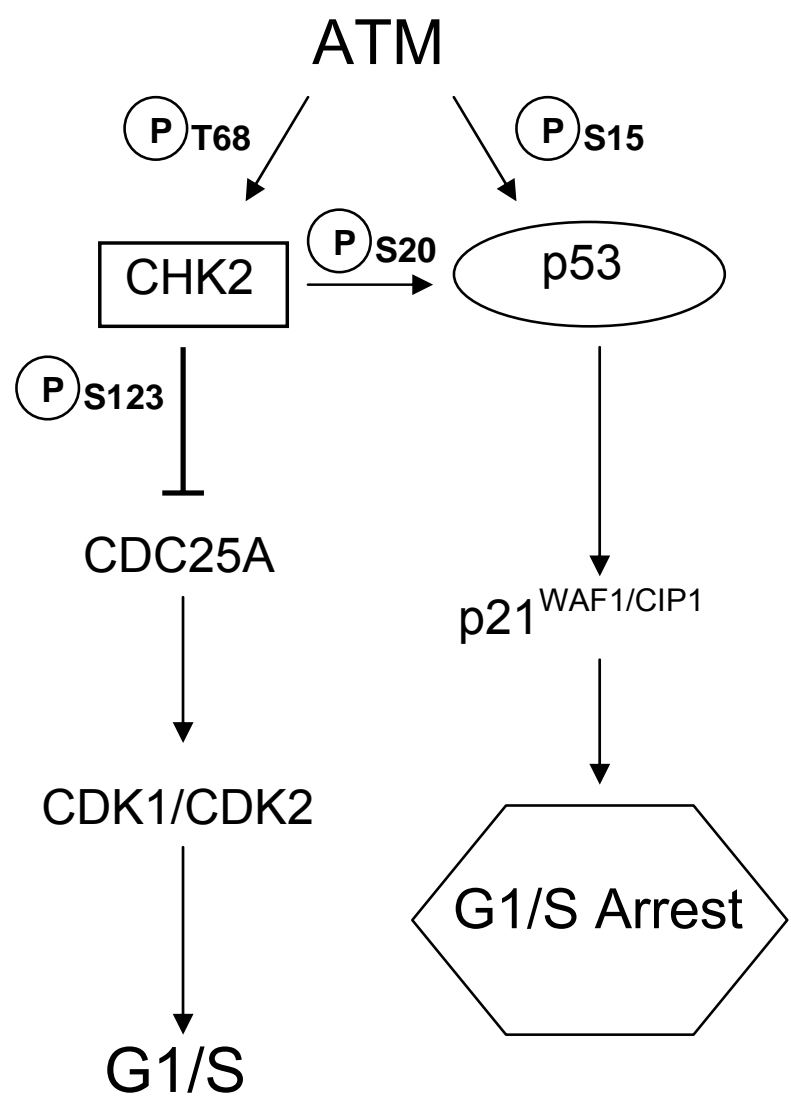

Figure 1-2. ATM Activation of p53-Induced Cell Cycle Arrest. Following DNA damage by ionizing radiation, ATM either directly phosphorylates p53 on S15 or will phosphorylate CHK2 which phosphorylates p53 on S20 to induce G1/S arrest. 
Patients with ataxia-telangectasia (A-T) are wild-type for $\mathrm{p53}$, but have ATM mutations and are hypersensitive to ionizing radiation, resulting in a predisposition to cancer (61). p53 stabilization in $\mathrm{Atm}^{-/-}$fibroblasts and lymphoblasts is delayed because Atm provides a more rapid response to DNA damage than other related protein kinases. Atm ${ }^{-/-}$mice are sensitive to ionizing radiation and die of T-cell lymphoma. By contrast, $\mathrm{Atm}^{-/-}$mice do not exhibit the human A-T phenotype $(45,60,62,63)$. Elevated levels of p53 and downstream targets, p21 and Bax, in the testes of Atm-null male mice during meiosis were suggested to contribute to the mouse pleiotropic phenotype (64).

Similarly, ATR is a serine/threonine kinase that plays a more long-term role in DNA damage than its related kinase, ATM. ATR maintains the phosphorylated state of its targets, including p53, whereas ATM is responsible for the rapid response to DNA damage leading to immediate substrate phosphorylation. ATR phosphorylates p53 on S15 and S37 $(45,60)$. However, this modification occurs following UV-induced DNA damage (65). ATR phosphorylates CHK1 on S345 and CDC25C on S317, preventing progression of the cell through G2. In contrast to ATM, ATR does not activate CHK2 (60). In addition, ATR does not have a significant effect on p53 stabilization after DNA damage. But this does not negate its role as a cell cycle checkpoint. ATR ${ }^{-/}$mice are embryonic lethal, demonstrating its importance in embryogenesis (66). ATR also phosphorylates transducer proteins such as BLM, mutations of which result in chromosomal instability and ultimately a strong cancer predisposition called Bloom Syndrome $(59,60)$. 
DNA-PK is a serine/threonine kinase that responds to double-strand DNA breaks caused by ionizing radiation. It also repairs DNA double strand breaks in the $\mathrm{V}(\mathrm{D}) \mathrm{J}$ recombination process. It consists of a catalytic subunit and two Ku subunits, 70 and 86 . Ku70 and Ku86 bind broken DNA ends together followed by activation of the catalytic subunit as a kinase. The catalytic subunit of DNA-PK phosphorylates p53 on S15 and S37 in response to DNA damage caused by ionizing radiation in vitro $(67,68)$. However, when slip mice, which are deficient for DNA-PK (DNA-PK ${ }^{-1-}$ ), are exposed to ionizing radiation, the p53mediated response to DNA damage is not compromised. Instead, p53 accumulates in the nucleus and is able to transcriptionally activate the proapoptotic gene, Bax, and p21 WAF1/CIP1, which mediates G1/S cell cycle arrest. This data suggests that the function of p53 to prevent chromosomal instability is uncompromised in the absence of DNA-PK and that the function of DNA-PK in response to ionizing radiation is redundant, possibly with some other kinase which phosphorylates p53, such as ATM (69).

\subsubsection{2 p53 Phosphorylation by Non-PIKK Family Members p53 is also} phosphorylated by kinases that are not in the PIKK family, including CK1, CK2, MAPK, and JNK, in response to UV and ionizing radiation-induced DNA damage. T18 of p53 is phosphorylated in vivo by casein kinase 1 (CK1) following S15 phosphorylation in response to ionizing radiation (70). S33 and S46 are phosphorylated by p38 mitogen-activated protein kinase (MAPK) following UV irradiation. Mutation of these residues may inhibit p53-dependent apoptosis, 
mediated by p53 apoptosis-inducing gene (p53AIP) (71). S392 is phosphorylated by casein kinase 2 (CK2) in response to UV irradiation along with the transcription elongation factor, FACT, enhancing the activity of p53 (72). TAF-1 (TATA box-binding protein-associated factor -1 ) a subunit of TFIID required for transcription initiation, phosphorylates T55 of p53, inhibiting p53-induced G1 arrest (45). T81 of the p53 protein is phosphorylated by Jun N-terminal kinase (JNK) in response to DNA damage and stress-inducing agents (73). In response to UV irradiation, CDK2 phosphorylates S315 of the p53 protein in vivo and in vitro, causing an increase in p53 transcriptional activity (45). This data supports that phosphorylation is a mode of regulation by various upstream signals of p53 and regulates p53 activity in response to different cellular stresses.

1.2.3.1.3 p53 Activation via Acetylation Acetylation of p53 regulates its sequence-specific DNA binding capability and maintains protein stability. PCAF (p300-CBP-associated factor) acetylates p53 at K320. CREB binding protein (CBP) and p300 acetylate p53 at K373 and K382. PCAF, CBP, and p300 are histone acetyltransferases (HATs) which bind to the N-terminus of p53 and acetylate C-terminal lysine residues, enhancing p53 sequence-specific DNA binding and p53-mediated transcription, especially following DNA damage (74). Acetylation of C-terminal residues also prevent MDM2 binding (75). In addition, TIP60 and hMOF, members of the MYST family of acetyltransferases, acetylate p53 on K120, promoting p53 activation of pro-apoptotic genes such as PUMA and BAX. Acetylation of K120 by MYST acetyltransferases currently serves as a 
model for p53 selectivity of genes that induce apoptosis over those that trigger cell cycle arrest (76).

1.2.3.1.4 p53 Activation via Sumoylation Sumoylation is a post-translational modification similar to ubiquitination and regulates many biological processes including gene expression, transcriptional activation, nucleo-cytoplasmic shuttling, protein stability, the cell cycle, and apoptosis. Instead of targeting a protein for degradation, like ubiquitination, sumoylation enhances protein half-life. Ubiquitination requires an E1 activating enzyme, which hydrolyzes ATP and forms a complex with ubiquitin adenylate. Ubiquitin is then transferred to the active site of the E1 enzyme followed by adenylation of an additional ubiquitin. Ubiquitin is then transferred to an E2 conjugating enzyme, which allows multiubiquitin chain formation via peptide bond formation between the carboxy terminus of one ubiquitin with the amino terminus of the next ubiquitin. The ubiquitin chain can then be transferred from the E2 ligase to an acceptor lysine on the target protein. An E3 ligase can also be used to recognize the acceptor protein and transfers the ubiquitin chain. Once the ubiquitin chain is transferred to the target protein, the protein can be directed to the $26 \mathrm{~S}$ proteasome. Sumoylation only uses an E1 and E2 ubiquitin ligase. SUMO-1 (small ubiquitinrelated modifier-1), which is approximately $18 \%$ identical to ubiquitin, is an E1 activating enzyme. It is linked to UBC-9, which is an E2 conjugating enzyme. SUMO-1 has been reported to sumoylate p53 on K386, enhancing p53 sequestration in the nucleolus by Mdm2 and the ARF tumor suppressor $(77,78)$. 


\subsection{Oncogenic Activation of p53 One of the most understood}

oncogenic signaling pathways to p53 is mediated by the ARF tumor suppressor, which interacts with MDM2 and p53 to abolish aberrant oncogenic signaling by promoting cell cycle arrest. ARF ( $\mathrm{p} 14^{\mathrm{ARF}}$-human) is encoded on the INK4A-ARF locus of human chromosome 9. ARF (Alternative Reading Frame) is the product of an alternatively spliced mRNA that includes sequences from exons 2 and 3 of the INK4A gene. ARF inhibits the E2F-DP1 interaction by binding to either E2F or DP1 prior to E2F-DP1 complex formation, interfering with cell cycle progression (79).

Abnormal oncogenic activity by transcription factors that participate in mitogenic signaling, such as $E 2 F$, induces ARF expression. ARF binds to MDM2 and sequesters it in the nucleolus, interfering with the MDM2-p53 interaction and increasing p53 protein levels to induce either cell cycle arrest or apoptosis (Fig. 1-3). This model of ARF interaction with MDM2 and p53 is supported by generated mouse models demonstrating roles of ARF and p53 in tumor suppression. Arf- and p53-null mice are both tumor prone. $p 53^{-/-}$mice are most susceptible to T-cell lymphomas. Arf ${ }^{--}$mice develop various tumor types, including sarcomas and T-cell lymphomas (79). Arf/p53 double knockout mice are prone to lymphoma and sarcoma development, in addition to a multiple tumor phenotype. Arf-Mdm2-p53 triple knockout mice are even more susceptible to a multiple tumor phenotype. Studies using these triple knockout mice suggested 


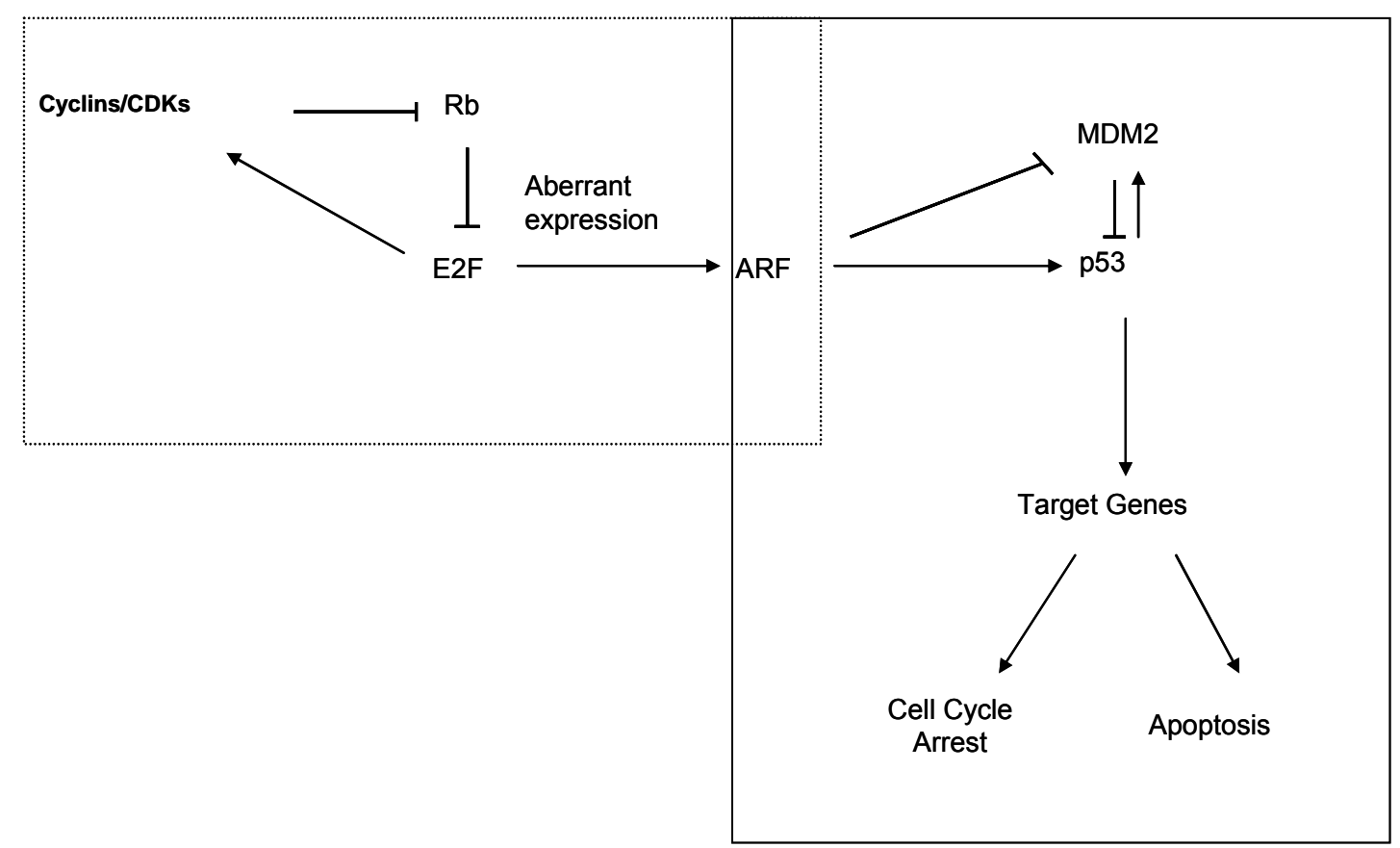

Figure 1-3. Rb-E2F-ARF and ARF-MDM-2-p53 Pathways. Cyclins/CDKs hyperphosphorylate $\mathrm{Rb}$, releasing the $\mathrm{E} 2 \mathrm{~F}$ transcription factor to drive S-phase entry. E2F aberrant expression activates the ARF tumor suppressor which blocks the MDM2-p53 interaction, increasing p53 protein levels and subsequently inducing either cell cycle arrest or apoptosis via transactivation of p53 target genes. 
that ARF can act independently of p53 in the induction of cell cycle arrest when MDM2 is inactivated (80).

\subsubsection{Negative Regulation of p53}

p53 negative regulation occurs via ubiquitination and proteosomal degradation. E6AP (E6-associated cellular protein), an E3 ubiquitin ligase, was shown to target p53 for ubiquitination and degradation. This mode of p53 inactivation is used in HPV E6-associated cervical cancers and was the first demonstrated mechanism of p53 ubiquitination and degradation (75). However, in a normal cell, p53 requires the proto-oncogene and E3 ubiquitin ligase, MDM2 (Murine ㅁouble Minute 2) (81-83). MDM2 associates with p53 in a negative autoregulatory feedback loop, resulting in low basal levels of p53 in a normal cell (84). Specifically, MDM2 binds the p53 transactivation domain in the $\mathrm{N}$-terminus, inhibiting p53 transcriptional activation via its association with TATA-binding protein associated factors $\mathrm{TAF}_{\|} 31$ and $\mathrm{TAF}_{\|} 70$ (85-88).

MDM2 (HDM2 in humans) contains a C-terminal RING-finger domain required for ubiquitination of p53 $(81,89,90)$. The last thirty C-terminal residues

of p53 are required for MDM2-mediated ubiquitination and degradation based on site-directed mutagenesis studies (91). MDM2 constitutively undergoes nucleocytoplasmic shuttling, and was primarily thought to be required for the nuclear export of p53 $(83,92-94)$. p53 mutants that localized to the nucleus and the cytoplasm were both ubiquitinated and degraded by MDM2, suggesting that 
nuclear export is not required for MDM2-targeted ubiquitination and degradation of p53 (95).

Furthermore, MDM2 fosters p53 ubiquitination in a dose-dependent manner. Low levels of MDM2 promote p53 monoubiquitination and nuclear export while high levels of MDM2 promote p53 polyubiquitination and nuclear degradation. Monoubiquitination may serve as a means of maintaining low levels of p53 in normal, unstressed cells while polyubiquitination may serve as a mechanism to destroy p53 in the latter stages of a cellular stress response $(75$, 96).

Mdm2 knockout mice are embryonic lethal, indicating that the loss of Mdm2 results in p53-mediated cell cycle arrest and apoptosis during embryogenesis. In addition, mice that lack both Mdm2 and p53 are viable but tumor-prone, demonstrating that the absence of p53 rescues the $\mathrm{Mdm}^{-{ }^{-}}$ phenotype (97).

\subsection{4 p53 Responses to Cellular Stress}

In order for a cell to maintain genomic integrity, mechanisms must be in place to counteract genotoxic stress. As discussed in Section 1.1, tumor suppressors contribute to the maintenance of chromosomal stability. The p53 tumor suppressor responds to a number of stress signals including DNA damage and oncogene activation by inducing cell cycle arrest and apoptotic programs (98). Specifically, cellular stress signals transduced to p53 via post-translational modifications and inhibition of the MDM2-p53 interaction (discussed in Section 
1.2.3) activate and stabilize $p 53$, increasing its half-life (from approximately 30 minutes to 2 hours) and protein levels, resulting in sequence-specific transactivation of its downstream target genes (14). Most importantly, loss of p53 function either through inactivation of p53 and/or any other component of the p53 pathways leading to cell cycle arrest and apoptosis, ultimately results in tumor formation (74).

\subsubsection{1 p53-Mediated Cell Cycle Arrest}

The cell cycle is a highly regulated process by which cellular growth and proliferation are controlled. The cell cycle contains four stages: gap 1 (G1), DNA synthesis (S phase), gap 2 (G2), and mitosis (M). A fifth stage of the cell cycle termed $\mathrm{G}_{0}$, represents the phase during which cells are either quiescent or not actively replicating. Cells that are quiescent, such as nerve cells, can be described as those that are terminally differentiated and can no longer replicate. Those cells that are not terminally differentiated can re-enter the cell cycle (77).

The cell cycle is catalyzed by cyclins and cyclin-dependent kinases (CDKs). Cyclin-CDK complexes phosphorylate serine or threonine residues on several target transcription factors required to activate downstream targets necessary for cellular growth and proliferation. Cell-cycle checkpoints, like p53, negatively regulate the cell cycle at both the G1/S and G2/M phases in response to DNA damage recognized by ATM and ATR and to oncogenic stress signaled by the ARF tumor suppressor $(77,98)$. 
Progression from $\mathrm{G} 1$ to S-phase is specifically inhibited by the p53 downstream target, p2 $1^{\text {WAF1/CIP1 }}$ (99). p21 is a "universal" cyclin dependent kinase inhibitor (CKI), which binds to CDK-cyclin complexes and prevents the cell from entering S-phase $(98,100)$. p21-null mice are viable and embryonic fibroblasts from these mice show partial cell cycle arrest when they are subjected to DNA damage (101), suggesting that there are alternate downstream targets activated in response to $\mathrm{p} 53$.

The cyclin B and CDK2 complex promote cellular progression from G2 to M phase. They are in an inactive complex via phosphorylation by the CKIs, WEE1 and MYT1. However, the CDC25 phosphatase dephosphorylates and activates the CDK2/Cyclin B complex. p53 inhibits this complex by inducing downstream targets GADD-45 and 14-3-36, in response to DNA damage. GADD-45 promotes dissociation of Cyclin B and CDK2 and 14-3-3 $\sigma$ prevents nuclear import of the CDK2/Cyclin B complex, blocking entry into mitosis (102).

\subsubsection{2 p53-Mediated Apoptosis}

Apoptosis, or programmed cell death, is characterized by morphological changes including membrane blebbing, DNA fragmentation, cell shrinkage, chromatin condensation, and cytoplasmic disorganization resulting from loss of organelle compartmentalization. Programmed cell death is also defined by signaling pathways leading to its characteristic morphological changes $(77,103)$.

Apoptosis requires activation of either the extrinsic or intrinsic pathways. The extrinsic pathway requires activation of death receptors such as tumor 
necrosis factor receptor-1 (TNFR-1), which binds to its ligand, tumor necrosis factor (TNF). This interaction promotes recruitment of TNFR-1 associated death domain (TRADD) and FAS-associated death domain (FADD). TRADD and FADD recruit and activate the initiator caspase, procaspase- 8 , which is cleaved to form active caspase-8. "Executioner" caspases, procaspases-3, -6 and -7, are activated by caspase- 8 cleavage. Cleavage and subsequent activation of these "executioner" caspases promote the downstream morphological changes associated with apoptosis $(104,105)$.

p53 promotes the intrinsic pathway by transactivation of BCL-2 family proapoptotic genes, BAX and BAK. BCL-2 antagonist/killer (BAK) and BCL-2associated $\mathrm{X}$ protein (BAX) contain the BCL-2 homology domain-3 (BH3 domain). The $\mathrm{BH} 3$ domain consists of 9-16 amino acids and an amphipathic alpha helix. The hydrophobic side of the alpha helix makes contact with the hydrophobic groove of $\mathrm{BH} 1, \mathrm{BH} 2$, and $\mathrm{BH} 3$ domains of pro-survival members of the BCL-2 family of proteins, e.g. BCL-2, BCL-XL, MCL-1, to block anti-apoptotic signals. Mutations in the $\mathrm{BH} 3$ domain result in loss of binding and pro-apoptotic activity. These proteins regulate mitochondrial outer membrane permeability (MOMP) leading to the release of cytochrome $\mathrm{c}$ from the mitochondria into the cytosol. APAF-1, cytochrome c, and caspase- 9 form the apoptosome within the cytosol. Once procaspase- 9 is cleaved, active caspase- 9 activates effector caspases, leading to the morphological changes that occur during apoptosis $(103,105,106)$. 
Both BAX and BAK mediate the intrinsic apoptotic response $(19,105)$. In response to ionizing radiation, $\mathrm{Bax}^{-/-}$murine thymocytes are susceptible to apoptosis due to functional redundancy with Bak. Ionizing radiation also kills $\mathrm{Bak}^{-1-}$ thymocytes. Therefore, as expected, Bax /Bak double knockout murine thymocytes do not respond to DNA damage by ionizing radiation (62). p53 also directly transactivates other pro-apoptotic factors, $\mathrm{BH} 3$-only proteins such as Puma and Noxa $(107,108)$. Both proteins translocate to the mitochondria to induce apoptosis $(103,108,109)$. In response to DNA damage, Puma and Noxa are both activated to block pro-survival signals from the anti-apoptotic Bcl-2 protein family members, Bcl-2 and Bcl-XL (105).

Another model of p53-induced apoptosis suggests that p53 binds antiapoptotic factors such as $\mathrm{Bcl}-2$ and $\mathrm{Bcl}-\mathrm{XL}$ in the cytoplasm at the mitochondria. In response to DNA damage, $\mathrm{p} 53$ protein binds the $\mathrm{Bcl}-2$ negative regulatory domain. When this region is deleted, p53 binding is abrogated, enhancing Bcl-2 activity. Bcl-2 phosphorylation in this region also reduces p53 binding and increases Bcl-2 activity (110). Under cellular stress, p53 cytoplasmic sequestration by $\mathrm{Bcl}-2$ and $\mathrm{Bcl}-\mathrm{XL}$ is relieved by nuclear $\mathrm{p} 53$ transactivation of $\mathrm{BH} 3$ domain, pro-apoptotic proteins such as Puma. It has been demonstrated that Puma will compete with p53 for binding of Bcl-XL in the cytoplasm. This releases p53 to possibly promote oligomerization of pro-apoptotic genes such as BAX and BAK (105) (Fig. 1-4). 


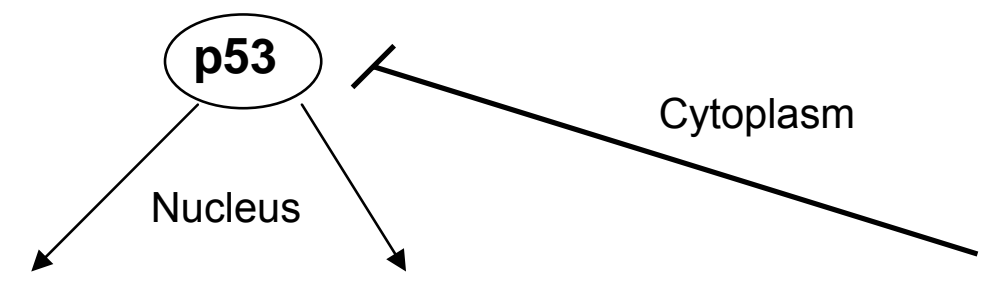

\section{Bax/Bak Puma/Noxa $\longrightarrow$ Bcl2/BcIXL}

\section{Apoptosis}

Figure 1-4. p53-Mediated Apoptosis. p53 directly transactivates pro-apoptotic proteins with a BH3-domain including Bax, Bak, Puma, and Noxa. p53 binds Bcl2/Bcl-XL in the cytoplasm. Under cellular stress, p53 competes with pro-apoptotic proteins such as Puma for binding of anti-apoptotic proteins such as Bcl-XL. Once p53 is released from $\mathrm{Bcl}-2 / \mathrm{Bcl}-\mathrm{XL}$, it is free to possibly promote oligomerization of pro-apoptotic genes including Bax and Bak, which induce apoptosis. 


\subsection{Li-Fraumeni Syndrome}

\subsubsection{Clinical Characteristics of LFS and LFLS}

In 1969, Frederick Li and Joseph Fraumeni initially identified five families with pediatric rhabdomyosarcoma probands having members with sarcomas, breast cancer, and other neoplasms (111). A retrospective study uncovered four of the five families who were extremely tumor-prone (112).

Li-Fraumeni Syndrome (LFS) was clinically defined in 1988 as a rare disease with strict diagnostic criteria (112). After investigating 151 cancer patients from 24 families, it was discovered that $79 \%$ (119 of 151 patients) were younger than 45 years of age. Specifically, 51 of 55 patients diagnosed with sarcomas acquired mostly soft tissue sarcomas before the age of 45 . Osteosarcomas mostly occurred in children and young adults (19 of 23 patients). The number of breast carcinoma cases was also increased (36 patients of 151) and all patients were female. Approximately $78 \%$ of breast cancer patients were younger than 45. Other neoplasms that occurred in these patients were leukemia, lymphomas, brain tumors, adrenocortical carcinoma, and cancers of the lung, pancreas, colon, prostate, and stomach. Leukemia, brain cancer, and adrenocortical carcinomas were found more often in patients from ages 0-29. These findings later defined LFS criteria as follows: A proband must be diagnosed with a sarcoma under the age of 45 ; there must be a first-degree relative diagnosed with any cancer under the age of 45 and a first- or seconddegree relative diagnosed with either any cancer or sarcoma at any age. 
In 1994, Li-Fraumeni-like Syndrome (LFLS) was defined based on a study of 21 families, all of which had an increased incidence of cancer. Of these families, 12 of them could be classified under LFS. Nine families did not adhere to the LFS criteria but were also increasingly tumor-prone. These 9 families were referred to as "Li-Fraumeni-like" based on the following criteria: A proband must be diagnosed with any childhood cancer or sarcoma, brain tumor, or adrenocortical carcinoma under the age of 45 ; One first- or second-degree relative must be diagnosed with any cancer defined in typical LFS (brain tumor, adrenocortical carcinoma, leukemia, breast cancer, or sarcoma); A first- or second-degree relative must be diagnosed with any cancer under age 60 (113).

Originally, it was suggested that LFS was an autosomal dominant disease (111). Data from families of 159 childhood soft tissue sarcoma patients was used for segregation analysis to determine an etiologic model, i.e. recessive or dominant, for LFS. Thorough computational analyses showed the data strongly favored an autosomal dominant gene predisposed family members to cancer (114).

\subsubsection{Germline p53 Mutations in LFS and LFLS}

Immediately after LFS was defined, it was suspected that this familial cancer syndrome was inherited due to its rarity and increased age-specific mortality. It was known that mutations in tumor suppressors were associated with cancer (1), i.e, the Retinoblastoma (Rb) gene and its connection to retinoblastoma (115). However, retinoblastomas were not associated with LFS. 
The next tumor suppressor candidate considered was p53 (116). More importantly, p53 mutations were characterized in sporadic sarcomas, leukemia, and breast, brain, colon, and lung cancers, all of which are defined in LFS (117123). The first mutations reported in the germline of LFS patients were missense mutants located in the four conserved regions of the p53 gene: a.a. 117-142 (I), 171-181 (II), 234-258 (III), and 270-286 (IV), spanning exons 5-8 (116-118). Specifically, a.a. $245,248,252$, and 258 , all in exon 7 of the TP53 gene, contained missense mutants $(117,118)$. After the discovery that germline p53 mutations were strongly linked to LFS, many cancer types were analyzed for these mutants, specifically, within the conserved regions of exons 5-8, restricting the search for mutations in other regions of the gene. Mutations in these conserved regions of the DNA binding domain can lead to structural alterations of the protein resulting in partial or complete loss of tumor suppressor function (18).

The DNA binding domain contains the most commonly mutated residues, i.e. R175, R248, R273, R249, and G245. Initially, p53 germline status of LFS and LFLS families was determined by analyzing exons 5-8. However, as other mutations outside of this region were discovered in LFS and LFLS families, analysis of p53 germline status included the entire TP53 coding region, exons 2$11(124,125)$. For example, L344P and R337C mutants, located in the p53 tetramerization domain, have been described $(126,127)$. Additionally, splice site mutations in introns 1 and 9 are associated with Li-Fraumeni Syndrome (128). Loss of heterozygosity (LOH), represents loss of the wild type allele and retention of the mutant allele. LOH is based upon Knudson's Hypothesis, 
adapted by Ponder et al. (129) which states "one defective allele must be inherited and the second must be inactivated by loss of either part or all of the wild-type chromosome". The mechanisms which can cause LOH in a tumor cell are: gene conversion or mitotic recombination leading to a partial exchange between homologous chromosomes during mitosis, complete deletion of the wild-type chromosome, and deletion and duplication of the mutant chromosome (130). p53 LOH occurs in approximately $44 \%$ of all tumors associated with LFS (131). It is not well understood why the rate of $\mathrm{LOH}$ in tumors expressing mutant p53 is lower than in tumors expressing other mutant tumor suppressors $(\sim 80 \%)$, i.e. $\mathrm{Rb}$ in retinoblastoma. It has been predicted that these mutants are dominantnegative (116).

\subsection{Pediatric Adrenocortical Cancer}

\subsubsection{Clinical Characteristics of Pediatric Adrenocortical Cancer}

The adrenal cortex is a highly specialized sub-organ responsible for the production of steroid hormones. During development, the adrenal cortex is divided into two zones: the definitive zone and the fetal zone, which ultimately separates into three zones, once the cortex has matured: zona glomerulosa, zona fasciculata, and zona reticularis, each zone specifically producing mineralocorticoids (aldosterone), glucocorticoids (cortisol), androgens and DHEA-S (Dihydroepiandrosterone sulfate), respectively (132). 
Pediatric adrenocortical cancer (ACT) is a rare and fatal disease with a worldwide incidence of $0.2-0.3$ cases per million worldwide and 1 case per million in the United States. In addition, the incidence of pediatric ACT in southern Brazil is $10-15$ times the worldwide incidence. The median age of pediatric adrenocortical tumor patients is approximately $3-4$ years of age $(133,134)$. In addition to Li-Fraumeni Syndrome, other diseases can predispose a patient to adrenocortical neoplasms including Beckwith-Wiedemann Syndrome (BWS), Carney's Complex, congenital adrenal hyperplasia, multiple endocrine neoplasia, and hemihyperplasia (135). Patients with multiple endocrine neoplasia type 1 mainly have adrenocortical carcinoma due to mutations in the MEN1 gene; however reports of ACC in BWS, hemihyperplasia, and congenital adrenal hyperplasia are rare. Patients present primarily with virilization, with or without Cushing's syndrome, indicating that this tumor is functional or producing hormones. Cushing's syndrome is characterized by excess production of glucocorticoids (cortisol) (135).

The only effective treatment of pediatric adrenocortical tumors is surgical resection of the tumor. Chemotherapeutic treatment is used, primarily mitotane, etoposide, and cisplatin. Mitotane (1, 1-dichloro-2-(o-chlorophenyl)-2-( $p$ chlorophenyl)ethane; o, $p^{\prime}-\mathrm{DDD}$ ) causes necrosis of the adrenal cortex and is commonly used as an adjuvant chemotherapeutic agent in metastatic ACT cases with a $15-60 \%$ response rate. Etoposide and cisplatin can be used in combination with doxorubicin and low doses of mitotane, resulting in "variable efficacy among patients" (135). 
There are two histological subtypes of adrenocortical tumors: adenoma and carcinoma. Adrenocortical tumors can be histologically classfied but are not clinically useful in predicting prognosis. Therefore, using tumor size has become acceptable in predicting prognosis because tumors can exceed $200 \mathrm{~g}$ in weight. Tumors that are less than $200 \mathrm{~g}$ in weight predict a greater tumor-free survival than tumors that exceed $200 \mathrm{~g}(133,135)$.

\subsubsection{Biology of Pediatric Adrenocortical Cancer}

The biology of pediatric adrenocortical cancer is not well understood. Insulin-like Growth Factor-II (IGF-II) is overexpressed in both adult and pediatric adrenocortical carcinoma (ACC) (136-139). /GF-// is mapped to the chromosomal region of $11 \mathrm{p} 15.5$ with a number of imprinted genes including KCNQ1, CDKN1C (p57 $7^{\mathrm{KIP} 2}$ ), and H19. IGF-II has affinity for two receptors: IGF1R and IGF2R.

Specifically, IGF-II binds with higher affinity to the IGF2R receptor, and becomes internalized in the pre-lysosomal compartment for degradation. However, IGF-II binds the IGF1R to promote cellular growth, especially during fetal development and adrenal maturation during gestation (140).

Genes at the IGF-II locus are regulated via genomic imprinting. Genomic imprinting is an epigenetic mechanism which uses DNA methylation in order to silence either a maternal or paternal allele. Genes that are imprinted are, therefore, expressed from either allele (141). However, when imprinting has failed, both alleles are expressed, leading to overexpression of a gene, in this case, IGF-II. Overexpression of IGF-II and other genes at the IGF-II locus on 
chromosome 11p15.5 (e.g. KCNQ1, CDKN1C) have been linked to BWS and ACC. Mice that overexpress the IGF-II gene acquire either a BWS phenotype or develop adrenal hyperplasia $(142,143)$. However, the mechanism affected by IGF-II overexpression is not understood. The aberrant expression of other genes at this locus has not been fully elucidated.

Other genetic alterations in pediatric ACC include amplification of chromosome 9q34 (144). Overexpression of several genes on and in proximity to chromosome 9q34 could serve as an additional alteration and possibly contribute to the onset of ACC, including steroidogenic factor-1 (SF-1). SF-1 is located on chromosome 9q33.3 and is involved in steroidogenesis. Specifically, SF-1 (NR5A1) is a member of the nuclear orphan receptor family and is present during adrenogenesis. It is responsible for the transcription of genes involved in hormone production. In male development, SF-1 helps to regulate steroidogenesis, especially testosterone production and Mullerian duct regression during gonadogenesis. In female gonadogenesis, SF-1 is not present (145). Sf-1 knockout mice lack both adrenal glands and gonads and die from adrenal insufficiency (146). More importantly, it is overexpressed in pediatric adrenocortical tumors (147).

Germline p53 mutations have been comprehensively reported in pediatric adrenocortical tumors. p53 mutations are associated with approximately $70 \%$ sporadic adult ACC cases. Specifically, p53 mutations are associated with $86 \%$ of adult functional tumors and $33 \%$ of non-functional tumors (148). However, approximately $80 \%$ of pediatric ACC cases reported in LFS are associated with 
germline p53 mutations (134). Specifically, pediatric ACC patients either with or without family history have germline p53 mutations $(134,149)$. Therefore, it is apparent that $A C C$ is highly associated with p53 germline mutations.

p53 germline mutations that are associated with pediatric ACC cases lie within the conserved regions of the DNA binding domain and are often at "hot spot" amino acids. However, there are a number of germline p53 mutations that lie within these regions that cannot be categorized as "hot spots". In 1999, Varley et al. conducted a study of 14 pediatric ACC patients that had either no family history or did not comply with LFS or LFLS criteria (134). Of 11 pediatric ACC cases, 9 had germline p53 mutations. In addition, they also observed loss of heterozygosity in only $50 \%$ of ACC tumors. Of the germline mutations found in this subset of patients, $\mathrm{R} 158 \mathrm{H}$ and $\mathrm{P} 152 \mathrm{~L}$ were the most common. Carriers either presented with cancer or were unaffected. Some carriers developed LFSlike cancers, i.e. ACC, but other members of the same family were unaffected. In addition, some carriers affected by cancer did not have tumors characteristic of LFS or LFLS, including uterine and cervical cancers. Considering that the penetrance for germline p53 mutation carriers in LFS families is $73 \%$ for males and $100 \%$ for females (150), data presented by Varley et al. (134) suggests that not only are some p53 mutations low-penetrance but they are found in pediatric ACC probands.

In the above study, a somatic mutation found in the tumor DNA of an ACC proband was located at codon 337 , resulting in an arginine to histidine substitution [R337H; (134)]. However, the R337H mutation was not germline. 
R337 is located in the $\alpha$-helix of the p53 tetramerization domain and, as mentioned in Section 1.2.1, forms a salt-bridge with D352 (39). In a group of 36 pediatric ACC probands from southern Brazil, this mutation was found in the germline of 35 patients (43). There was loss of heterozygosity in $100 \%$ of the patient tumors. Cancer histories from 25 of 36 patient families were obtained. Twenty-four were not tumor prone. The remaining family had a cancer history meeting the LFLS criteria. Functional studies showed that this mutation retained wild-type function. However, structural observation showed that $\mathrm{R} 337 \mathrm{H}$ is unstable at $37^{\circ} \mathrm{C}, \mathrm{pH} 8$. Specifically, approximately $70 \%$ of $\mathrm{R} 337 \mathrm{H}$ molecules are unstable under these conditions (151). The penetrance of the R337H mutation is low $(9.9 \%)$, compared to the lifetime penetrance $73 \%$ for males and $100 \%$ for females (152). However, this mutation increases the likelihood of carriers developing pediatric ACC by 20,000 fold (151). In addition, this mutation has been found in other tumor types including breast, brain, and soft tissue sarcomas and has been linked to LFLS (153). However, none of the 36 families tested in the initial study analyzing the R337H mutation were associated with LFS (43) and with 30 families as R337H carriers (152), none met LFS criteria. Additionally, in Ribeiro et al. (43) 1 of 35 R337H families met LFLS critieria and only 7 of 30 families with the R337H mutation met LFLS criteria in Figueiredo et al. (152). $\mathrm{R} 337 \mathrm{H}$ involvement in other cancers remains to be elucidated, strongly arguing that cancer arises in a tissue-specific manner due to this mutation (154). 


\subsubsection{Purpose}

The biology of pediatric adrenocortical tumors is largely unknown. However, germline p53 mutations and their associations with pediatric adrenocortical tumors have been well documented. Over the past decade, lowpenetrance p53 mutations and their role in pediatric ACC have become an increasingly important topic based on these postulates: 1) Low-penetrance p53 alleles are specifically present in pediatric ACC; 2) Some low-penetrance p53 germline mutation carriers are more subject to this specific cancer type than others; 3) Families that are affected by low-penetrance p53 germline mutations may or may not meet criteria for either LFS or LFLS; 4) Structure-function relationships of p53 mutants may be useful in predicting the clinical outcome of patient families. In addition, other biological mechanisms in pediatric adrenocortical tumors are not well understood or documented. Therefore these hypotheses will be addressed: 1) Structure-function relationships of lowpenetrance germline p53 mutations, i.e. $\mathrm{R} 337 \mathrm{H}$, may be used to indicate the importance of thorough genetic screening in families with pediatric ACC probands; 2) Identifying cooperating events in pediatric adrenocortical tumors will significantly contribute to the etiology and biological aspects of this disease. 


\section{CHAPTER 2: IDENTIFICATION OF A NOVEL GERMLINE VARIANT HOT SPOT MUTANT p53-R175L IN PEDIATRIC ADRENOCORTICAL CARCINOMA*}

\subsection{Introduction}

The p53 tumor suppressor plays a prominent role in the prevention of cancer by functioning as a transcription factor that induces downstream targets which negatively control cell growth (e.g., p21 ${ }^{\text {Cip1 }}$ ) and viability (e.g., Puma and Noxa) $(99,107,155)$. It is, therefore, not surprising that half of all human cancers have sustained inactivating somatic mutations in p53. Several residues are more frequently targeted than others and these are referred to as hot spot mutations [for review, see (156)]. Interestingly, hot spot mutations disrupt critical DNA contact points or alter the structure in such a way that the protein no longer binds DNA in a sequence specific manner (23). In either case, protypical hot spot mutants are unable to efficiently induce target gene expression, cell cycle arrest and cell death.

Germline p53 hot spot mutations strongly predispose carriers to cancer as children or young adults. Indeed, epidemiology studies estimate that approximately $70 \%$ of males and $100 \%$ of females who inherit a p53 mutation will develop cancer, including tumors of the breast, brain, soft tissue, bone, blood and adrenal cortex (150). The extraordinarily high occurrence of tumors

* Permission to reproduce by The American Association for Cancer Research. West AN, Ribeiro RC, Jenkins J, Rodriguez-Galindo C, Figueiredo BC, Kriwacki R, Zambetti GP. Identification of a Novel Germline Variant Hotspot Mutant p53-R175L in Pediatric Adrenal Cortical Carcinoma. Cancer Res 2006 May 15;66(10):5056-5062. 
associated with germline p53 mutations is referred to as Li-Fraumeni Syndrome (LFS) (118). LFS is formally defined by a proband with a sarcoma before the age of 45 years and a first-degree relative with any cancer under 45 years of age, and an additional first-or-second degree family member with any cancer before 45 years or sarcoma at any age (112). Subsequent studies identified a variation of LFS, referred to as Li-Fraumeni-Like syndrome (LFLS), which includes a proband with any childhood cancer or a sarcoma, brain tumor or adrenocortical tumor before 45 years of age, and a first-degree or second-degree relative with a LFS-type tumor and an additional first or second degree relative with any cancer before 60 years of age (113). A telling feature of LFS and LFLS is a child who has developed an adrenocortical tumor, although other mechanisms (e.g., Beckwith-Wiedemann Syndrome) are also recognized to promote childhood adrenocortical tumorigenesis.

Pediatric adrenocortical tumors (ACT) are extremely rare with an annual worldwide incidence of 0.3-0.4 per million children under the age of 15 (157). Because childhood ACT often arises within LFS and LFLS families, they are usually associated with a germline p53 mutation (158). In many of these cases, the proband has inherited a hot spot p53 mutation. However, childhood ACT can also occur outside the context of LFS/LFLS, and yet be associated with a low penetrant constitutional mutant p53 allele (134). For example, recent studies identified a group of pediatric ACT patients from southern Brazil who inherited a mutation in exon 10, corresponding to an arginine to histidine substitution at amino acid $337(\mathrm{R} 337 \mathrm{H})(43)$. Interestingly, the mutation occurs within the 
$\mathrm{COOH}$-terminal oligomerization domain and not the DNA binding region.

Although the mutation could be tracked through multiple generations within the ACT families, there were no reports of sarcoma or indications of an increased susceptibility to cancer in general. The $\mathrm{R} 337 \mathrm{H}$ mutation strongly predisposes carriers to ACT, but not to LFS or any other tumors (159). Interestingly, the histidine substitution at this site within the oligomerization domain alters the stability of the protein structure in a $\mathrm{pH}$-dependent manner, which presumably forms the basis for the tumor specificity of this particular mutant (151).

The overall structure of p53 relies on arginine 175 (Arg 175), which is located in the L2 loop of the DNA binding domain (23). Arg175 mediates the interaction between the L2 and L3 loops to maintain structural stability.

Substitution of histidine for arginine at amino acid $175(\mathrm{R} 175 \mathrm{H})$ is one of the most common somatic mutations of p53 detected in human cancers $(31,160)$. The $\mathrm{R} 175 \mathrm{H}$ DNA binding domain is unable to bind specifically to the gadd45 promoter sequence, is significantly less thermodynamically stable than the wild-type domain, and is predicted to be completely denatured at $37^{\circ} \mathrm{C}$. Furthermore, fulllength mutant p53 R175H lacks wild-type-like p53 function and is, therefore, transcriptionally inactive and unable to induce cell cycle arrest or apoptosis. Consequently, the $\mathrm{R} 175 \mathrm{H}$ mutant is severely compromised in tumor suppressor function and when inherited is associated with LFS.

In this study, we identified a carrier of a novel germline variant of the p53$\mathrm{R} 175 \mathrm{H}$ hot spot mutation, in which arginine is substituted for leucine, and developed pediatric adrenocortical carcinoma. The R175L variant has been 
infrequently detected in sporadic tumors (e.g., lung, liver, colon and breast; 21 of

more than 21,000 reported cases) and never before as a germline mutation (31). Based on family history, the R175L germline mutation is not associated with LFS or LFLS. We therefore investigated the in vitro and in vivo consequences of this mutation on p53 function and found that it retains partial activity in transcription and growth control. In contrast, the classical LFS hot spot mutant p53-R175H was completely defective in each assay. These findings show that not all amino acid substitutions, even when involving critical residues such as Arg-175, have the same outcome with respect to function and tumor susceptibility. Notably, these findings bear important implications for genetic counseling and possibly clinical management.

\subsection{Materials and Methods}

\subsubsection{DNA Analysis}

DNA was isolated from peripheral blood using the PureGene DNA Isolation kit according to manufacturer's recommendations (Gentra Systems, Minneapolis, MN). Tumor DNA was extracted in xylene-100\% ethanol (1:1) and digested in $50 \mathrm{mM}$ Tris- $\mathrm{HCl}(\mathrm{pH} 8.0)$, and proteinase $\mathrm{K}(14 \mathrm{mg} / \mathrm{ml})$ overnight at $37^{\circ} \mathrm{C}$. Proteinase $\mathrm{K}$ was inactivated at $100^{\circ} \mathrm{C}$ for 5 minutes and the supernatant containing the DNA was collected after centrifugation. Whole blood DNA was quantified and amplified using the multiplex PCR protocol developed by Affymetrix (Valencia, CA). Samples were analyzed by the Hartwell Center (St. 
Jude Children's Research Hospital, SJCRH) using the Affymetrix GeneChip p53 probe array, according to manufacturer's instructions. In addition, genomic DNA from whole blood and tumor samples were PCR amplified and sequenced. Specifically, whole blood DNA was screened using primers spanning exons 5 and 6 of the p53 gene and genomic DNA from the tumor was screened using primers spanning exon 5. Primer sequences are as follows: E5F (forward) [5'CTTGTGCCCTGACTTCAACTCTGTCTC-3'] and E6R (reverse) [5'GCCACTGACAACCACCCTTAACCCCTC3']. The E5R primer (reverse) was derived from the Affymetrix p53 gene chip protocol [5'TGGGCAACCAGCCCTGTCGTCTCTCCA-3'] and used in combination with E5F to amplify tumor DNA. Whole blood DNA was purified by dialysis on $0.025 \mu \mathrm{m}$ filter discs (Millipore, Bedford, MA) and diluted 1:50 in nuclease-free water. Tumor DNA was purified using ExoSAP-IT (US Biochemical, Cleveland, OH) according to manufacturer's instructions. Both blood and tumor DNA was analyzed by high-throughput DNA sequencing (Hartwell Center) and compared with a human p53 genomic sequence (NCBI accession\# U94788). p53 mutation status was also confirmed by DNA sequencing through the Carolinas Medical Center DNA Diagnostics Laboratory (Charlotte, NC).

\subsubsection{Transactivation Assay}

Human SaOS-2 osteosarcoma cells and murine 10(1) fibroblasts $\left(5 \times 10^{5}\right.$ per $10 \mathrm{~cm}$ dish) were grown in Dulbecco's Modified Eagle's Medium (DMEM) containing $10 \%$ fetal bovine serum (FBS), penicillin ( $50 \mu \mathrm{g} / \mathrm{ml}$, streptomycin (100 
$\mathrm{U} / \mathrm{ml}$ ) and $2.5 \mathrm{mM}$ glutamine (complete DMEM) in $100 \mathrm{~mm}$ tissue culture dishes at $37^{\circ} \mathrm{C}$ under $5 \% \mathrm{CO}_{2}$. The cells were co-transfected in duplicate with $250 \mathrm{ng}$ of the p50-2Luc promoter-reporter and either $100 \mathrm{ng}$ or $1 \mu \mathrm{g}$ CMV-Neo Bam (vectoronly) or CMV-Neo-Bam expressing wild-type p53 (WTp53), R175H or R175L.

The cells were lysed after 72 hours and protein yields determined using the BCA Protein Assay kit (Pierce, Rockford, IL). Normalized samples were analyzed by the Single Luciferase Assay kit according to the manufacturer's recommendations (Promega, Madison, WI).

\subsubsection{Apoptosis Assay}

Human H1299 lung adenocarcinoma cells and human SaOS-2 osteosarcoma cells were grown at $4 \times 10^{3}$ cells/dish (35 mm glass coverslipembedded dishes) in complete DMEM at $37^{\circ} \mathrm{C}$ under $5 \% \mathrm{CO}_{2}$. Cells were microinjected with $50 \mathrm{ng} / \mu \mathrm{l}$ pGreenLantern (Life Technologies, Inc. now Invitrogen Corporation, Carlsbad, CA) which expresses green fluorescent protein, and co-injected with either $100 \mathrm{ng} / \mu \mathrm{l} \mathrm{CMV-Neo-Bam,} \mathrm{WTp53,} \mathrm{R175L,} \mathrm{or}$ $\mathrm{R} 175 \mathrm{H}$. Control injections included $100 \mathrm{ng} / \mathrm{\mu l}$ pGreenLantern only. Cells were microinjected using an Eppendorf Transjector system with a Zeiss Axiovert 135TV microscope as previously described (161). Viable fluorescent cells were counted at specific time points after microinjection and photographed (Microinjection Core Lab, SJCRH). 


\subsubsection{Colony Reduction Assay}

SaOS- 2 cells were plated in duplicate in $100 \mathrm{~mm}$ tissue culture dishes and transiently transfected with 100ng and $1 \mu \mathrm{g}$ of either CMV-Neo-Bam, WTp53, R175H, or R175L. Cells were selected in G418 antibiotic (Invitrogen Corporation, Carlsbad, CA) at $0.8-1 \mu \mathrm{g} / \mathrm{ml}$ for up to 21 days. Colonies were washed briefly with phosphate buffered saline (PBS) and fixed with methanol. Cells were stained with 1:20 Giemsa dye (Sigma-Aldrich, St. Louis, MO) for 45 minutes, washed briefly with distilled water and air-dried. Colonies were counted and photographed (Biomedical Communications, SJCRH).

\subsubsection{Protein Analysis}

SDS-PAGE analysis was done with $30 \mu \mathrm{g}$ protein/sample and the Novex NuPAGE Bis-Tris gel system (Invitrogen). Proteins were electrophoretically transferred to nitrocellulose membranes and blocked in TBS-T buffer $(10 \mathrm{mM}$ Tris- $\mathrm{HCl}, \mathrm{pH} 7.4,150 \mathrm{mM} \mathrm{NaCl}, 0.1 \%$ Tween-20) containing 5\% non-fat milk. Membranes were hybridized with sheep polyclonal anti-human p53 Ab-7 (Calbiochem, San Diego, CA) diluted 1:2,500 in TBS-T with 5\% non-fat milk at room temperature for 4 hours. Mouse monoclonal anti-human actin (SigmaAldrich, St. Louis, MO) was diluted at 1:3,000. Membranes were washed with TBS-T and hybridized with either HRP-linked rabbit anti-sheep at 1:5,000 (Pierce, Rockford, IL) or HRP-linked sheep anti-mouse (Amersham Biosciences, Piscataway, NJ) at 1:3000 secondary antibodies for 1 hour at room temperature. The membranes were washed with TBS-T and developed with Supersignal West 
Dura Extended Substrate kit according to the manufacturer's recommendations (Pierce).

\subsubsection{Tissue Preparation and Immunohistochemistry}

Adrenal samples were fixed in $10 \%$ neutral phosphate buffered formalin and processed through graded ethanol to xylene and embedded in paraffin. Multiple 3 to 4 micron sections were cut and attached to lysine-treated glass slides. Heat-induced epitope retrieval was performed with EDTA at pH 8.0. Tissue sections were placed in plastic Coplin jars containing preheated target retrieval solution (DAKO, Carpinteria, CA), heated in a household vegetable steamer (Sunbeam-Oster, Model Sunbeam 4713/5710, $900 \mathrm{~W}$ ) for 35 minutes, and allowed to cool at room temperature for at least 15 minutes. Subsequent steps of the immunohistochemical staining procedure were performed using the DAKO Autostainer at room temperature and included the following: A) blocking of endogenous peroxidase in $3 \% \mathrm{H}_{2} \mathrm{O}_{2}$ in phosphate buffered saline (PBS) at $\mathrm{pH}$ 7.4 for 5 minutes; B) blocking of nonspecific protein-binding sites using protein blocking solution (DAKO) for 5 minutes; $C$ ) incubation with the primary p53 antibody (DAKO clone DO-7) for 1 hour; and D) detection using the streptavidinbiotin-peroxidase based LSAB+ kit (DAKO) for $2 \times 15$ minutes. 3,3' diaminobenzidine/ $\mathrm{H}_{2} \mathrm{O}_{2}$ (Biogenex, San Ramon, $\mathrm{CA}$ ) was used as the chromogen and hematoxylin as the counterstain. Samples that were positive for p53 are identified by the nuclear deposition of a permanent brown precipitate that is readily detected by light microscopy. 


\subsection{Results}

\subsubsection{Identification of the Germline p53-R175L Mutation Associated with}

ACC

An international pediatric adrenocortical tumor registry and bank (IPACTRB) has been established at St. Jude Children's Research Hospital (SJCRH) in order to centralize clinical information regarding the subjects and to collect tissue specimens. The registry component has been in existence since 1990 and has enrolled more than 250 subjects. The intention of the registry and bank is to broaden our understanding of the biology of adrenocortical tumors and how to best treat the patients. The registry and bank have been approved by the SJCRH Institutional Review Board for the protection of human research subjects.

Recently, a female patient from North America who developed adrenocortical carcinoma (ACC) at 3 years of age was enrolled in the IPACTRB. Pediatric ACC is often associated with Li-Fraumeni Syndrome; however, the proband's family history does not fulfill LFS or LFLS criteria (Fig. 2-1). Indeed, there was only one other case of cancer within this family, which was a uterine tumor at 38 years of age (paternal grandmother). Uterine cancer is not an LFS tumor type and is rarely associated with somatic p53 mutations (61 cases of 21,512 total tumors) (31). Nevertheless, given the strong association between p53 mutations and pediatric ACC, the germline status of p53 in the proband was initially determined by Affymetrix p53 chip array analysis using genomic DNA 


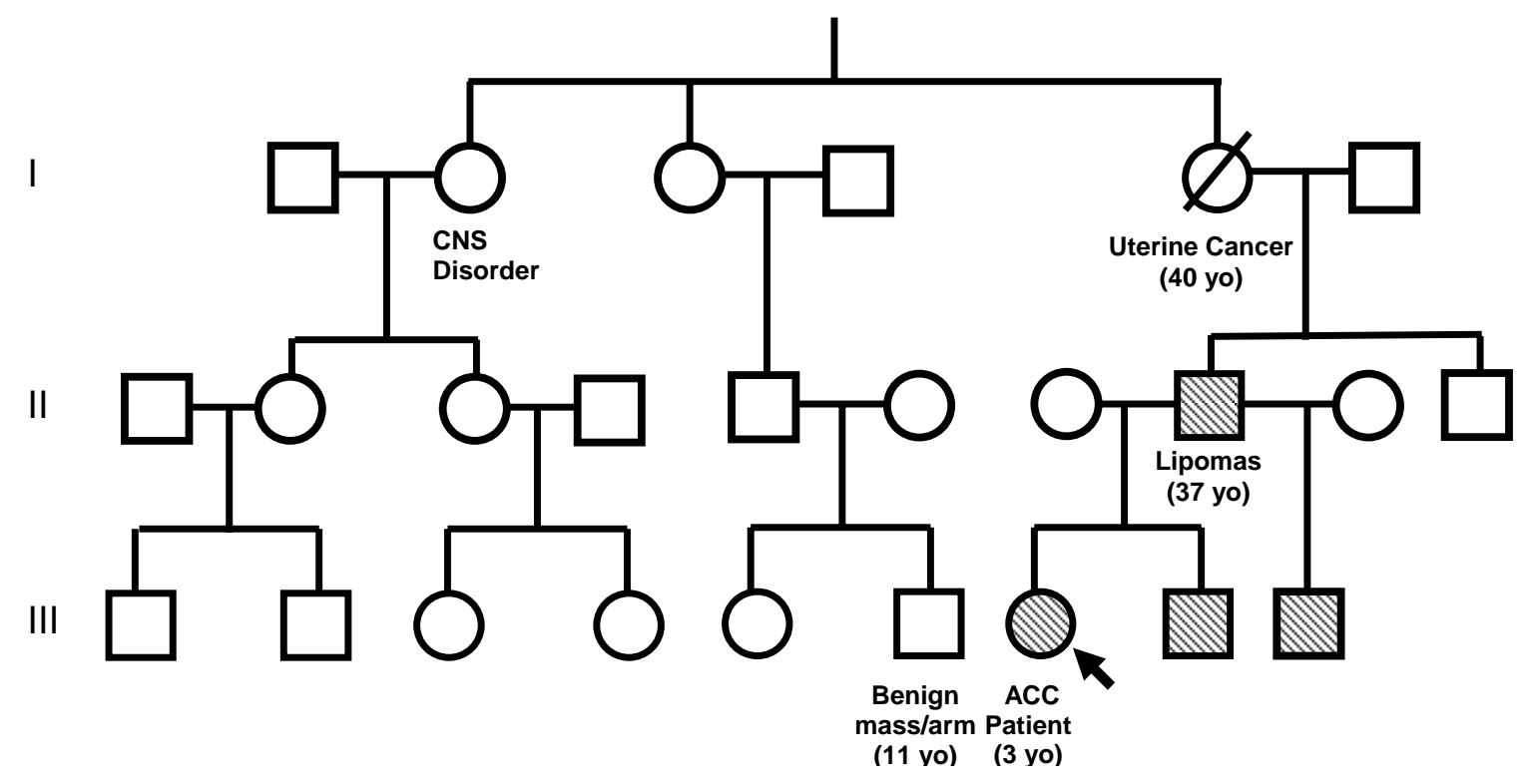

Figure 2-1. Pedigree of the p53-R175L Family. Three generations of the affected family are presented. Deceased individuals are identified by leftward diagonal lines. Identified carriers of the R175L mutation are designated by hatched lines.

prepared from peripheral blood leukocytes (PBLs). Affymetrix analysis revealed a single point mutation (CGC to CTC) in exon 5 at codon 175 , resulting in an arginine to leucine substitution (R175L) (data not shown). DNA sequence analysis confirmed the Affymetrix results and demonstrated the presence of the germline wild-type and mutant p53-R175L alleles (Fig. 2-2). The father and two siblings of the proband are also carriers of the R175L mutation (data not shown), but none of these individuals developed cancer. These findings indicate that the R175L mutation may predispose carriers to adrenocortical tumors without causing LFS. 


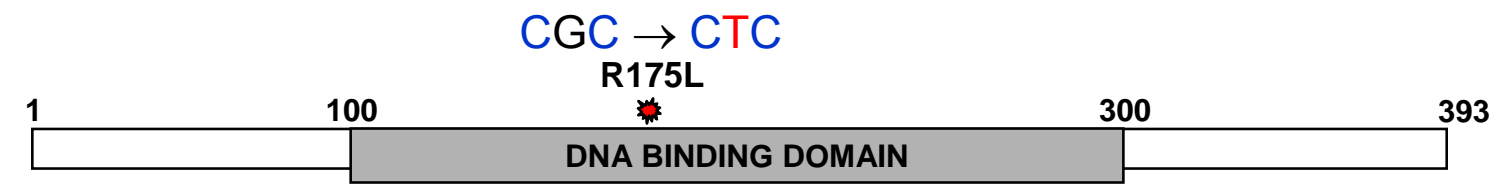

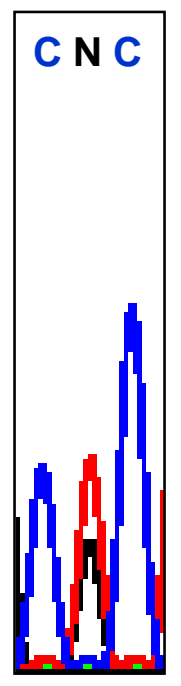

PBL

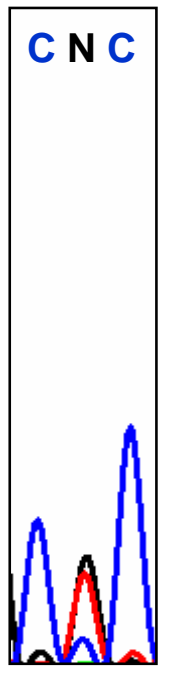

Tumor

Figure 2-2. DNA Sequencing Analysis of the Germline p53-R175L Mutation Associated with Adrenocortical Carcinoma. Schematic diagram of the p53 tumor suppressor highlighting the site of the $\mathrm{R} 175 \mathrm{H}$ mutation found in the proband with ACC (upper panel). Blood DNA from the proband was analyzed by high-throughput sequencing, which revealed both wild-type (CGC) and mutant alleles (CTC) (lower left panel). The heterozygous germline mutation is represented by the double peak at codon 175 . The tumor also revealed both mutant and wild-type alleles, as shown by a double peak at codon 175 (lower right panel). Blue $=$ Cytosine, Red $=$ Thymidine, Black $=$ Guanidine . 


\subsubsection{Elevated Expression of Mutant p53-R175L in ACC}

A hallmark of tumor suppressor genes that have been targeted in human cancers is the elimination of the wild-type allele with retention of the mutant allele, which is referred to as loss of heterozygosity (LOH). Particularly for the p53 tumor suppressor, the mutant allele is usually expressed and the missense protein accumulates to high levels in the nucleus. However, DNA sequence analysis showed that the adrenal tumor of the proband did not undergo $\mathrm{LOH}$ and retained both the wild-type and mutant allele (Fig. 2-2). No second site mutations were detected throughout the coding region. This result is rare but not uncommon in pediatric adrenocortical tumors harboring low-penetrance p53 mutations, as described by Varley et al. (134). As expected for a tumor carrying a p53 mutation, the p53 protein was well expressed and accumulated within the nucleus as shown by immunohistochemical analysis (Fig. 2-3). In contrast, an adrenocortical tumor with wild-type p53 alleles failed to stain for p53 protein expression, consistent with the predicted short half life of the protein (Fig. 2-3). Taken together, these results support the concept that mutant p53-R175L is functionally impaired within the adrenocortical tumor.

\subsubsection{In Vitro Characterization of Mutant p53-R175L Function}

\subsubsection{Transactivation}

The consequence of the R175L mutation on p53 function was explored under a variety of controlled conditions. First, the ability of the R175L mutant to 


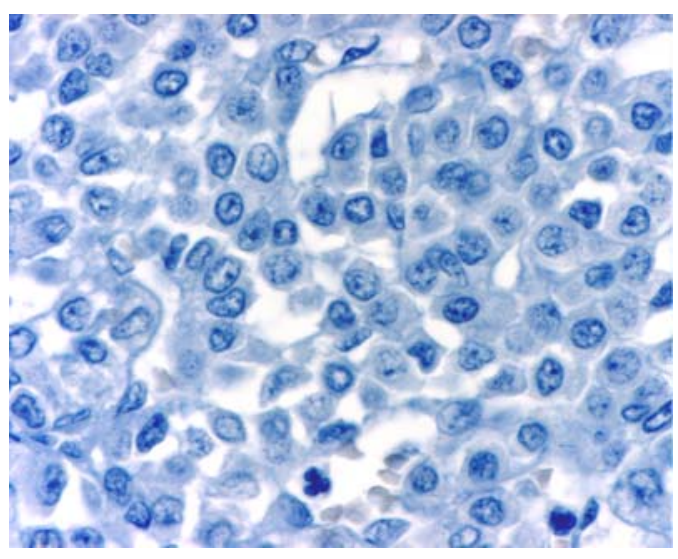

WTp53

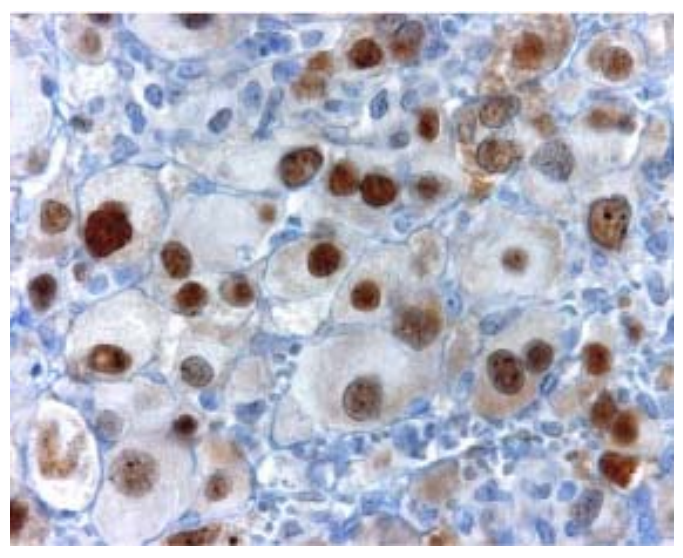

R175L

Figure 2-3. p53 Immunohistochemistry of R175L Tumor. p53

immunohistochemistry illustrates nuclear accumulation of mutant p53-R175L in the adrenocortical tumor (40x magnification, right panel). Adrenocortical tumor expressing wild-type p53 fails to stain for p53 (60x magnification, left panel).

transactivate a p53-responsive promoter was tested using the p50-2Luc reporter plasmid, which contains p53 DNA binding elements from the murine muscle creatine kinase promoter (162). Human osteosarcoma SaOS-2 cells and murine (10)1 fibroblasts, both p53-null cell lines (avoids dominant negative effects), were co-transfected with p50-2Luc and either CMV-Neo-Bam empty vector (CMV-only) or CMV-Neo-Bam-based vectors expressing human wild-type and mutant p53 proteins. The $\mathrm{R} 175 \mathrm{H}$ mutant serves as a negative control, since it is well established that it exhibits a denatured conformation and is severely defective in DNA binding and transactivation functions (163). As expected, wild-type p53, but not mutant p53-R175H, strongly induced promoter-reporter activity in SaOS-2 cells (Fig. 2-4) and (10)1 fibroblasts (Fig. A-1). Mutant p53-R175L retained partial function and upregulated the promoter at approximately $20-40 \%$ efficiency of that 
A
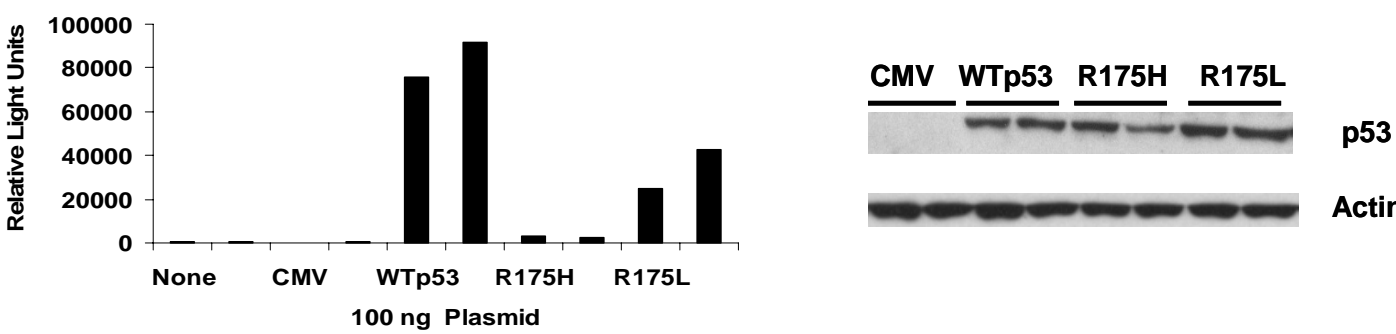

B

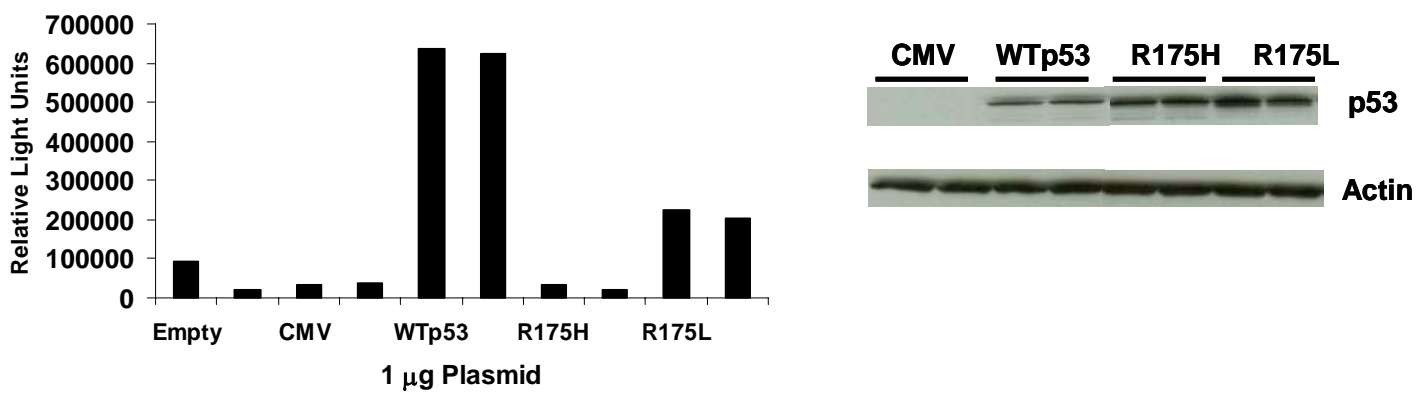

Figure 2-4. Transactivation of the Wild-Type p53 Responsive PromoterLuciferase Reporter by WTp53 and Mutant p53 Proteins. SaOS-2 cells were transfected with 100ng (A) and $1 \mu \mathrm{g}(\mathrm{B})$ CMV p53 expression plasmids in duplicate and reporter activity measured as described in the Materials and Methods (left panel). Protein expression was analyzed by western blot (right panel). 
observed for wild-type p53 (Fig. 2-4A and B; A-1). Western blot analysis showed relatively equal expression of each form of $\mathrm{p} 53$, indicating that the differences in activity reflect alterations in function and are not due to variations in protein levels (Fig. 2-4A and B; A-1). These findings demonstrate that mutant p53-R175L exhibits low, but significant transactivation function.

\subsubsection{Growth Suppression}

To test the effect of the R175L mutation on growth suppression, SaOS-2 cells were transfected with CMV-only or CMV vectors expressing either wild-type or mutant p53. Cells were selected for antibiotic resistance in $0.8-1 \mathrm{mg} / \mathrm{ml} \mathrm{G418}$ for 2-3 weeks, stained with Giemsa dye and photographed. As expected, cells transfected with CMV-only readily formed colonies whereas wild-type p53 efficiently suppressed colony formation (Fig. 2-5). Mutant p53-R175H enhanced the number and size of the colonies at 100ng DNA (Fig. 2-5), consistent with its reported gain-of-function activity that promotes cell growth and survival (163, 164). By contrast, mutant $\mathrm{p} 53-\mathrm{R} 175 \mathrm{~L}$ markedly reduced colony formation, approximately equivalent to wild-type p53 (Fig. 2-5). Similar results were obtained when using $1 \mu \mathrm{g}$ of each plasmid (Fig. A-2). Taken together, these results show that mutant $\mathrm{p} 53-\mathrm{R} 175 \mathrm{~L}$ maintains considerable growth suppressive activity. 

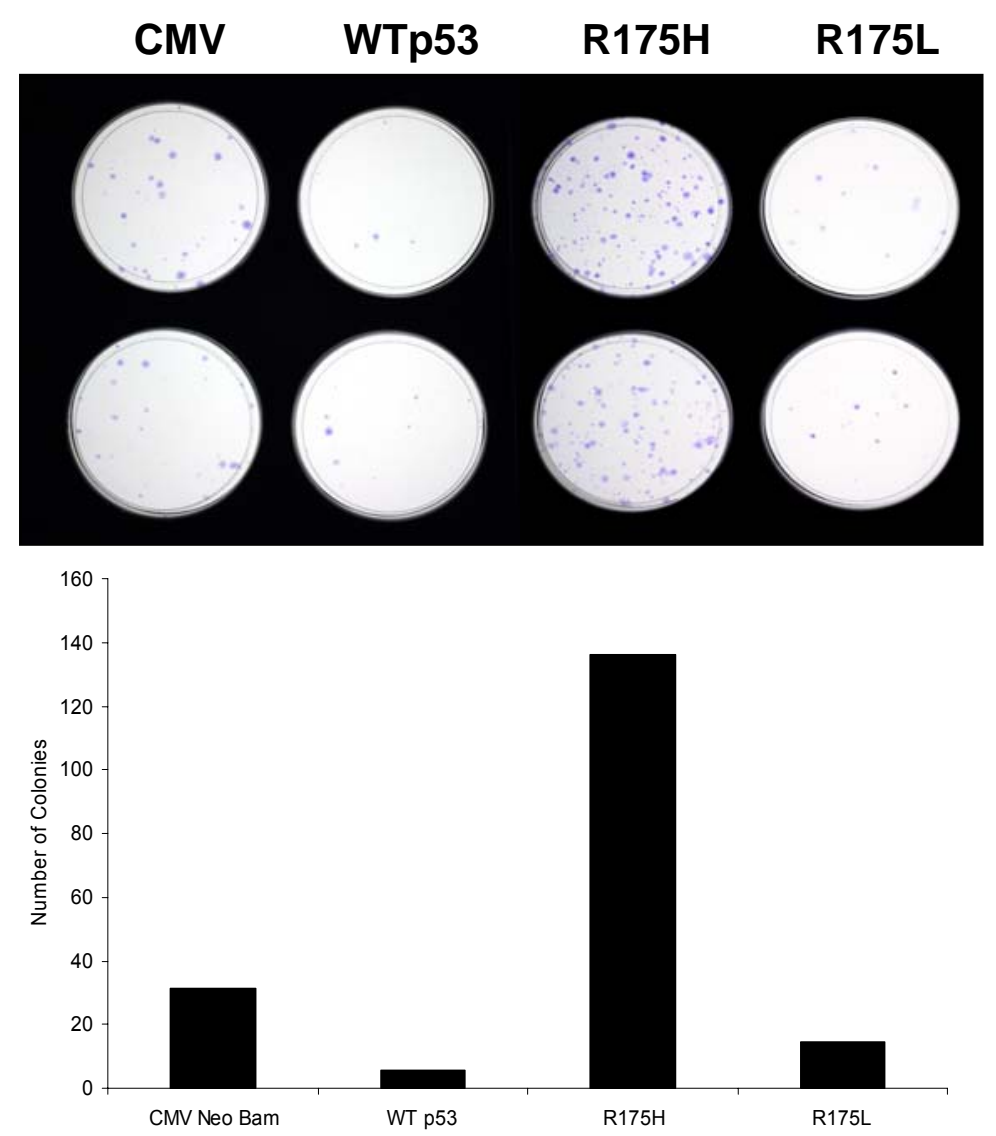

Figure 2-5. p53 Colony Reduction Assay. SaOS-2 cells were transfected in duplicate with 100ng CMV p53 expression plasmids and selected by neomycin (G418) resistance. Colonies were stained by Giemsa dye and photographed (upper panel) and subsequently counted (lower panel). 


\subsubsection{Apoptosis}

Induction of apoptosis by wild-type p53 is thought to be its primary tumor suppressor function. To determine whether mutant $\mathrm{p} 53-\mathrm{R} 175 \mathrm{~L}$ is competent for inducing programmed cell death, SaOS-2 and p53-null human lung adenocarcinoma H1299 cells were microinjected with CMV-only or CMV vectors expressing wild-type or mutant p53 proteins. A vector that expresses green fluorescent protein (pGreenLantern) was included to identify productively injected cells. Cells microinjected with the GFP- and CMV- only plasmids maintained viability and increased in number over a 72 hour period (Fig. 2-6). In contrast, cells expressing wild-type p53 displayed hallmark features of apoptosis and detached from the plate, resulting in a significant loss of viability (Fig. 2-7). Mutant $\mathrm{p} 53-\mathrm{R} 175 \mathrm{H}$ and $\mathrm{p} 53-\mathrm{R} 175 \mathrm{~L}$ were essentially indistinguishable and had no impact on survival or cell number (Fig. 2-7). Similar findings were obtained using human H1299 lung carcinoma cells (Fig. A-3). Therefore, mutant p53-R175L exhibits a clear defect in triggering apoptosis.

\subsubsection{Modeling Structural Effects of the R175L Substitution}

The residues within the L2 (residues 163-195) and L3 (residues 236-251) loops of the DNA binding domain of p53 coordinate $\mathrm{Zn}^{2+}$ which, in turn, maintains key residues within L3 in a conformation competent for binding DNA (23). Arginine-175 lies within the L2 loop and plays a role in orienting Cys176 and His179, also within $\mathrm{L} 2$, for $\mathrm{Zn}^{2+}$ binding. Further, Arg175 may form a salt bridge with Asp184 to stabilize the L2 conformation and hydrogen bond with residues in 


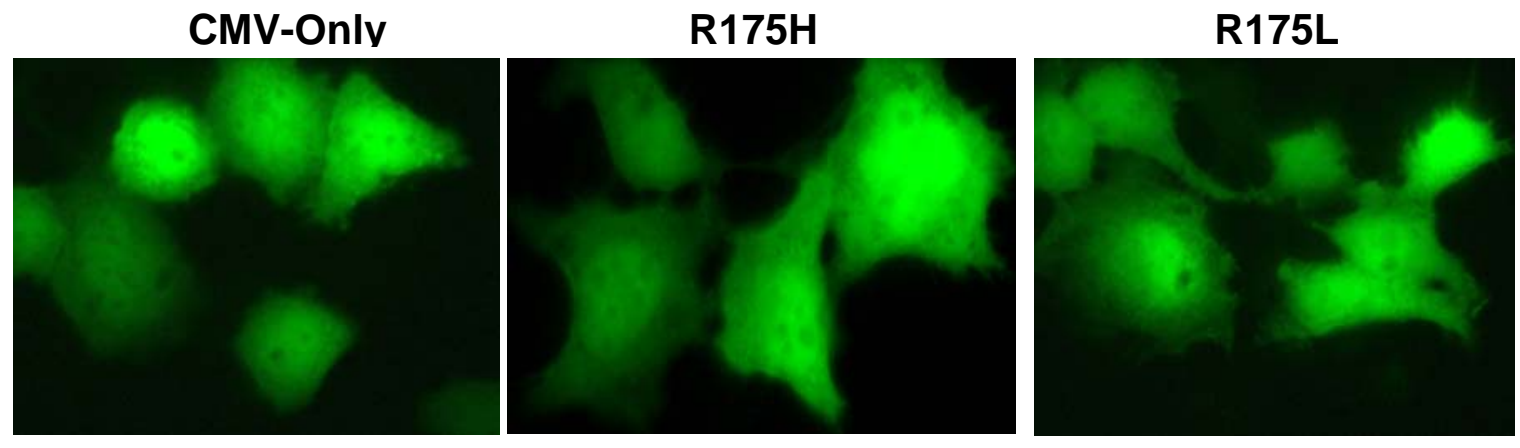

WTp53

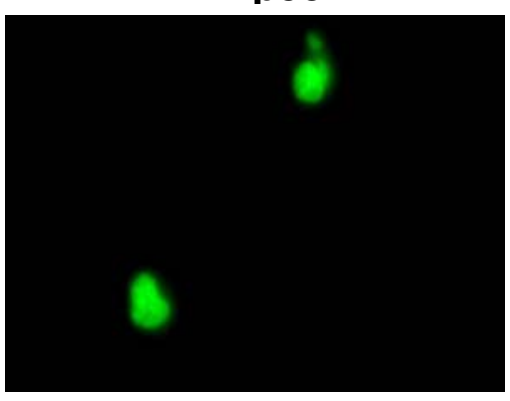

Figure 2-6. p53 Apoptosis Assay. SaOS-2 cells were plated at $4 \times 10^{3}$ per $35 \mathrm{~mm}^{2}$ dish and co-microinjected with pGreenLantern (GFP) and CMV p53 expression plasmids and monitored for apoptosis as described in Materials and Methods. SaOS-2 cells injected with CMV-only, R175H, R175L and WTp53 and photographed at 60 hours. Representative of three independent experiments. 


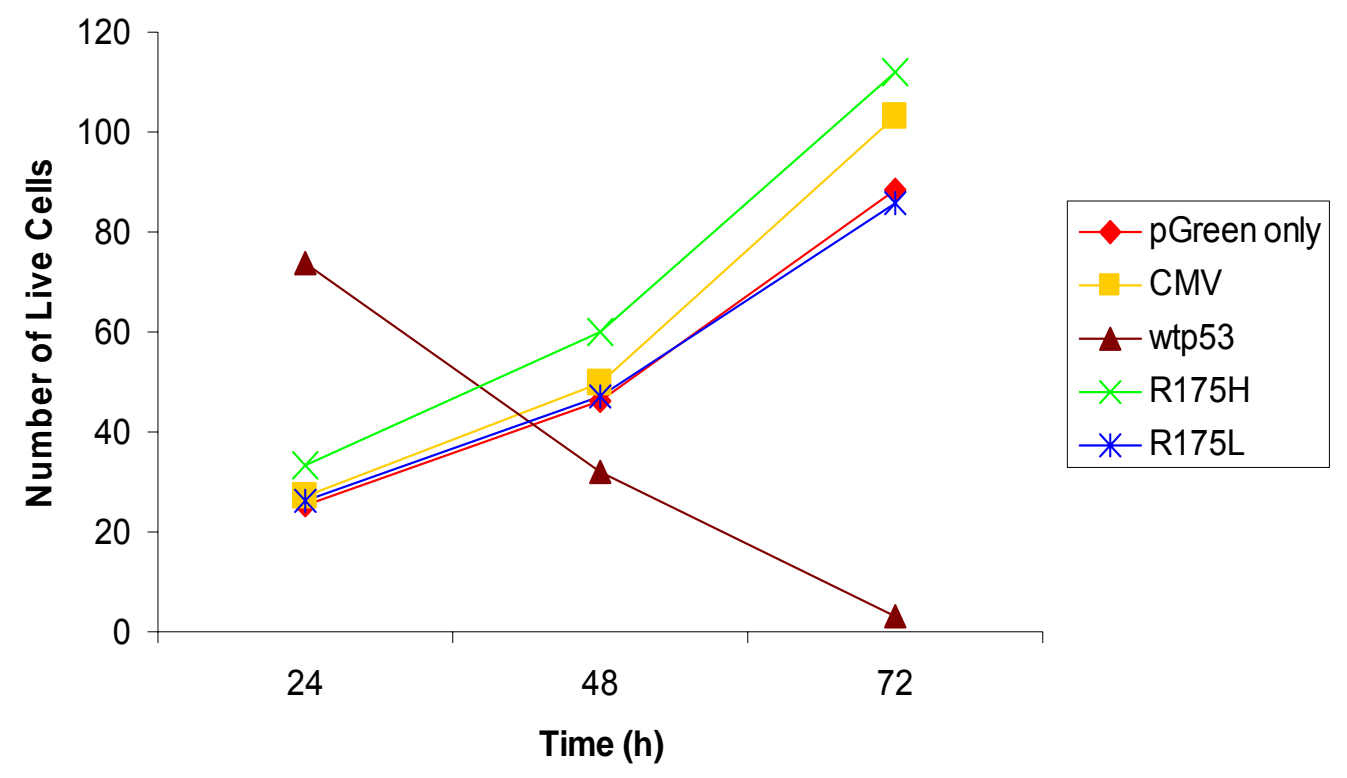

Figure 2-7. Quantitation of p53 Apoptosis Assay. SaOS-2 cells were plated at $4 \times 10^{3}$ per $35 \mathrm{~mm}^{2}$ dish and co-microinjected with pGreenLantern (GFP) and CMV p53 expression plasmids and monitored for apoptosis as described in Materials and Methods. SaOS-2 cells counted at 24, 48, and 72 hours. Representative of three independent experiments. 
L3 to stabilize the L2/L3 interface. It is well established that the R175H substitution significantly destabilizes the p53 native conformation, which exposes an epitope (monoclonal PAb240 reactivity) that usually only becomes accessible when the protein is denatured. This may arise because the His 175 side chain provides an alternative ligand for $\mathrm{Zn}^{2+}$, disrupting the loop L2 conformation.

We have used computerized modeling to infer how the Leu175 mutation may lead to altered stability of loop L2 and thus influence the conformation of the entire DNA binding domain. A structural view of one wild-type p53 DNA binding domain protomer from the crystal structure with DNA is presented in Fig. 2-8. The $\mathrm{Zn}^{2+}$ ion which is tightly bound and required for DNA binding activity is tetrahedrally coordinated by the side chains of Cys176 and His179 in loop L2 and Cys238 and Cys242 in loop L3. In this p53 protomer, the side chain of Arg175 projects from one side of the L2 loop toward that of Asp184 on the other side and may participate in a stabilizing electrostatic interaction (Fig. 2-8B). Further, the conformation of the Arg175 guanidinium group may be further stabilized by hydrogen bonds with backbone atoms of Pro191 in L2 and Met237 in the L3 loop. In contrast, in the Leu175 mutant, the shorter, uncharged side chain (Fig. 2$8 \mathrm{C}$ ) is unable to participate in the salt bridge or in hydrogen bonding to residues in L2 and L3 and may destabilize the native structure by creating a void at the L2/L3 interface. Although the loss of these interactions may destabilize the conformation in the vicinity of the L2/L3 interface, their loss would not necessarily disrupt the overall conformation of the DNA binding domain. The retention of 


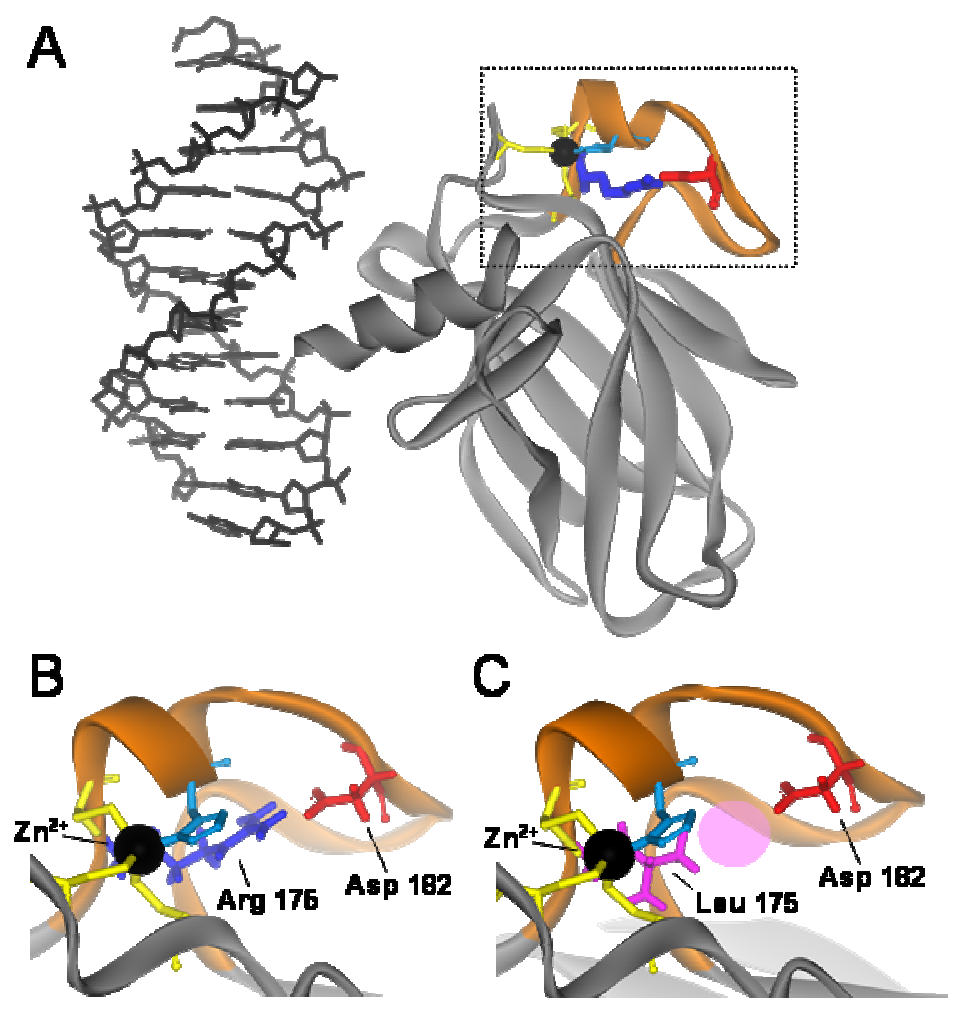

Figure 2-8. Structural View of R175L Mutation within p53 DNA Binding Domain (DBD). A) Wild-type p53 DBD (protomer "B" from 1TUP.pdb). The Cys ligands (residues 176, 238 and 242) of the $\mathrm{Zn}^{2+}$ ion are colored yellow and the His ligand (residue 179) is colored cyan. Arg 175 is colored blue and Asp 182, which forms a salt bridge with Arg 175, is colored red. B) Expanded view of boxed region in Panel A, with the same coloring scheme. C) Arg 175 was mutated to Leu using SwissPdbViewer (http://au.expasy.org/spdbv/); Leu 175 is colored magenta. Leu 175 cannot form a salt bridge with Asp 182, possibly destabilizing the illustrated sub-structure containing the $\mathrm{Zn}^{2+}$ center (shaded black). In addition, substitution of Arg 175 with Leu creates an unoccupied pocket that may cause side chain packing within this sub-domain to be non-ideal and energetically unfavorable. 
significant transactivation and growth suppression activities indicates that this must indeed be the case.

\subsection{Discussion}

We have identified a family that harbors a novel germline variant hot spot mutation, p53-R175L. Although the R175L mutation has been previously reported in the literature, albeit rarely (21 cases in more than 21,000 samples), this is the first incidence of it occurring as a germline mutation (31). The typical mutation at codon 175 results in an arginine to histidine substitution $(\mathrm{R} 175 \mathrm{H})$, which is the third most common somatic and germline p53 mutation listed in the p53 database (31). A wealth of evidence shows that the $\mathrm{R} 175 \mathrm{H}$ mutant is structurally unstable and functionally inactive. Indeed, it no longer binds DNA, transactivates target genes, or induces cell cycle arrest and apoptosis (163). Rather, it acts as a dominant-negative factor that inactivates wild-type p53 and cooperates with activated Ras to transform cells. Carriers of an inherited R175H mutation are associated with LFS and are at a remarkably high risk for developing a wide spectrum of tumors at a young age (165). Interestingly, one other inherited variant hot spot codon 175 mutation, R175G, has been previously reported (166). This mutation is also associated with LFS and predisposes carriers to early onset cancers. Functional studies in a yeast reporter system demonstrated that the R175G mutant was equally defective in transactivation as the $\mathrm{R} 175 \mathrm{H}$ hot spot mutant (166). By contrast, the R175L mutation identified here exists within a family that is not predisposed to cancer. In fact the only tumor, in 
addition to the ACC, that occurred on the affected side of the family was a uterine cancer (paternal grandmother, 38 years of age) (Fig. 2-1), which is not a tumor type involved in LFS or spontaneous tumors associated with p53 mutations (31). The p53 status of the paternal grandfather was wild-type implying that the mutant allele was derived from the paternal grandmother. It should be noted that the father, who is a carrier, developed multiple lipomas. In addition, a second cousin from the affected side of the family also developed a benign soft tissue mass in his forearm at 11 years of age. Other low penetrant germline mutant p53 alleles have been identified that increase the risk of adrenocortical tumors without causing LFS or LFLS $(43,134)$. Analysis of this class of mutants generally shows that they are also impaired in activity, in contrast to the complete inactivation of function seen with classical hot spot mutants.

Our characterization of the adrenocortical tumor provides additional evidence that mutant p53-R175L is functionally compromised in vivo and contributes to tumorigenesis. DNA sequence analysis of the tumor shows that p53 has not selected against the wild type allele (Fig. 2-2). It has been shown that heterozygous p53 mutations occur in pediatric adrenocortical carcinoma without the incidence of a second site mutation (134). In addition, the missense protein is expressed at elevated levels in the nucleus of the adrenocortical tumor cells (Fig. 2-3). Intuitively, mutant p53 must not be sufficiently active for the tumor to tolerate nuclear accumulation of $\mathrm{p} 53-\mathrm{R} 175 \mathrm{~L}$ and to survive and proliferate. The apparent low tumor penetrance associated with the R175L mutation, especially in comparison to the $\mathrm{R} 175 \mathrm{H}$ mutant, may reflect the partial activity of $\mathrm{R} 175 \mathrm{~L}$ in 
transactivation and growth suppression (Figs. 2-4 and 2-5). The R175L mutant has also been shown by others to transactivate the $p 21^{\mathrm{CIP1}}$ promoter, but is unable to transactivate the Bax and IGF-BP3 promoters $(167,168)$. These findings, taken together with the results presented here, show that R175L controls partial tumor suppressor function. Loss of further activity would likely predispose carriers of the R175L mutation to LFS or LFLS syndrome.

Other somatic mutations at codon 175 have been observed in human tumors. One such example is R175P. Functional studies showed that R175P is defective in apoptosis, but less so in cell cycle arrest (169). The R175P mutant was critically assessed by generating a mouse knock-in mutation model. Thymocytes from homozygous mutant R175P mice are completely resistant to DNA damage-induced apoptosis, but cells can undergo cell cycle arrest to some extent. The mice are tumor prone, but tumor onset is delayed compared with p53-knockout mice, demonstrating that the R175P also retains a substantial degree of activity.

Mutant p53-R175H associates with hsp70 and binds to monoclonal antibody PAb240 (recognizes the denatured conformation) but not PAb1620 (specific for the native structure), indicating that the missense protein is unfolded $(163,167)$. By contrast, the p53-R175L mutant does not associate with hsp70 and is positive for binding to PAb1620 and not PAb240 (167). These findings suggest that the leucine substitution at codon 175 is less disruptive to the native p53 conformation, which is consistent with our data demonstrating that mutant p53-R175L displays significant transactivation function and contributes to growth 
suppression, as well as being associated with a less penetrant tumor phenotype in carriers.

Here we have identified a naturally occurring human p53 germline hot spot variant mutation, which is indeed a rare occurrence. Although we cannot reach a firm conclusion regarding the penetrance of the R175L mutation due to human subject consent issues, our data indicate that the R175L variant exhibits a milder phenotype than the LFS-associated germline R175H and R175G mutations. It is becoming increasingly clear that the biochemical nature of the amino acid substitution at a particular residue, including hot spot mutants, can have very different clinical outcomes. Germline R337H mutations selectively predispose carriers to childhood adrenocortical tumors whereas the R337C mutant is associated with breast cancer and LFLS syndrome $(43,127,170)$. Similarly, the $\mathrm{R} 175 \mathrm{H}$ hot spot mutation causes LFS while our results to date indicate that the R175L can cause ACC without being associated with LFS or LFLS syndrome. Although a number of knock-in mutant p53 mouse models have been recently generated to test the effects of different amino acid substitutions in a selected site $(169,171,172)$, the identification of the $\mathrm{R} 175 \mathrm{~L}$ mutation in a family with a child who developed ACT offers a unique opportunity to study this phenomenon in a human setting. It will be important to continually monitor these individuals in the future to fully evaluate the effect of the germline R175L mutation on tumorigenesis. Finally, the information provided by the genetic and biochemical data presented in this article shows the importance of thorough screening for p53 
status in cancer patients and their families for use in diagnosis, treatment, and genetic counseling. 


\section{CHAPTER 3: GENE EXPRESSION PROFILING OF CHILDHOOD ADRENOCORTICAL TUMORS}

\subsection{Introduction}

Pediatric adrenocortical tumors (ACT) are rare malignancies occurring at a rate of 0.3-0.4 annual cases per million children under the age of $18(133,173)$. Signs and symptoms of ACT include virilization, acne, deep voice, facial hair, muscle weakness, facial hyperemia, hypertension, and other signs of Cushing syndrome. The tumor size and weight, disease staging, and selected histologic criteria have been used to classify ACT as either carcinoma (ACC) or adenoma (ACA). Large tumors (> $200 \mathrm{~g}$ ), and locally invasive or metastatic tumors, have been associated with poor outcome. However, in many cases, clinical and pathological features fail to identify patients with localized disease that eventually relapse. Current therapy for pediatric ACT relies primarily on surgical resection of the tumor, although mitotane (a DDT-related compound)—with or without DNA damaging agents—has been used with some success (174). The overall 5-year disease-free survival is $50 \%$, however, patients with Stage IV disease have less than a $10 \%$ chance of long-term survival (173).

The adrenal cortex synthesizes essential steroids (e.g., glucocorticoids, androgens, and mineralocorticoids) that regulate diverse biological processes such as blood pressure, glucose metabolism, immune surveillance, and sexual

* Permission to reproduce by The American Association for Cancer Research. West AN, Neale GA, Pounds S, Figueiredo BC, Rodriguez-Galindo C, Pianovski MA, Oliveira-Filho AG, Malkin D, Lalli E, Ribeiro R, Zambetti GP. Gene Expression Profiling of Childhood Adrenocortical Tumors. Cancer Res 2007 Jan 15;67(2):600-608. 
development $(132,175)$. During gestation, the cortex is subdivided into the outerdefinitive and inner-fetal zones, which contribute to the maintenance of normal pregnancy through the production of dihydroepiandrosterone sulphate (DHEA-S). As this function is no longer required after birth, the adrenal gland rapidly loses $50 \%$ of its volume within the first 2 weeks due to massive apoptosis.

Subsequently, the adrenal cortex undergoes significant tissue remodeling and develops into 3 defined regions: outer zona glomerulosa, middle zona fasciculata, and inner zona reticularis. The zona glomerulosa is primarily responsible for the production of aldosterone, whereas the zona fasciculata and zona reticularis produce corticosteroids and androgens, respectively. Various genetic abnormalities, either acquired or inherited (see below), promote ACT development during childhood or late adulthood (176).

Pediatric ACT is frequently reported in families with Li-Fraumeni Syndrome (LFS) and Li-Fraumeni-Like Syndrome (LFLS), which are usually associated with TP53 tumor suppressor germline mutations $(113,118)$. The most frequently observed tumors in LFS include soft tissue sarcomas, osteosarcomas, breast carcinomas, brain tumors, and adrenocortical carcinoma. Indeed, it has been proposed that pediatric ACT is almost diagnostic of a germline TP53 mutation (158), but clearly alternative factors can contribute to this tumor type (e.g., Beckwith-Wiedemann Syndrome (BWS), Carney's complex, and multiple endocrine neoplasia type I) (135). BWS is characterized by the overgrowth of tissues and organs, including the adrenal gland. BWS is usually sporadic, but also occurs as a familial autosomal dominant form linked to the loss of imprinting 
(LOI) at the Insulin-Like Growth Factor-II (IGF-II) locus on chromosome 11p15.5; resulting in the overproduction of IGF-II (176). The underlying genetic events responsible for the BWS phenotype are complex, with multiple genes (e.g., KCNQ1 and CDKN1C) being implicated in its etiology $(141,177)$.

The cooperating factors and signaling pathways that promote the development of childhood ACT are not well defined. Animal studies implicate Inhibin- $\alpha$, a glycoprotein with homology to TGF- $\beta$, as a suppressor of ACT development (178). Deletion of Inhibin- $\alpha$ by gene targeting in gonadectomized mice causes fully penetrant adrenocortical tumors by $4-5$ weeks of age. Consistent with the mouse model, mutation of INHIBIN- $\alpha$ (INHA) with loss of heterozygosity $(\mathrm{LOH})$ at chromosome $2 \mathrm{q} 33$ was commonly observed in human pediatric adrenocortical tumors (178). Comparative genomic hybridization analysis of pediatric ACT also demonstrated recurrent chromosomal alterations, such as the amplification of chromosome 9q34 (144). Localized within this region is the nuclear orphan receptor Steroidogenic Factor-1 (SF1, NR5A1), which is required for normal adrenal gland development. Subsequent studies demonstrated that SF1 is amplified and overexpressed in about $90 \%$ of pediatric adrenocortical tumors $(147,179)$. Similarly, both pediatric and adult ACT express elevated levels of IGF-II $(136,180)$.

Due to the rarity of pediatric $\mathrm{ACT}$, it becomes necessary to consolidate resources to maximize efforts in studying this disease in a comprehensive and thorough manner. We therefore established an International Pediatric Adrenocortical Tumor Registry and Bank (IPACTRB) at St. Jude Children's 
Research Hospital (St. Jude; www.stjude.org). More than 250 subjects have enrolled in the registry component since 1990 (the adrenal tissue bank has been in existence since 2000). To identify key factors and signaling pathways that may be involved in adrenocortical tumorigenesis, we conducted an Affymetrix gene expression profiling analysis of pediatric ACT. As we report here, distinct expression signatures have been identified that discriminate between normal adrenal cortex and ACT. In addition, our retrospective analyses identified profiles that may aid in the differential diagnosis of adenoma from carcinoma. Insight into the cell type of origin that gives rise to ACT has also been generated. Our findings provide the basis for identifying signaling pathways that are corrupted during adrenocortical tumorigenesis, with the goal of establishing new therapeutic targets that could be exploited in treating this often fatal disease.

\subsection{Materials and Methods}

\subsubsection{IRB Approval}

The Institutional Review Boards of St. Jude and the Hospital for Sick Children, and the Ethics Committees of the Hospital de Clinicas of the Federal University of Parana, Hospital Erasto Gaertner, and the Centro Infantil de Investigações Hematológicas Dr. Domingos A. Boldrini approved the genetic analysis of pediatric normal adrenal cortex and adrenocortical tumors. Informed consent was obtained for each subject. 


\subsubsection{Total RNA Preparation}

Tissue samples were classified according to established histopathological criteria and verified by 2 independent pathologists. Total RNA was isolated from 50-100 mg of pediatric adrenocortical tumors using the Qiagen RNeasy RNA Midi-Prep kit (Valencia, CA). Tumors were prepared in a $4^{\circ} \mathrm{C}$ cold room, sliced into fine pieces using a sterile scalpel and homogenized with 18 and 19 gauge needles in lysis Buffer RLT (Qiagen) containing $\beta$-mercaptoethanol. Total RNA was isolated by the 'Animal Tissues' protocol following the manufacturer's recommendations. The RNA was resuspended in diethyl pyrocarbonate-treated water, quantified by UV absorbance at $260 / 280 \mathrm{~nm}$, and stored at $-80^{\circ} \mathrm{C}$.

\subsection{3 cDNA Amplification and Real-Time PCR Analysis}

cDNA was generated from $1 \mu \mathrm{g}$ total RNA using the iScript cDNA amplification kit according to the manufacturers' instructions (Bio-Rad Laboratories, Hercules, CA). cDNA was diluted 1:2 using sterile double distilled $\mathrm{H}_{2} \mathrm{O}$ prior to real-time PCR analysis. The following genes were amplified by realtime PCR using the iQSybrGreen PCR amplification mix (Bio-Rad Laboratories; according to the manufacturer's instructions) and 400 ng per primer: IGF-II, HSD3B2, FGFR4, NURR1, NGF1-B, and NOV. Ubiquitin was also amplified as a loading control. Each normal adrenal and tumor sample was amplified in triplicate via separate PCR conditions and compared to ubiquitin expression levels using the $\Delta \Delta \mathrm{cT}$ method (181). Primer sequences and PCR conditions are described in Table B-1. 


\subsubsection{Western Blot Analysis}

Protein was isolated from normal adrenal cortex and tumor tissues by homogenization in T-PER lysis buffer (Pierce Chemical, Rockford, IL) containing a protease-inhibitor cocktail (Roche Diagnostics Corporation, Indianapolis, IN). Total protein $(50 \mu \mathrm{g})$ was analyzed by SDS-PAGE using the Novex NuPAGE system (Invitrogen, Carlsbad, CA). Proteins were separated by electrophoresis and transferred to $0.45 \mu \mathrm{m}$ nitrocellulose membranes. Membranes were blocked in TBS-T buffer (10 mmol/L Tris-HCl [pH 7.4], $150 \mathrm{mmol} / \mathrm{L} \mathrm{NaCl}, 0.1 \%$ Tween 20) containing $5 \%$ nonfat milk and probed with the following primary antibodies: goat polyclonal anti-human IGF-II (1:500; Sigma-Aldrich Chemical, St. Louis, MO), rabbit polyclonal anti-human HSD3B2 (1:500; gift from Dr. C. Richard Parker Jr., University of Alabama, Birmingham, AL), and mouse monoclonal anti-human Actin (1:2000; Sigma-Aldrich Chemical). Membranes were washed with TBS-T and hybridized with the following horseradish peroxidase-linked antibodies diluted in TBS-T containing 5\% nonfat milk: rabbit anti-goat $(1: 1,000$; Calbiochem, San Diego, CA), donkey anti-rabbit (1:3,000; Amersham Biosciences, Piscataway, NJ), and sheep anti-mouse (1:2,000; Amersham Biosciences). The membranes were washed with TBS-T and developed using Supersignal West Dura chemiluminescence reagent (Pierce Chemical), according to the manufacturer's protocol. 


\subsubsection{Microarray Analysis}

The Affymetrix U133A GeneChip was used to collect expression data for 22,215 probe sets on each of 31 samples (18 adrenocortical carcinomas, 5 adenomas, 1 undetermined adrenocortical tumor, and 7 normal adrenal cortex). Microarray analysis was performed in the Hartwell Center Affymetrix core laboratory at St. Jude. High quality RNA, confirmed by UV spectrophotometry and an Agilent 2100 Bioanalyzer, was processed according to the Affymetrix one-cycle labeling protocol (http://www.affymetrix.com/support/technical/manual/ expression manual.affx). In brief, 5 to $10 \mu \mathrm{g}$ total RNA was annealed to an oligodT(24)-T7 primer to initiate cDNA synthesis. Purified double-stranded cDNA was used as a template to synthesize biotin-labeled cRNA using T7 RNA polymerase. Labeled cRNA $(20 \mu \mathrm{g})$ was fragmented, added to a mixture containing blocking agents and array controls, and hybridized overnight at $45^{\circ} \mathrm{C}$ to the gene chip array. Following hybridization, arrays were stringently washed, stained with streptavidin-conjugated phycoerythrin, and scanned using an Affymetrix GeneChip Scanner 3000. Relative expression signals for each gene was calculated using the Affymetrix GCOS software (version 1.4) using the global normalization method where the $2 \%$ trimmed mean signal was set to a target value of 500 .

\subsubsection{Statistical Analysis}

Microarray signals were summarized and normalized using Affymetrix GCOX software as described above. No probe set was excluded prior to 
subsequent statistical analysis because filtering has been found to be of questionable value (182). The Wilcoxon rank-sum test was used to compare each probe set's median expression between normal and tumor tissues (183). Likewise, the rank-sum test was used to compare the median expression level of each probe set between ACA and ACC. To account for multiple testing in each of these analyses, we used a robust method to estimate the false discovery rate (184). These analyses were implemented using S-plus (www.splus.com) software, version 6.2 for Windows (Microsoft). The robust FDR method was implemented using our freely available routines (http://www.stjuderesearch.org/ depts/biostats/robustfdr/index.html).

To compare expression profiles in our pediatric ACT samples with data in other reports $(137,138)$ U133A probesets were matched by either GenBank accession ID (137) or by the Affymetrix "best match" criteria (138). Fold-change point estimates were computed by exponentiation of the difference of means of log-transformed signals. This estimate of fold-change can be interpreted as an estimate of the ratio of two groups' median expression levels. The t-distribution was used to compute $95 \%$ confidence intervals for the difference of means of log-signals; these intervals were transformed into confidence intervals for foldchanges by exponentiation. The fold-change confidence intervals are not adjusted for multiple-testing.

As measures of how fold-changes observed in our study correlated with fold-changes observed in other studies, we computed the number of probe sets with a directional agreement (i.e., the fold-change estimates from the two studies 
were in the same direction) and Kendall's T (185) with the two sets of foldchanges as input. We used a permutation method to assess the statistical significance of the observed values of these measures of agreement. The permutation assessment was performed by computing the fold-changes on 1,000 data sets, derived by randomly reassigning group labels in our data set to the expression profiles in our data set, and then computing the agreement statistics. We counted the number of permuted data sets in which stronger values of the agreement statistics were observed to obtain the p-value.

Estimates of overall and relapse-free survival were computed using the Kaplan-Meier method with standard errors determined using the method of Peto and Pike (186). Overall survival was defined as the duration from date of diagnosis to date of death with those living at lost follow-up considered censored. Relapse-free survival was defined as the duration from date of diagnosis to date of relapse or death with those alive and relapse-free at last follow-up censored.

\subsection{Results}

\subsubsection{Clinical Information}

Pediatric ACA and ACC patients were enrolled on the International Pediatric Adrenocortical Tumor Registry and Bank protocol. Tumor specimens were harvested during surgery and snap-frozen in liquid nitrogen to preserve tissue integrity. Data have been compiled for 8 males and 15 females between 0 and 16 years of age. Table 3-1 summarizes the primary clinical information for 
Table 3-1. Clinical Data of 24 Pediatric Adrenocortical Cancer Patients.

\begin{tabular}{|c|c|c|c|c|c|c|c|c|c|c|}
\hline Sample & Sample ID & Sex & $\begin{array}{l}\text { Age } \\
\text { (in years) }\end{array}$ & $\begin{array}{l}\text { Tumor or } \\
\text { Normal }\end{array}$ & $\begin{array}{l}\text { Histological } \\
\text { Type (Adenoma or } \\
\text { ACC) }\end{array}$ & $\begin{array}{l}\text { Tumor } \\
\text { Stage }\end{array}$ & Virilization & $\begin{array}{l}\text { Cushing } \\
\text { Syndrome }\end{array}$ & Outcome & Treatment \\
\hline 1 & ACC1 & $M$ & 8 & $\mathrm{~T}$ & $\mathrm{ACC}$ & 4 & $\bar{Y}$ & $\mathrm{~N}$ & $\mathrm{CR}^{*}$ & $\mathrm{SC}^{*}$ \\
\hline 2 & ACA1 & $F$ & 12 & $\mathrm{~T}$ & Adenoma & $\star * *$ & Y & $Y$ & $\mathrm{CCR}^{*}$ & $S^{*}$ \\
\hline 3 & ACC2 & $\mathrm{F}$ & 5 & $\mathrm{~T}$ & $\mathrm{ACC}$ & 2 & $Y$ & $\mathrm{~N}$ & $\mathrm{DD}^{*}$ & SC \\
\hline 4 & ACA2 & $F$ & $<1$ & $\mathrm{~T}$ & Adenoma & $* * *$ & Y & $Y$ & CCR & $S$ \\
\hline 5 & ACC3 & M & 2 & $\mathrm{~T}$ & $\mathrm{ACC}$ & 3 & $Y$ & $\mathrm{~N}$ & DD & SC \\
\hline 6 & ACC4 & $\mathrm{F}$ & 2 & $\mathrm{~T}$ & ACC & 1 & $Y$ & $\mathrm{~N}$ & CCR & $S$ \\
\hline 7 & Unk1* & Unk* & Unk & $\mathrm{T}$ & Unk & Unk & Unk & Unk & Unk & Unk \\
\hline 8 & ACC5 & $\mathrm{M}$ & 4 & $\mathrm{~T}$ & $\mathrm{ACC}$ & 2 & Y & $\mathrm{N}$ & CR & SC \\
\hline 9 & ACC6 & $F$ & 13 & $\mathrm{~T}$ & $\mathrm{ACC}$ & 4 & Y & $\mathrm{Y}$ & Deceased* & SC \\
\hline 10 & ACA3 & $\mathrm{F}$ & 3 & $\mathrm{~T}$ & Adenoma & $* * *$ & Y & $\mathrm{N}$ & CCR & S \\
\hline 11 & ACA4 & $\mathrm{F}$ & 2 & $\mathrm{~T}$ & Adenoma & $* * *$ & $Y$ & $Y$ & CCR & $S$ \\
\hline 12 & ACA5 & $\mathrm{F}$ & 4 & $\mathrm{~T}$ & Adenoma & $* * *$ & $Y$ & $\mathrm{~N}$ & CCR & $S$ \\
\hline 13 & $\mathrm{ACC} 7$ & $\mathrm{~F}$ & 11 & $\mathrm{~T}$ & $\mathrm{ACC}$ & 2 & Y & $Y$ & $\mathrm{CR}$ & SC \\
\hline 14 & ACC8 & $M$ & 9 & $\mathrm{~T}$ & ACC & 2 & $Y$ & $Y$ & DD & SC \\
\hline 15 & ACC9 & $M$ & 2 & $\mathrm{~T}$ & ACC & 1 & $Y$ & $Y$ & DD & SC \\
\hline 16 & ACC10 & $F$ & $<1$ & $\mathrm{~T}$ & ACC & 2 & $Y$ & $Y$ & CCR & $S$ \\
\hline 17 & ACC11 & $M$ & 2 & $\mathrm{~T}$ & ACC & 1 & $Y$ & $\mathrm{~N}$ & CCR & $S$ \\
\hline 18 & ACC12 & $M$ & 12 & $\mathrm{~T}$ & ACC & 3 & $Y$ & $Y$ & CCR & SC \\
\hline 19 & ACC13 & $M$ & 4 & $\mathrm{~T}$ & ACC & 3 & $Y$ & $Y$ & $\mathrm{CR}$ & SC \\
\hline 20 & ACC14 & $\mathrm{F}$ & 10 & $\mathrm{~T}$ & ACC & 3 & $Y$ & $\mathrm{~N}$ & CR & SC \\
\hline 21 & ACC15 & $\mathrm{F}$ & 3 & $\mathrm{~T}$ & $A C C$ & 1 & $Y$ & $Y$ & $\mathrm{CR}$ & SC \\
\hline 22 & ACC16 & $\mathrm{F}$ & 6 & $\mathrm{~T}$ & ACC & 2 & $Y$ & $\mathrm{~N}$ & & SC \\
\hline 23 & ACC17 & $\mathrm{F}$ & 15 & $\mathrm{~T}$ & ACC & 4 & $Y$ & $\mathrm{~N}$ & DD & SC \\
\hline 24 & ACC18 & $\mathrm{F}$ & 3 & $\mathrm{~T}$ & ACC & 3 & $Y$ & $\mathrm{~N}$ & CCR & SC \\
\hline
\end{tabular}


Table 3-1 (continued).

\begin{tabular}{|c|c|c|c|c|c|c|c|c|c|c|}
\hline Sample & $\begin{array}{l}\text { Sample } \\
\text { ID }\end{array}$ & Sex & $\begin{array}{l}\text { Age } \\
\text { (in years) }\end{array}$ & $\begin{array}{l}\text { Tumor or } \\
\text { Normal }\end{array}$ & $\begin{array}{l}\text { Histological } \\
\text { Type (Adenoma or } \\
\text { ACC) }\end{array}$ & $\begin{array}{l}\text { Tumor } \\
\text { Stage }\end{array}$ & Virilization & $\begin{array}{l}\text { Cushing } \\
\text { Syndrome }\end{array}$ & Outcome & Treatment \\
\hline 25 & Nor001 & Unk & Unk & $\mathrm{N}$ & $\mathrm{NA}^{*}$ & NA & NA & NA & NA & NA \\
\hline 26 & Nor004 & Unk & Unk & $\mathrm{N}$ & NA & NA & NA & NA & NA & NA \\
\hline 27 & Nor006 & Unk & Unk & $\mathrm{N}$ & NA & NA & NA & NA & NA & NA \\
\hline 28 & Nor007 & Unk & Unk & $\mathrm{N}$ & NA & NA & NA & NA & NA & NA \\
\hline 29 & Nor009 & Unk & Unk & $\mathrm{N}$ & NA & NA & NA & NA & NA & NA \\
\hline 30 & Nor010 & Unk & Unk & $\mathrm{N}$ & NA & NA & NA & NA & NA & NA \\
\hline 31 & Nor011 & Unk & Unk & $\mathrm{N}$ & NA & NA & NA & NA & NA & NA \\
\hline
\end{tabular}

*Abbreviations: Unk - Unknown, NA - Not applicable, D - Bilateral disease, CR - Complete remission, CCR Continuous complete remission, DD - Died from disease, Deceased - Died from unknown causes, S - Surgical resection only, SC - Surgical resection plus chemotherapy

${ }^{* *}$ Ages rounded to nearest full year

${ }^{* * *}$ Adenomas are not staged based on standard adrenocortical tumor staging criteria (173). 
each subject (excluding sample Unk1 with ACT of undetermined histology), including stage of the disease, tumor class, sex, age, relapse-free survival, and overall survival. Details regarding clinical features and treatment were also collected.

All subjects presented with virilization. Eleven patients had signs and symptoms consistent with an increased secretion of glucocorticoids (Cushing syndrome) and 8 patients were hypertensive at presentation. Normal adrenal glands were obtained with IRB approval as discarded tissue from 7 cases of Wilms' tumor. These patients, whose age ranged from 2 to 6 years, had not received chemotherapy prior to surgery; thus avoiding complications of chemotherapeutic effects. Normal adrenal cortex was subsequently isolated by an American Board certified pathologist and processed as described in the Materials and Methods.

\subsubsection{Gene Expression Profiling Distinguishes Adrenocortical Tumors from Normal Adrenal Tissue}

Gene expression profiles for the ACT and normal adrenal cortex samples were generated using the Affymetrix U133A gene chip, which recognizes 14,500 genes using 22,215 probe sets. We estimate that at least $33 \%$ of the probe sets on the array are differentially expressed between tumor and normal tissues; for 1,019 of the probe sets, we detected differences that were significant at 
$p=0.001(187)$. Furthermore, we estimate that $1.5 \%$ or fewer of the 1,019 detected differences are false discoveries. Hierarchical clustering analysis was used to visualize the variability between ACT and normal cortex (Fig. 3-1).

\subsubsection{Validation of the Gene Expression Dataset}

Among the 1,019 significant probe sets, we identified 25 with the greatest and least ratios of median expression in tumor samples to that of normal samples (Table 3-2). The median expression of Fibroblast Growth Factor Receptor-4 (FGFR4) in the ACT samples was 21 times that of the normal samples $(95 \% \mathrm{Cl}=$

$11.4-38.8)$ and represents the highest induced gene within the group. Previous studies implicate FGFR4 in breast cancer progression and other tumors (188).

The median expression of Insulin-Like Growth Factor-II (IGF-II) in ACT samples was 18 times that of the normal samples $(95 \% \mathrm{Cl}=7.8-42.7)$. Overexpression of IGF-I/ in the ACT samples was subsequently verified at the RNA and protein level by quantitative real time-PCR (qRT-PCR) and western blot analysis, respectively (Fig. 3-2). The qRT-PCR assay revealed higher expression values in the ACT samples than that determined by microarray analysis, most likely due to the larger dynamic range of the real time PCR assay. IGF-II protein levels were also significantly higher in the tumors than in the normal adrenal cortex samples and correlated with changes in mRNA expression. These results are concordant with previous biochemical and microarray analyses of adult and pediatric ACT $(136,138,139,189)$. However, the $7.5 \mathrm{kDa}$ mature form of IGF-II was selectively expressed in the normal adrenal tissue, whereas multiple 


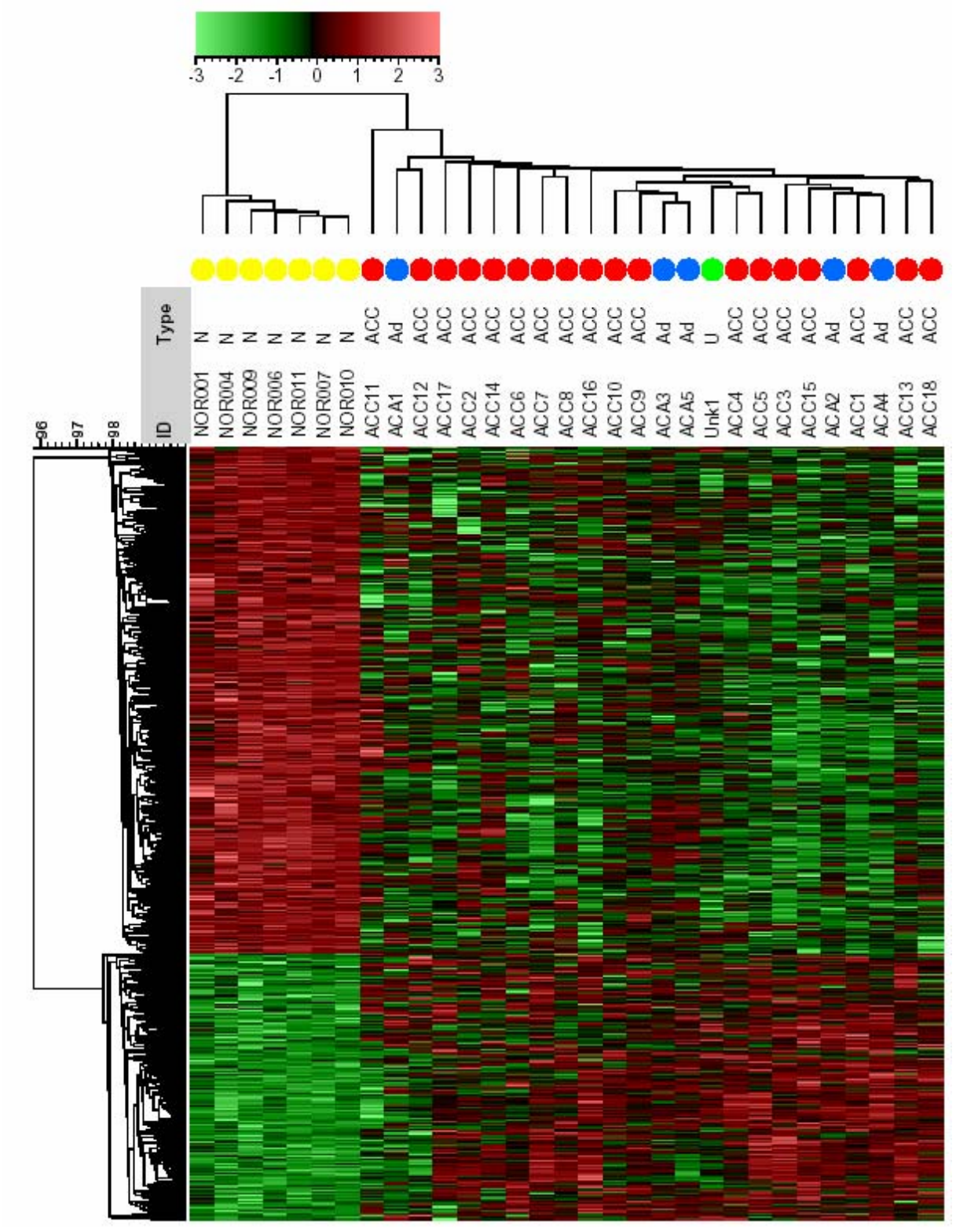

Figure 3-1. Heat Map and Hierarchical Clustering Analysis Comparing Pediatric Adrenocortical Tumor and Normal Cortex. Relative expression signals of 1,019 unique probe sets are represented in red (over-expressed) and green (under-expressed). Differentially expressed genes were significant at $p=0.001$. The scale bar represents standard deviation from the mean. 
Table 3-2. Dysregulated Genes in Pediatric ACT.

\begin{tabular}{|c|c|c|c|c|c|}
\hline & Probe Set ID & Gene Symbol & $\begin{array}{l}\text { Ratio of } \\
\text { Medians }\end{array}$ & 95\% Low & 95\% High \\
\hline \multicolumn{6}{|l|}{ Increased } \\
\hline & 211237_s_at & FGFR4 & 21.1 & 11.4 & 38.8 \\
\hline & 204597_x_at & STC1 & 19.1 & 8.2 & 44.4 \\
\hline & 210881 s at & IGF2 & 18.3 & 7.9 & 42.7 \\
\hline & 202410_x_at & IGF2 & 16.0 & 6.2 & 41.4 \\
\hline & 203213 at & $\mathrm{CDC} 2$ & 13.8 & 5.7 & 33.6 \\
\hline & 219918_s_at & ASPM & 13.4 & 4.2 & 43.5 \\
\hline & 204285_s_at & PMAIP1 & 13.1 & 5.9 & 29.1 \\
\hline & 213562_s_at & SQLE & 12.9 & 6.2 & 27.1 \\
\hline & 205345_at & BARD1 & 12.8 & 8.6 & 18.9 \\
\hline & 218755_at & KIF20A & 12.0 & 5.6 & 25.7 \\
\hline & 204056_s_at & MVK & 10.6 & 4.1 & 27.4 \\
\hline & 218009 s_at & PRC1 & 10.4 & 4.2 & 25.9 \\
\hline & 220091 at & SLC2A6 & 10.2 & 5.3 & 19.7 \\
\hline & 207414_s_at & PCSK6 & 10.0 & 3.7 & 26.9 \\
\hline & 218585_s_at & RAMP & 9.6 & 3.7 & 24.6 \\
\hline & 203828_s_at & NK4 & 9.3 & 4.2 & 20.4 \\
\hline & 204641_at & NEK2 & 8.6 & 3.3 & 22.5 \\
\hline & 201292_at & TOP2A & 8.6 & 3.2 & 23.0 \\
\hline & 201890_at & RRM2 & 8.6 & 3.0 & 24.8 \\
\hline & 201291 s_at & TOP2A & 8.6 & 2.5 & 29.3 \\
\hline & 213126 at & MED8 & 8.2 & 3.8 & 18.0 \\
\hline & 203708 at & PDE4B & 8.0 & 3.0 & 21.4 \\
\hline & 209218_at & SQLE & 8.0 & 4.1 & 15.3 \\
\hline & 202779 s_at & UBE2S & 7.9 & 2.3 & 27.5 \\
\hline & 213479_-at & NPTX2 & 7.8 & 4.4 & 13.9 \\
\hline \multicolumn{6}{|l|}{ Decreased } \\
\hline & 204487_s_at & KCNQ1 & 85.5 & 49.2 & 148.6 \\
\hline & 206294 at & HSD3B2 & 41.1 & 16.1 & 104.7 \\
\hline & 204621_s_at & NR4A2 & 26.9 & 11.5 & 63.0 \\
\hline & 214630 at & CYP11B2 & 26.2 & 11.9 & 57.9 \\
\hline & 214321_at & NOV & 24.4 & 10.8 & 55.3 \\
\hline & $209613 \mathrm{~s}$ at & $\mathrm{ADH} 1 \mathrm{~B}$ & 21.6 & 10.9 & 42.8 \\
\hline & 216248 s_at & NR4A2 & 19.2 & 8.5 & 43.6 \\
\hline & 204501_at & NOV & 19.1 & 9.6 & 38.2 \\
\hline & 211959_at & IGFBP5 & 18.2 & 11.3 & 29.5 \\
\hline & 203523 at & LSP1 & 17.9 & 10.5 & 30.5 \\
\hline & 208606 s at & WNT4 & 17.3 & 8.3 & 36.1 \\
\hline & 213764_s_at & MFAP5 & 15.7 & 4.3 & 56.6 \\
\hline & $204622 \mathrm{x}$ at & NR4A2 & 15.5 & 7.8 & 31.1 \\
\hline & 209496 at & RARRES2 & 14.3 & 6.7 & 30.2 \\
\hline & 202768 at & FOSB & 14.0 & 4.8 & 41.2 \\
\hline & 217767_at & C3 & 13.7 & 7.2 & 26.2 \\
\hline & $211217 \mathrm{~s}$ at & KCNQ1 & 13.6 & 6.4 & 29.1 \\
\hline & 202994_s_at & FBLN1 & 13.2 & 6.9 & 25.3 \\
\hline & 203131 at & PDGFRA & 13.0 & 7.9 & 21.6 \\
\hline & 205969_at & AADAC & 12.2 & 5.4 & 27.8 \\
\hline & 203798 s at & VSNL1 & 12.0 & 6.0 & 23.8 \\
\hline & $203424 \mathrm{~s}$ at & IGFBP5 & 11.1 & 6.6 & 18.5 \\
\hline & 204457_s_at & GAS1 & 11.0 & 5.3 & 22.9 \\
\hline & 213994_s_at & SPON1 & 10.8 & 3.9 & 30.0 \\
\hline & 211896 s at & $\mathrm{DCN}$ & 10.8 & 6.2 & 18.8 \\
\hline
\end{tabular}


A

IGF2

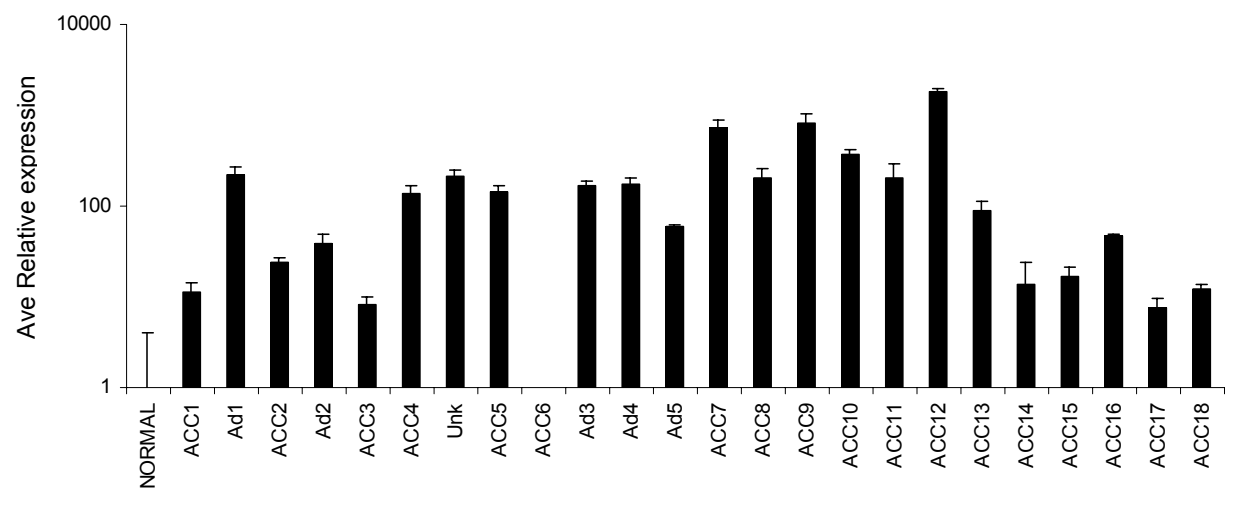

B

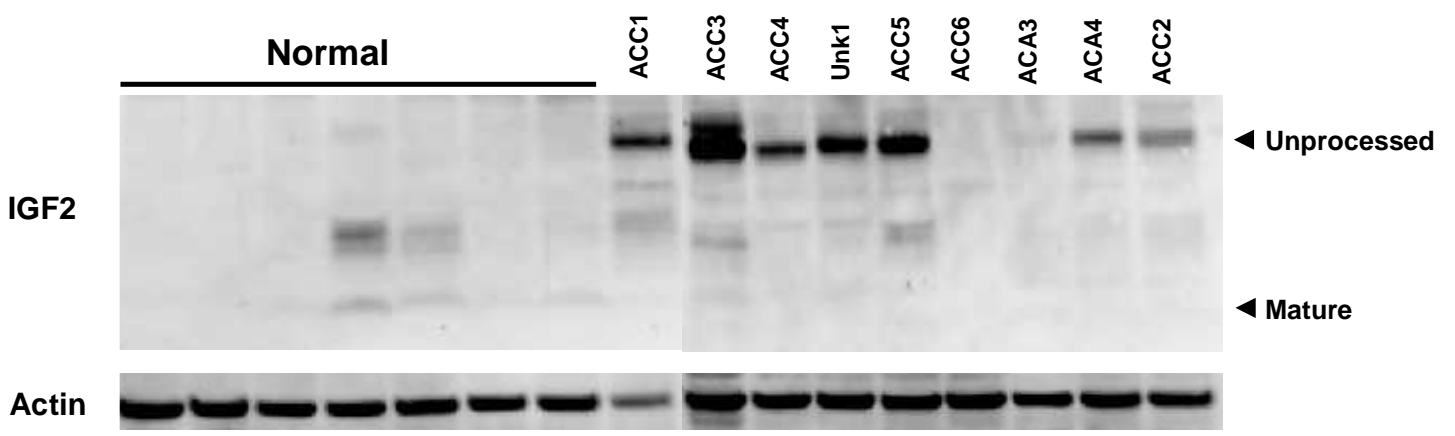

Figure 3-2 Dysregulation of IGF-II Gene Expression in Pediatric

Adrenocortical Cancer. A) IGF-II mRNA levels are significantly higher in tumors compared to normal tissue. B) IGF-II protein is overexpressed in adrenal tumors, but incompletely processed. 
pro-forms of IGF-II, including the prominent $20 \mathrm{kDa}$ form of the protein, were overexpressed in the ACT samples. In addition, the expression of NOV (nephroblastoma overexpressed), a member of the $C C N$ gene family of secretory proteins that plays a role in cell adhesion, was significantly lower in the ACT samples compared to normal adrenal tissue (Table 3-2; Fig. B-1). Loss of NOV expression in the pediatric ACT samples is also in agreement with those reported in adult ACT studies by Martinerie et al (190), further corroborating our dataset.

\subsubsection{Cell Origin of Pediatric Adrenocortical Tumors}

Type II 3ß-hydroxysteroid dehydrogenase (HSD3B2), a steroidogenic enzyme responsible for the conversion of pregnenolone to progesterone in the synthesis of glucocorticoids, mineralocorticoids, and androgens, is expressed at programmed times during adrenal development [for review, see (191)]. During late embryogenesis, $H S D 3 B 2$ is preferentially expressed in the adrenocortical definitive zone, but not the fetal zone. After birth, $H S D 3 B 2$ expression is restricted largely to the zona glomerulosa and zona fasciculata. Microarray analyses demonstrated that the median expression of $H S D 3 B 2$ in pediatric ACT samples is roughly 40 -fold less than that of normal controls. This finding was confirmed by qRT-PCR and Western blot analysis (Fig. 3-3). Moreover, the expression of NURR1 (NR4A2) and NGF1-B (NR4A1), transcriptional regulators of HSD3B2 gene expression (192), were concomitantly lower in the ACT samples (Table 3-2; Figs. B-2 and B-3). The expression of KCNQ1, which 
A

HSD3B2
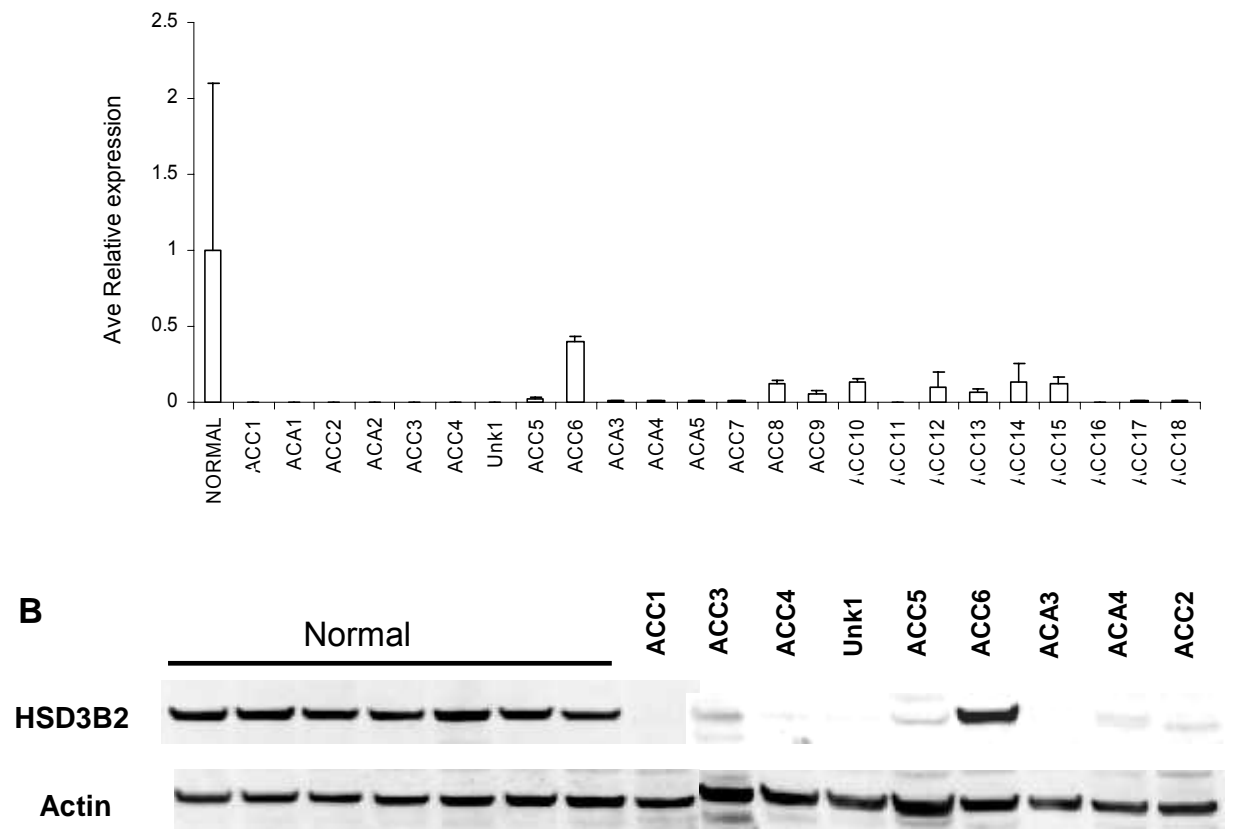

Figure 3-3 Dysregulation of HSD3B2 Gene Expression in Pediatric Adrenocortical Cancer. A) HSD3B2 transcripts are markedly lower in adrenal tumors than in normal tissue. B) HSD3B2 protein levels are reduced in tumors compared to normal tissue. 
encodes a voltage-dependent potassium channel, was also lower ( 85 -fold) in the pediatric ACT samples than in normal adrenal cortex (Table 3-2). Murine Kcnq1 is preferentially expressed in the cortical zona glomerulosa (193), but not in the adrenal medulla. Taken together these results suggest that pediatric adrenocortical tumors may arise from either the fetal zone or the more developmentally mature zona reticularis or zona fasciculata.

\subsubsection{Comparison between Adult and Pediatric Adrenocortical Tumors}

Giordano and coworkers recently identified differences in gene expression patterns between adult ACT and normal tissue using the Affymetrix human U95A gene chip (138). Independently, Rainey and colleagues compared the gene expression profiles of normal human fetal and adult adrenal cortex using a cDNA microarray approach (137). To our knowledge there have been no published studies to date comparing adult and pediatric ACT gene expression in a comprehensive manner.

To compare expression profiles across studies, we queried our microarray dataset for the genes identified as significantly changed in the other 2 studies. We then used expression values relative to normal tissues within each study (Log2Ratio) to compare gene profiles across studies. These analyses showed that the most significant differences identified in the comparison between adult adrenal tumors and normal adult adrenal cortex were remarkably similar to our findings comparing childhood adrenocortical tumors (adenoma and carcinoma) to normal cortex $(\tau=0.56, p=0.001 ;$ Fig. 3-4, left panel). Moreover, the observed 

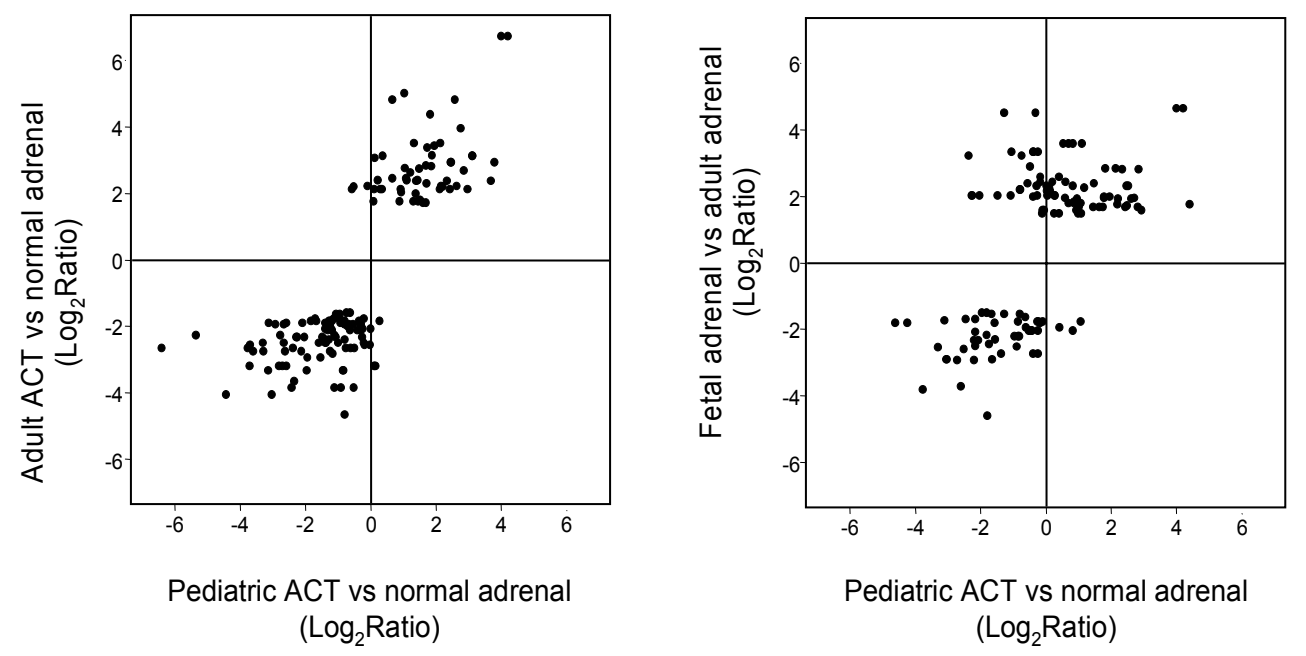

Figure 3-4. Comparisons of Pediatric ACT Gene Expression Profiles to Adult ACT (left panel) and Fetal Adrenal Cortex (right panel) Gene Expression Profiles. 
direction of association was the same for 147 of 153 probe sets in our study corresponding to their reported fold-changes $(p<0.001)$.

Expression of IGF-II and HSD3B2 was dysregulated in a similar manner in both adult and childhood ACT, however, the degree of IGF-II expression appears to be greater in the adult tumors [200- versus 20-fold; (187)], possibly due to the relatively lower levels of IGF-II in the normal adult adrenal cortex $(137,138)$. There was also remarkable correlation in gene expression profiles between normal fetal adrenal tissue (137) and pediatric adrenocortical tumors $(\tau=0.34$, $p=0.022 ;$ Fig. 3-4, right panel). Additionally, the direction of association agreed for 99 of 127 probe sets corresponding to genes for which they report foldchanges $(p=0.006)$. These results indicate that both adult and pediatric ACT resemble fetal tissue with respect to gene expression patterns. Furthermore, our findings suggest that adult and childhood adrenocortical tumors may select for common genetic and biochemical alterations and may be more physiologicallyrelated than previously considered.

\subsubsection{Differences between Pediatric Adrenocortical Carcinoma and Adenoma}

There are no definitive tests to predict ACT malignant potential. Tumor size is one of the most consistent prognostic indicators in children with completely resected ACT (133), although it is not uncommon for patients with small tumors to experience relapses. We therefore compared gene expression profiles of ACT that were classified by histologic criteria as either ACA or ACC to identify changes that may distinguish between these risk groups. 
For 52 probe sets, we detected differences in expression between ACA and ACC that were significant at the $p=0.001$ level [Figs. 3-5; 3-6; (187)]. We estimate that $56 \%$ or more of the detected differences represent true discoveries. Among this set was a consistent and marked decrease in the expression of major histocompatibility class II genes. Specifically, the median expressions of HLADRB1, HLA-DPB1, HLA-DRA, and HLA-DPA1 mRNA levels were 6- to 8-fold lower in pediatric ACC than in ACA. Similar findings have been recently reported by Bornstein and coworkers in a study of adult ACT $(194,195)$. HLA-class II expression may therefore serve as a marker for distinguishing between ACC and ACA.

\subsection{Discussion}

We have established the first pediatric ACT gene expression profile database. Analysis of the ACT panel revealed a marked increase in FGFR4 and IGF-I/ expression, and a sharp decrease in KCNQ1, CDKN1C, and HSD3B2 gene expression in the ACT samples compared to normal adrenal cortex. In support of these results, qRT-PCR and western blot analyses confirmed the differential expression of several of these factors (Figs. 3-2; 3-3). Giordano and coworkers also detected a similar pattern of IGF-II, KCNQ1, and CDKN1C expression in adult ACC (138). All three of these genes are localized to an imprinted locus on chromosome $11 \mathrm{p} 15$, with IGF-II being normally expressed from the paternal allele and $C D K N 1 C$ and $K C N Q 1$ being expressed only from the 


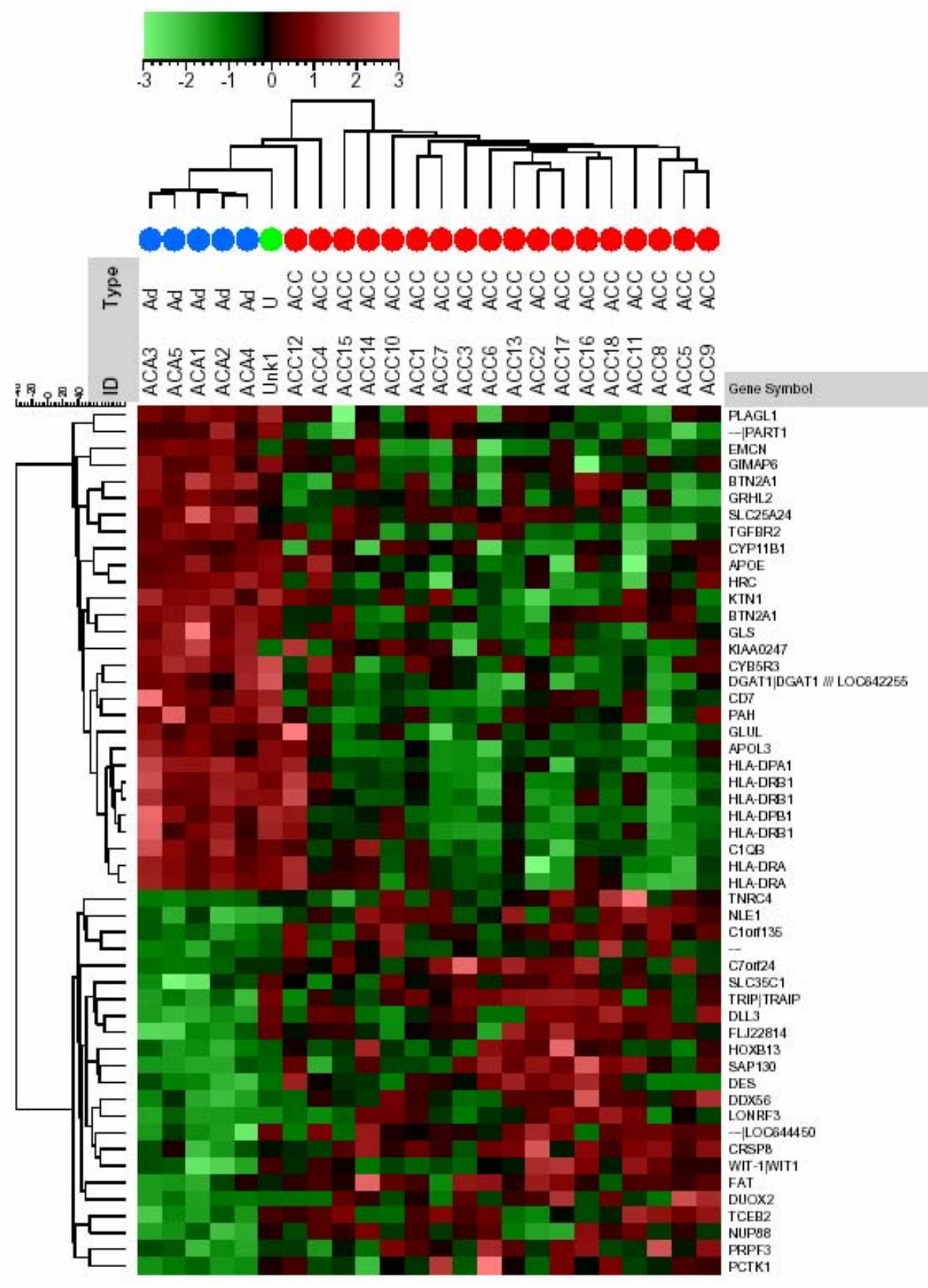

Figure 3-5. Heat Map of Differentially Expressed Genes Comparing Pediatric Adrenocortical Carcinomas and Adenomas. Median expression values calculated by the Wilcoxon rank-sum test generated data for 52 unique probe sets between adenoma and carcinoma significant at $p=0.001$. Red, overexpressed; green, under-expressed. The scale bar represents standard deviation from the mean. 


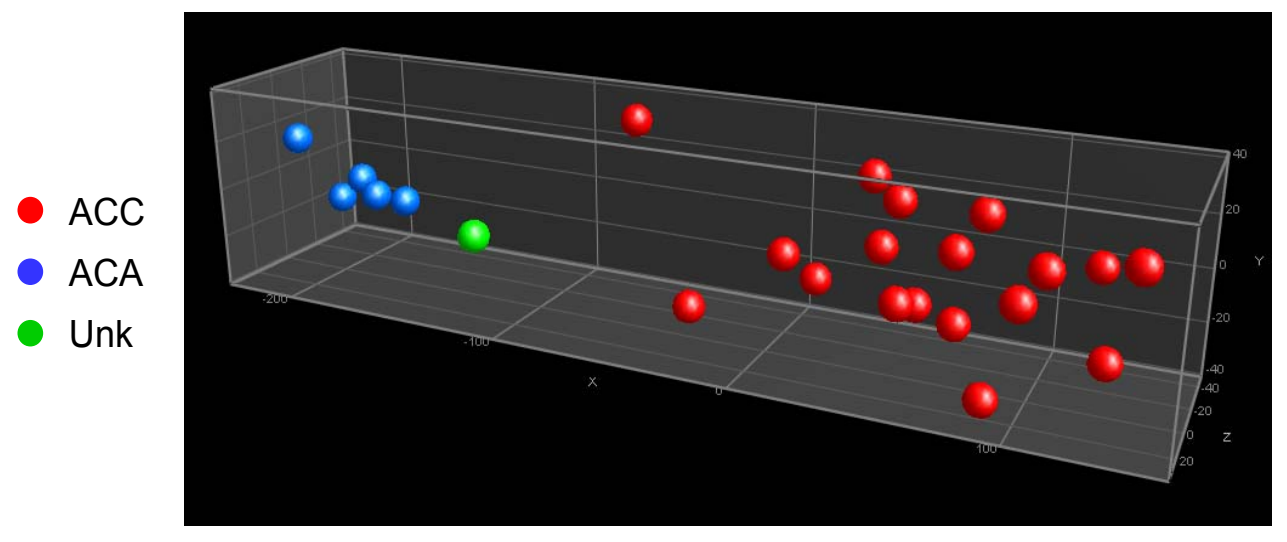

Figure 3-6. Three-Dimensional Scaling of ACC and ACA Samples by Principle Component Analysis. Generated using the 52 probesets that best discriminate ACC vs ACA. 
maternal allele [for review, see $(141,177)]$. The coupled dysregulation of IGF-II, CDKN1C, and KCNQ1 (Table 3-2) implies an imprinting defect, similar to what has been observed in Beckwith-Wiedemann syndrome $(141,177)$.

Overexpression of IGF-II in pediatric ACT was anticipated based on previously published reports (Fig. 3-1, Table 3-2) $(136,138,189,196)$. However, the finding that the majority of the tumors grossly overexpress immature forms of IGF-II was surprising, but not unprecedented based on adult ACT studies (139). Pro-IGF2 must be post-translationally modified by glycosylation and proteolytic cleavage before its mature, active $7.5 \mathrm{kDa}$ form is secreted (197). Here, we have detected in the ACT samples, IGF-II proteins ranging from 14 to $22 \mathrm{kDa}$, but not the $7.5 \mathrm{kDa}$ form, which was readily evident in normal adrenal cortex tissue. It is generally considered that the overexpression of IGF-II in ACT provides a growth advantage that drives tumorigenesis. Consistent with this hypothesis, transgenic mice engineered to express high levels of IGF-II develop adrenal hyperplasia (143) and recombinant IGF-II stimulates human fetal adrenocortical cell proliferation in culture (198). Since the IGF-type I receptor is concomitantly upregulated in the pediatric tumors analyzed here (187), it is reasonable to speculate that IGF-II may also play a role in pediatric adrenocortical tumorigenesis and therefore serve as a drug target. However, further consideration must be given as to whether these adrenal tumors secrete an active form of IGF-II that contributes to the growth and survival of these cells. Interestingly, basic Fibroblast Growth Factor-2 (bFGF-2) suppresses the processing of IGF-II in human adrenocortical tumor cells-thereby blocking its 
secretion—resulting in a marked accumulation of intracellular IGF-II (199).

Consistent with the high levels of partially processed IGF-II protein in the adrenal tumors, FGFR-1 and FGFR-4, both of which can be activated by bFGF-2, were found by microarray analysis to be significantly upregulated in the ACT samples (Table 3-2). Moreover, since bFGF is a potent angiogenic factor and is mitogenic for fetal adrenal cortex cells $(200,201)$, the inhibition of the FGFR signaling pathway may represent a rational approach in developing new treatments for pediatric ACT. In support of this concept, 17 of the most significant genes dysregulated in pediatric ACT [Fig. 3-1; (187)] function within the MAPK pathway, including NRAS, an immediate downstream target of FGFR signaling.

The finding that the expression of $K C N Q 1, H S D 3 B 2$, and its corresponding transcriptional regulators NURR1 and NGF1B is markedly lower in pediatric ACT compared to normal adrenal cortex, supports the thesis that the tumors originate from either the fetal zone during embryogenesis, or the developing zona fasciculata or zona reticularis during the first few years of life. At the very least, the pediatric adrenal tumors share biochemical characteristics of these compartments. Since normal adult tissue is significantly different from the fetal adrenal cortex (137), the remarkable and somewhat unexpected similarity between adult and pediatric ACT implies the existence of an adrenal stem cell that may become corrupted to give rise to the developing tumor. Alternatively, the tumors, whether adult or pediatric, may undergo dedifferentiation as they develop (202). 
In the present study, patterns of gene expression have been identified that distinguish ACC from ACA, which is often difficult to assess by standard histopathological approaches. Interestingly, 2 ACC cases, which have not yet relapsed, segregated with the ACA group [Fig. 3-5; 3-3 and (187)], underscoring the limitations of the histological criteria to predict tumor malignant potential. Future prospective studies should determine the utility of gene expression analysis in the classification and prognosis of pediatric ACT.

Significant changes in the expression profiles between ACA and ACC included the MHC class II genes, which are largely restricted to hematopoietic lineages. Interestingly, the adrenocortical reticular zone also expresses MHC class II antigens after 4 years of age $(194,195)$. Based on the age of the patients diagnosed with $A C A$, it is reasonable to speculate that the relatively high $\mathrm{MHC}$ class II expression reflects an infiltration of immune cells that limits tumor potential (B.F., data not shown). Conversely, the association of low MHC-class II expression in the carcinomas may represent a mechanism to evade immune surveillance, which could contribute to its malignant phenotype (195).

Little is known regarding the pathways and factors that promote pediatric $\mathrm{ACT}$ and there is no proven therapy for this rare malignancy other than surgery. Our findings identify potentially important components that may contribute to adrenocortical tumorigenesis. However, the establishment of genetically engineered mice, primary tissue culture cell lines, and/or human adrenocortical tumor xenografts will be required to explore new potential targets, such as FGFR4, IGF-II, and other dysregulated genes identified here. Only through these 
efforts can advancements in the treatment of pediatric adrenocortical tumors be made. 


\section{CHAPTER 4: CONCLUSION}

\subsection{Introduction}

We have identified dysregulation of several genes in pediatric adrenocortical cancer at the DNA, RNA, and protein levels. The first of these genes is the tumor suppressor p53. In Chapter 2, the novel germline p53 mutation, R175L, was described in a pediatric ACC case in which the family did not have a prevalent cancer history. More importantly, the association of amino acid substitution within the p53 gene, especially the DNA binding domain with the incidence of cancer supports the importance of genetic screening for p53 mutations and the assessment of their functions. However, p53 mutations do not fully explain the etiology of pediatric adrenocortical cancer. In Chapter 3, aberrant expression of gene transcripts such as IGF-II and FGFR4 were identified. In addition, loss of MHC Class II gene expression in pediatric adrenocortical carcinomas may be used as an alternative tool to pathologically distinguish between adenomas and carcinomas. Although the dataset is not large enough at this time to use transcript expression as a definitive method for diagnostic and prognostic purposes, the relevance of the data is significant considering this is the first study of its kind, comparing normal pediatric adrenocortical tumors to age-matched normal adrenocortical tissue and more importantly, distinguishing adenomas from carcinomas, thus giving it future potential to be utilized as a clinical tool. 


\subsection{The Impact and Future of p53 Mutation Screening on Genetic Counseling for Pediatric Adrenocortical Cancer Patients and Their Families}

Because p53 is one of the most mutated genes in cancer $(<50 \%)$ and is associated with LFS and LFLS, p53 genetic screening is critical to genetic counselors and physicians in predicting cancer susceptibility. Approximately 50$70 \%$ of tumor-prone families are carriers of p53 germline mutations, as defined by LFS criteria. The frequency is lowered to approximately $20-40 \%$ when the criteria become less stringent as defined in LFLS. The remaining percentage of LFS families can possibly attribute cancer susceptibility to CHK2 mutations, although an accurate frequency has not yet been determined (203-205). Additionally, males in LFS families have a $70-90 \%$ increased lifetime risk of developing cancer while women have a $100 \%$ increased risk due to the incidence of breast cancer $(150,206)$.

Estimating the genetic predisposition to cancer based on the penetrance and frequency of p53 germline mutations is not only important to physicians but is of utmost importance to cancer patients who might experience surgery and post-operative radiation or chemotherapy and to their families who might undergo preventive treatment. Although the decision to undergo genetic testing is made available to all patients, about $40 \%$ actually follow through with screening (206). Genetic testing for families that have children with early-age tumor onset is of even greater importance due to the psychological burden it puts on the parent(s) or legal guardian(s). Parents and guardians experience increased awareness of their child's illness and the devastation of the child's inheritance of a genetic abnormality (207). If this is indeed the case and parents/guardians are properly 
made aware of genetic screening, not only would members of Li-Fraumeni and Li-Fraumeni-Like Syndrome families be likely to complete genetic testing but those who belong to families that do not have a history of cancer would be expected to enroll in p53 genetic testing programs. This cohort of patients and their families would include those families that have children diagnosed with adrenocortical cancer.

Although pediatric adrenocortical cancer comprises only $3.6 \%$ of cancer cases in LFS, the incidence of germline p53 mutations is approximately $80 \%$ in pediatric adrenocortical cancer patients $(134,158)$. A number of these gene alterations are hot spot mutants. An exact frequency of hot spot mutants that occur in childhood adrenocortical cancer has not been assessed in the literature. However, accounting for tumors classified as either "adrenal cancer carcinoma" or "adrenocortical carcinoma" in the human TP53 mutation database, approximately $38 \%$ of p53 germline mutations associated with adrenocortical tumors occur in the DNA binding domain. Of that percentage, only $12 \%$ are associated with LFS. The remaining $58 \%$ are attributed to the mutations that occur in the tetramerization domain, specifically at codon 337 (31). Since childhood adrenocortical cancer is so highly associated with germline p53 mutations compared to adult adrenocortical tumors, it should be assumed that the majority of these cancer cases listed in the database occur in children. Of ACT patient samples reported here, we found that approximately $90 \%$ of patients screened had a germline p53 mutation, approximately $70 \%$ of them harboring the $\mathrm{R} 337 \mathrm{H}$ mutation due to the high number of patients originating from southern 
Brazil. In pediatric ACT, the number of p53 germline hot spot mutations associated with LFS is reported to be quite low compared to mutations that are not classically associated with LFS, raising the question of the exact biology regarding p53 germline mutations in the onset of this tumor type.

Low-penetrance germline p53 mutations have been detected in pediatric adrenocortical tumors (134). Specifically, 9 of 11 patients carried mutations in the p53 DNA binding domain, i.e. P152L and R158H. Although these mutations occur in the hot spot region of $p 53$, they are not considered hot spot mutants based on the frequency and penetrance at which they occur in tumor-prone families. At the time these mutations were found, there was only one other study that reported the $\mathrm{P} 152 \mathrm{~L}$ mutation in the germline of pediatric $\mathrm{ACC}$ patients and the $\mathrm{R} 158 \mathrm{H}$ germline mutation had never been described. To date, the P152L and $\mathrm{R} 158 \mathrm{H}$ mutations have been reported in approximately $4 \%$ and $0.9 \%$ of cancer cases, respectively. Neither mutant has been reported to be associated with LFS, but patients carrying these mutations have been categorized as belonging to LFLS families (31). As we have determined with the R175L mutation, it is important to characterize the structure-function relationship of these mutants in order to best advise families on genetic screening and preventive measures to take following cancer diagnosis. Function of the P152L mutant has not been analyzed in human cell lines but has been studied as a temperature-sensitive mutant in yeast cell lines. Data showed that P152L cannot transactivate the p21, Bax, or PIG3 promoters, suggesting that this mutant has impaired ability to transactivate target genes (208). 
The $\mathrm{R} 337 \mathrm{H}$ mutation has been characterized as a low-penetrance mutation based on the incidence of cancer occurring in families with ACC probands. In a study of 36 ACC patients from 34 families in southern Brazil, 35 of these patients carried the $\mathrm{R} 337 \mathrm{H}$ mutation ( 97\%) (43). Classical studies testing functions of this mutant including transactivation, colony suppression, and ability to induce apoptosis showed that $\mathrm{R} 337 \mathrm{H}$ has activity comparable to wild-type p53 protein. In addition, this mutant has yet to be associated with LFS or LFLS syndrome (154). Another mutant at this residue, R337C, is associated with LFS (42). Functionally, both proteins can bind to the p53 consensus sequence; however, the R337C mutant is structurally unstable at physiological temperature, while the stability of the $\mathrm{R} 337 \mathrm{H}$ mutation is $\mathrm{pH}$-dependent at physiological temperature. Specifically, the R337C mutation favors the monomeric over the tetrameric form of $\mathrm{p} 53$ at $37^{\circ} \mathrm{C}$. The $\mathrm{R} 337 \mathrm{H}$ mutant protein is stable at $\mathrm{pH} 5$ and 6 at $37^{\circ} \mathrm{C}$ and $90 \%$ of $\mathrm{R} 337 \mathrm{H}$ molecules are folded. However, as the $\mathrm{pH}$ is increased to 8 , approximately $70 \%$ of $\mathrm{R} 337 \mathrm{H}$ molecules are unfolded $(42,151)$. The R337H mutation has been structurally characterized as more stable than the $\mathrm{R} 337 \mathrm{C}$ at both physiological temperature and $\mathrm{pH}\left(37^{\circ} \mathrm{C}\right.$ and $\left.\mathrm{pH} 7.0\right)$. However, in cells that exceed $\mathrm{pH} 7$, the $\mathrm{R} 337 \mathrm{H}$ protein may not structurally be stable enough to maintain its function, possibly explaining its involvement in the onset of adrenocortical cancer (151). A mouse model has been constructed using the $\mathrm{R} 337 \mathrm{H}$ mutation. This model will provide phenotypic information and serve as a tool to study a low-penetrant p53 mutation that does not occur in the DNAbinding domain. Heterozygous and homozygous $\mathrm{R} 337 \mathrm{H}$ mutant mice will provide 
information regarding the involvement of this mutant in the onset of tumors, especially those that arise in the adrenal gland. Because pediatric adrenocortical tumor patients in Brazil are heterozygous in the germline for the $\mathrm{R} 337 \mathrm{H}$ mutation, the phenotype of heterozygous and homozygous $\mathrm{R} 337 \mathrm{H}$ mice must be examined for tumor susceptibility. Heterozygous and homozygous $\mathrm{R} 337 \mathrm{H}$ mice and hemizygous ( $R 337 \mathrm{H} /-)$ mice must be challenged under various cellular stresses, including DNA damage by irradiation and chemical carcinogens, in order to determine the physiological effect of this mutant.

This study uncovered a low-penetrance p53 germline mutation associated with childhood adrenocortical cancer, R175L, which is now categorized in a class of structural p53 germline mutations that retains partial function under a specific set of conditions (discussed in Chapter 2). Particularly, the R175L mutant is active under stress conditions that signal cell cycle arrest but cannot function under conditions that require the cell to undergo apoptosis. Another mutation, p53-I332F, was also revealed in screening pediatric adrenocortical tumors for p53 germline mutations. The mutation was identified in both blood and tumor DNA. Penetrance of this mutation cannot be determined due to lack of patient family history. We are also unable to conclude whether or not this mutation is de novo. Functional studies identical to those performed for the R175L mutant showed that the I332F mutant retains wild-type function. This mutant may be similar to the $\mathrm{R} 337 \mathrm{H}$, though its structural stability has yet to be determined. In addition to mutations, polymorphisms within the p53 gene must also be considered. A polymorphism at codon 72 in exon 4 either results in arginine 
(R72) or proline (P72). An ethnic variation of this polymorphism was investigated over a decade ago, suggesting that P72 arose in Africans versus R72 which developed in northern European populations (209). In vitro studies in p53-null cells showed that the R72 form was a better apoptotic regulator than P72 (210). Within various ethnic populations, the R72/P72 polymorphism has been identified in a number of tumor types including lung cancer, hepatocellular carcinoma, breast, colorectal, cervical, thyroid, and skin cancer and is thought to be associated with p53 mutations (211-217). Although the in vitro data suggests that $\mathrm{R} 72$ is more effective at inducing apoptosis than P72, clinical data suggests in some tumor types, most affected patients are positive for R72, while in other cancers, P72 is selected. In our current database, only 2 of 35 patients are carriers of the P72 polymorphism. It is inconclusive at this time what role the R72P polymorphism plays in cancer and needs to be further elucidated. Another polymorphism at codon 47 resulting in either a proline or serine residue (P47S) has also been identified as an ethnic variation, occurring at a higher frequency in the African-American population than in the Caucasian population (218). Since its characterization in the human population, it was demonstrated in vitro that the S47 variant induces apoptosis 5-fold less well than its counterpart, P47, due to its inability to transactivate apoptotic regulators, such as p53AIP (p53-apoptosisinducing protein) and PUMA. We have not identified the P47 polymorphism in any of our pediatric adrenocortical cancer patients. However, both the S47/P47 and the R72/P72 polymorphisms should be further characterized and their 
cooperation with the low-penetrance p53 germline mutations, if any, should be clarified.

Low-penetrance germline p53 mutations account for only a small percentage of those associated with cancer. However, they comprise a large percentage of those germline mutations associated with pediatric adrenocortical cancer. If this is indeed the case, it is important to continue to screen for p53 mutations in the germline and in tumors of pediatric adrenocortical patients and to determine their structure-function relationship in vitro and in vivo in order to provide more in-depth and accurate information for physicians to present to patients and their families.

\subsection{Future Importance of Gene Expression Profiling for Pediatric Adrenocortical Cancer Patients}

We have characterized 24 pediatric adrenocortical tumors for global gene expression using Affymetrix microarray analysis. As mentioned above, this is the first study of its kind, comparing these tumors to age-matched normal adrenal tissue. Expression of dysregulated genes, including IGF-II and HSD3B2 were confirmed by real-time quantitative PCR and compared to protein levels by western blot analysis. We were also able to compare the expression profiles of these tumors to published normal fetal adrenal and adult ACT profiles. Most importantly, we have used this method in order to classify ACT as adrenocortical adenomas or carcinomas, based on MHC Class II gene expression, which was downregulated in carcinomas. 
Gene expression profiling is rapidly becoming an increasingly important diagnostic tool, first suggested almost a decade ago $(219,220)$. Microarray has been used to identify gene expression associated with tumors in comparison with their normal controls. Microarray technology was initially used in cancer biology to distinguish between different cancer classes and subclasses. One of the first studies performed to divide cancers into classes using microarray technology compared 38 acute lymphoblastic leukemia (ALL) and acute myeloid leukemia (AML) samples for global gene expression (221). Another microarray study identified genes from 130 pediatric AML patients discriminating subsets of the disease which were used to classify 20 adult AML cases (222). In 2001, breast cancer gene expression studies using microarray were used to distinguish between estrogen receptor positive and negative tumors and breast tumors that expressed BRCA1 and BRCA2 (Breast cancer type 1 and breast cancer type 2), which puts women at a $50-85 \%$ lifetime risk for breast cancer $(223,224)$. Following these studies, a more comprehensive gene expression study using microarray compared 117 BRCA1 and BRCA2 breast tumors, metastatic breast tumors, and tumors arising in women who were disease-free for at least 5 years (225). These studies explored alternative methods in predicting survival and outcome for breast cancer patients based on gene expression instead of histologic grades and tumor staging, which is important for treatment. For example, $70 \%$ of breast tumors that are positive for both ER and PgR (Estrogen Receptor and Progesterone Receptor) are responsive to tamoxifen treatment, while ER positive/PgR negative tumors are not responsive to tamoxifen. 
Predicting survival and outcome for breast cancer patients is important due to the poor prognosis and survival rates of women diagnosed at later stages of this disease, which is often catastrophic and fatal $(226,227)$. Considering pediatric adrenocortical tumors are histologically difficult to identify, it is important that alternative methods are used for diagnostic and prognostic purposes, such as gene expression profiling using microarray. Current treatment of adrenocortical tumors is surgical resection of the tumor. Chemotherapy including mitotane, cisplatin, and etoposide are also used and has some impact on patient outcome (discussed in section 1.4). According to microarray data, growth factors and their receptors are dysregulated in ACT profiles. For example, FGFR4 is upregulated approximately 21 fold in tumors compared to normal. In addition, IGF-/I probes are also upregulated 16-18 fold. Mechanisms of their dysregulation in ACT are unknown. However, it has been well-described in the literature that IGF-I/ is dysregulated in adrenocortical tumors. Specifically, IGF-II levels are increased in the higher $20 \mathrm{kDa}$ protein form (discussed in section 3.4).

IGF-II is located on an imprinted locus of chromosome 11p15.5, which includes a number of imprinted genes including KCNQ1, H19, and CDKN1C $\left(\mathrm{p} 57^{\mathrm{KIP2/CIP2}}\right)$. Imprinted genes are preferentially expressed from either the maternal or paternal allele. The alleles which are not expressed, or imprinted, are silenced via methylation of the $\mathrm{CpG}$ dinucleotide by a number of de novo methylation enzymes during development of the germ cells into sperm and ova and maintained in somatic cells. Both $K C N Q 1$ and IGF-II are maternally imprinted while $H 19$ and CDKN1C are paternally imprinted (228). We also found 
dysregulation of both $C D K N 1 C$ and $K C N Q 1$ in the pediatric ACT gene expression profiles. It is unclear whether or not there is an imprinting problem during embryonic development or if mutations arise in these genes during tumorigenesis. However, since these genes are imprinted, there is more likely an imprinting problem. Imprinting could possibly be confirmed using methylationspecific PCR. H19 transcript expression could not be determined using the Affymetrix Human U133A array chip. However, quantitative real-time PCR should be used to determine $H 19$ expression in pediatric ACT. IGF-I/ secretion in pediatric adrenocortical tumors can be measured by western blot from whole cell protein lysates isolated from a pediatric adrenocortical tumor cell line.

FGFR4 (Fibroblast Growth Factor Receptor-4) is a member of the FGFR family, consisting of four tyrosine kinase receptors that bind FGFs (Fibroblast Growth Factors). FGFs are mitogens involved in a number of biological processes ranging from tissue regeneration to organ development. Specifically, FGFR4 binds FGF1, 2, 4, 6, 8, and 9 (229). In the H295R adult adrenal cell line, FGF2 (bFGF) stimulates proliferation and blocks IGF-II secretion, prohibiting the pro-form from maturation into the final 7.5kDa form (199). This is another possible mechanism for IGF-II overexpression. FGFR4 overexpression should be confirmed by qRT-PCR and western blot for transcript and protein expression, respectively. Pediatric ACTs should be analyzed for FGF2 expression and mice with adrenal tumors, i.e. ACT xenograft models, should be analyzed for increased transcript and protein expression of FGFR4 and FGF2. Similarities in our prospective assessment of gene expression comparing adult and pediatric 
ACT, inhibition of IGF-II by FGFR4 could be highly likely, thus making FGFR4 a strong candidate for therapeutic targeting using specific inhibitors.

Of 21 ACT samples examined in the microarray study, all were positive for p53 germline mutations. p53-responsive genes were not comprehensively identified from the entire list of 14,500 genes. However, of the most dysregulated probe sets, pro-apoptotic regulator PMAIP, whose gene product is NOXA and GADD45A, which induces cell cycle arrest, were 13.1-fold and 2.67-fold overexpressed, respectively. Tumors that were positive for the $\mathrm{R} 337 \mathrm{H}$ mutation must be compared against tumors that had other p53 mutations, including one which was associated with LFS (R273C), for expression of p53-responsive targets. This data must be elucidated to determine the downstream consequences of p53 germline mutations.

There were 52 probe sets that differed between pediatric adrenocortical adenomas and carcinomas. Among those probe sets were MHC Class II genes which were downregulated in carcinomas and upregulated in adenomas. Downregulation of these genes may indicate the evasion of immune surveillance in pediatric ACT. MHC Class II genes, specifically HLA-DRB1 are downregulated in human adrenocortical carcinomas $(194,230)$ and in pancreatic carcinomas (231). MHC Class II genes are involved in Fas-mediated apoptosis through recognition of T-cell receptors on CD4+ cells. Downregulation of these genes could possibly compromise this interaction, Fas-mediated apoptosis and thus, immune surveillance (230). Because the sample size for this study was not statistically large enough to clearly confirm the differences between adenoma 
and carcinoma, it must be expanded in order for this type of testing to be used for clinical diagnostics. Nonetheless, the differential expression between adenomas and carcinomas signifies that alternative testing can be used to histologically distinguish between these two subclasses of pediatric ACT. 


\section{LIST OF REFERENCES}

1. Sager R. Tumor suppressor genes: the puzzle and the promise. Science 1989 Dec 15;246(4936):1406-12.

2. Linzer DI, Levine AJ. Characterization of a $54 \mathrm{~K}$ dalton cellular SV40 tumor antigen present in SV40-transformed cells and uninfected embryonal carcinoma cells. Cell 1979 May;17(1):43-52.

3. Lane DP, Crawford LV. T antigen is bound to a host protein in SV40transformed cells. Nature 1979 Mar 15;278(5701):261-3.

4. DeLeo AB, Jay G, Appella E, Dubois GC, Law LW, Old LJ. Detection of a transformation-related antigen in chemically induced sarcomas and other transformed cells of the mouse. Proc Natl Acad Sci U S A 1979 May;76(5):2420-4.

5. Crawford LV, Pim DC, Gurney EG, Goodfellow P, Taylor-Papadimitriou J. Detection of a common feature in several human tumor cell lines--a 53,000-dalton protein. Proc Natl Acad Sci U S A 1981 Jan;78(1):41-5.

6. Eliyahu D, Raz A, Gruss P, Givol D, Oren M. Participation of $p 53$ cellular tumour antigen in transformation of normal embryonic cells. Nature 1984 Dec 13-19;312(5995):646-9.

7. Land $\mathrm{H}$, Parada LF, Weinberg RA. Tumorigenic conversion of primary embryo fibroblasts requires at least two cooperating oncogenes. Nature 1983 Aug 18-24;304(5927):596-602.

8. Hinds $P$, Finlay $C$, Levine AJ. Mutation is required to activate the p53 gene for cooperation with the ras oncogene and transformation. J Virol 1989 Feb;63(2):739-46.

9. Levine AJ, Finlay CA, Hinds PW. P53 is a tumor suppressor gene. Cell 2004 Jan 23;116(2 Suppl):S67-9, 1 p following S9. 
10. Eliyahu D, Goldfinger N, Pinhasi-Kimhi O, et al. Meth A fibrosarcoma cells express two transforming mutant p53 species. Oncogene 1988 Sep;3(3):313-21.

11. Finlay CA, Hinds PW, Levine AJ. The p53 proto-oncogene can act as a suppressor of transformation. Cell 1989 Jun 30;57(7):1083-93.

12. Sompayrac LM, Gurney EG, Danna KJ. Stabilization of the 53,000-dalton nonviral tumor antigen is not required for transformation by simian virus 40. Mol Cell Biol 1983 Feb;3(2):290-6.

13. Soussi T. The TP53 Web Site. [Internet] 1994 04/26/2007 [accessed 05/2/2007]. Available from: http://p53.free.fr

14. Levine AJ. p53, the cellular gatekeeper for growth and division. Cell 1997 Feb 7;88(3):323-31.

15. Bullock AN, Fersht AR. Rescuing the function of mutant p53. Nat Rev Cancer 2001 Oct;1(1):68-76.

16. Harms KL, Chen X. The functional domains in p53 family proteins exhibit both common and distinct properties. Cell Death Differ 2006 Jun;13(6):890-7.

17. Walker DR, Bond JP, Tarone RE, et al. Evolutionary conservation and somatic mutation hotspot maps of p53: correlation with p53 protein structural and functional features. Oncogene 1999 Jan 7;18(1):211-8.

18. Soussi T, Beroud C. Assessing TP53 status in human tumours to evaluate clinical outcome. Nat Rev Cancer 2001 Dec;1(3):233-40.

19. Chipuk JE, Kuwana T, Bouchier-Hayes L, et al. Direct activation of Bax by p53 mediates mitochondrial membrane permeabilization and apoptosis. Science 2004 Feb 13;303(5660):1010-4.

20. Walker KK, Levine AJ. Identification of a novel p53 functional domain that is necessary for efficient growth suppression. Proc Natl Acad Sci U S A 1996 Dec 24;93(26):15335-40. 
21. Lowe SW, Schmitt EM, Smith SW, Osborne BA, Jacks T. p53 is required for radiation-induced apoptosis in mouse thymocytes. Nature $1993 \mathrm{Apr}$ 29;362(6423):847-9.

22. Toledo F, Krummel KA, Lee CJ, et al. A mouse p53 mutant lacking the proline-rich domain rescues Mdm4 deficiency and provides insight into the Mdm2-Mdm4-p53 regulatory network. Cancer Cell 2006 Apr;9(4):273-85.

23. Cho Y, Gorina S, Jeffrey PD, Pavletich NP. Crystal structure of a p53 tumor suppressor-DNA complex: understanding tumorigenic mutations. Science 1994 Jul 15;265(5170):346-55.

24. Butler JS, Loh SN. Structure, function, and aggregation of the zinc-free form of the p53 DNA binding domain. Biochemistry 2003 Mar 4;42(8):2396-403.

25. el-Deiry WS, Kern SE, Pietenpol JA, Kinzler KW, Vogelstein B. Definition of a consensus binding site for p53. Nat Genet 1992 Apr;1(1):45-9.

26. Wang L, Wu Q, Qiu P, et al. Analyses of p53 target genes in the human genome by bioinformatic and microarray approaches. J Biol Chem 2001 Nov 23;276(47):43604-10.

27. Mirza A, Wu Q, Wang L, et al. Global transcriptional program of $\mathrm{p} 53$ target genes during the process of apoptosis and cell cycle progression. Oncogene 2003 Jun 5;22(23):3645-54.

28. Shaulian E, Zauberman A, Ginsberg D, Oren M. Identification of a minimal transforming domain of p53: negative dominance through abrogation of sequence-specific DNA binding. Mol Cell Biol 1992 Dec;12(12):5581-92.

29. Jacks $\mathrm{T}$, Remington $\mathrm{L}$, Williams $\mathrm{BO}$, et al. Tumor spectrum analysis in p53-mutant mice. Curr Biol 1994 Jan 1;4(1):1-7.

30. Purdie CA, Harrison DJ, Peter A, et al. Tumour incidence, spectrum and ploidy in mice with a large deletion in the p53 gene. Oncogene 1994 Feb;9(2):603-9. 
31. Olivier M, Eeles R, Hollstein M, Khan MA, Harris CC, Hainaut P. The IARC TP53 database: new online mutation analysis and recommendations to users. Hum Mutat 2002 Jun;19(6):607-14.

32. Kraiss S, Quaiser A, Oren M, Montenarh M. Oligomerization of oncoprotein p53. J Virol 1988 Dec;62(12):4737-44.

33. Schmieg FI, Simmons DT. Characterization of the in vitro interaction between SV40 T antigen and p53: mapping the p53 binding site. Virology 1988 May;164(1):132-40.

34. Friedman PN, Chen X, Bargonetti J, Prives C. The p53 protein is an unusually shaped tetramer that binds directly to DNA. Proc Natl Acad Sci U S A 1993 Apr 15;90(8):3319-23.

35. Stenger JE, Mayr GA, Mann K, Tegtmeyer P. Formation of stable p53 homotetramers and multiples of tetramers. Mol Carcinog 1992;5(2):102-6.

36. Chene $P$, Mittl $P$, Grutter $M$. In vitro structure-function analysis of the betastrand 326-333 of human p53. J Mol Biol 1997 Nov 7;273(4):873-81.

37. Weinberg RL, Veprintsev DB, Fersht AR. Cooperative binding of tetrameric p53 to DNA. J Mol Biol 2004 Aug 27;341(5):1145-59.

38. Waterman JL, Shenk JL, Halazonetis TD. The dihedral symmetry of the p53 tetramerization domain mandates a conformational switch upon DNA binding. Embo J 1995 Feb 1;14(3):512-9.

39. Mateu MG, Fersht AR. Nine hydrophobic side chains are key determinants of the thermodynamic stability and oligomerization status of tumour suppressor p53 tetramerization domain. Embo J 1998 May 15;17(10):2748-58.

40. Chene $P$. The role of tetramerization in p53 function. Oncogene 2001 May 10;20(21):2611-7.

41. Stommel JM, Marchenko ND, Jimenez GS, Moll UM, Hope TJ, Wahl GM. A leucine-rich nuclear export signal in the p53 tetramerization domain: 
regulation of subcellular localization and p53 activity by NES masking. Embo J 1999 Mar 15;18(6):1660-72.

42. Davison TS, Yin P, Nie E, Kay C, Arrowsmith $\mathrm{CH}$. Characterization of the oligomerization defects of two p53 mutants found in families with $\mathrm{Li}$ Fraumeni and Li-Fraumeni-like syndrome. Oncogene 1998 Aug 6;17(5):651-6.

43. Ribeiro RC, Sandrini F, Figueiredo B, et al. An inherited p53 mutation that contributes in a tissue-specific manner to pediatric adrenal cortical carcinoma. Proc Natl Acad Sci U S A 2001 Jul 31;98(16):9330-5.

44. Waterman MJ, Stavridi ES, Waterman JL, Halazonetis TD. ATMdependent activation of p53 involves dephosphorylation and association with 14-3-3 proteins. Nat Genet 1998 Jun;19(2):175-8.

45. Appella E, Anderson CW. Post-translational modifications and activation of p53 by genotoxic stresses. Eur J Biochem 2001 May;268(10):2764-72.

46. Lee S, Elenbaas B, Levine A, Griffith J. p53 and its 14 kDa C-terminal domain recognize primary DNA damage in the form of insertion/deletion mismatches. Cell 1995 Jun 30;81(7):1013-20.

47. Hupp TR, Sparks A, Lane DP. Small peptides activate the latent sequence-specific DNA binding function of p53. Cell 1995 Oct 20;83(2):237-45.

48. May P, May E. Twenty years of p53 research: structural and functional aspects of the p53 protein. Oncogene 1999 Dec 13;18(53):7621-36.

49. Jayaraman J, Prives C. Activation of p53 sequence-specific DNA binding by short single strands of DNA requires the p53 C-terminus. Cell 1995 Jun 30;81(7):1021-9.

50. Yakovleva T, Pramanik A, Kawasaki T, et al. p53 Latency. C-terminal domain prevents binding of p53 core to target but not to nonspecific DNA sequences. J Biol Chem 2001 May 11;276(19):15650-8. 
51. Hupp TR, Lane DP. Regulation of the cryptic sequence-specific DNAbinding function of p53 by protein kinases. Cold Spring Harb Symp Quant Biol 1994;59:195-206.

52. Foord OS, Bhattacharya P, Reich Z, Rotter V. A DNA binding domain is contained in the C-terminus of wild type p53 protein. Nucleic Acids Res 1991 Oct 11;19(19):5191-8.

53. Anderson ME, Woelker B, Reed M, Wang P, Tegtmeyer P. Reciprocal interference between the sequence-specific core and nonspecific Cterminal DNA binding domains of p53: implications for regulation. Mol Cell Biol 1997 Nov;17(11):6255-64.

54. Ayed A, Mulder FA, Yi GS, Lu Y, Kay LE, Arrowsmith CH. Latent and active p53 are identical in conformation. Nat Struct Biol 2001 Sep;8(9):756-60.

55. Lain S, Xirodimas D, Lane DP. Accumulating active p53 in the nucleus by inhibition of nuclear export: a novel strategy to promote the p53 tumor suppressor function. Exp Cell Res 1999 Dec 15;253(2):315-24.

56. Liang SH, Clarke MF. Regulation of p53 localization. Eur J Biochem 2001 May;268(10):2779-83.

57. Zhang Y, Xiong Y. A p53 amino-terminal nuclear export signal inhibited by DNA damage-induced phosphorylation. Science 2001 Jun 8;292(5523):1910-5.

58. Fabbro M, Henderson BR. Regulation of tumor suppressors by nuclearcytoplasmic shuttling. Exp Cell Res 2003 Jan 15;282(2):59-69.

59. Zhou BB, Elledge SJ. The DNA damage response: putting checkpoints in perspective. Nature 2000 Nov 23;408(6811):433-9.

60. Shiloh Y. ATM and related protein kinases: safeguarding genome integrity. Nat Rev Cancer 2003 Mar;3(3):155-68.

61. Lavin MF, Shiloh Y. The genetic defect in ataxia-telangiectasia. Annu Rev Immunol 1997;15:177-202. 
62. Lozano G, Zambetti GP. What have animal models taught us about the p53 pathway? J Pathol 2005 Jan;205(2):206-20.

63. Canman CE, Lim DS, Cimprich KA, et al. Activation of the ATM kinase by ionizing radiation and phosphorylation of p53. Science 1998 Sep 11;281(5383):1677-9.

64. Barlow C, Liyanage M, Moens PB, Deng CX, Ried T, Wynshaw-Boris A. Partial rescue of the prophase I defects of Atm-deficient mice by p53 and p21 null alleles. Nat Genet 1997 Dec;17(4):462-6.

65. Unsal-Kacmaz K, Makhov AM, Griffith JD, Sancar A. Preferential binding of ATR protein to UV-damaged DNA. Proc Natl Acad Sci U S A 2002 May 14;99(10):6673-8.

66. de Klein A, Muijtjens M, van Os R, et al. Targeted disruption of the cellcycle checkpoint gene ATR leads to early embryonic lethality in mice. Curr Biol 2000 Apr 20;10(8):479-82.

67. Fiscella $\mathrm{M}, \mathrm{U}$ llrich SJ, Zambrano N, et al. Mutation of the serine 15 phosphorylation site of human p53 reduces the ability of p53 to inhibit cell cycle progression. Oncogene 1993 Jun;8(6):1519-28.

68. Lees-Miller SP, Sakaguchi K, Ullrich SJ, Appella E, Anderson CW. Human DNA-activated protein kinase phosphorylates serines 15 and 37 in the amino-terminal transactivation domain of human p53. Mol Cell Biol 1992 Nov;12(11):5041-9.

69. Jhappan C, Yusufzai TM, Anderson S, Anver MR, Merlino G. The p53 response to DNA damage in vivo is independent of DNA-dependent protein kinase. Mol Cell Biol 2000 Jun;20(11):4075-83.

70. Sakaguchi K, Saito S, Higashimoto Y, Roy S, Anderson CW, Appella E. Damage-mediated phosphorylation of human p53 threonine 18 through a cascade mediated by a casein 1-like kinase. Effect on Mdm2 binding. J Biol Chem 2000 Mar 31;275(13):9278-83.

71. Oda K, Arakawa H, Tanaka T, et al. p53AIP1, a potential mediator of p53dependent apoptosis, and its regulation by Ser-46-phosphorylated p53. Cell 2000 Sep 15;102(6):849-62. 
72. Keller DM, Zeng X, Wang Y, et al. A DNA damage-induced p53 serine 392 kinase complex contains CK2, hSpt16, and SSRP1. Mol Cell 2001 Feb;7(2):283-92.

73. Buschmann T, Potapova O, Bar-Shira A, et al. Jun NH2-terminal kinase phosphorylation of p53 on Thr-81 is important for p53 stabilization and transcriptional activities in response to stress. Mol Cell Biol 2001 Apr;21(8):2743-54.

74. Balint EE, Vousden $\mathrm{KH}$. Activation and activities of the p53 tumour suppressor protein. Br J Cancer 2001 Dec 14;85(12):1813-23.

75. Brooks CL, Gu W. p53 ubiquitination: Mdm2 and beyond. Mol Cell 2006 Feb 3;21(3):307-15.

76. Sykes SM, Mellert HS, Holbert MA, et al. Acetylation of the p53 DNAbinding domain regulates apoptosis induction. Mol Cell $2006 \mathrm{Dec}$ 28;24(6):841-51.

77. Lodish H, Berk A, Zipursky SL, Matsudaira P, Baltimore D, Darnell J, editors. Molecular Cell Biology. Fourth ed. New York: W.H. Freeman and Company; 2000.

78. Chen L, Chen J. MDM2-ARF complex regulates p53 sumoylation. Oncogene 2003 Aug 14;22(34):5348-57.

79. Sherr CJ. Divorcing ARF and p53: an unsettled case. Nat Rev Cancer 2006 Sep;6(9):663-73.

80. Weber JD, Jeffers JR, Rehg JE, et al. p53-independent functions of the p19(ARF) tumor suppressor. Genes Dev 2000 Sep 15;14(18):2358-65.

81. Honda $\mathrm{R}$, Tanaka $\mathrm{H}$, Yasuda $\mathrm{H}$. Oncoprotein MDM2 is a ubiquitin ligase E3 for tumor suppressor p53. FEBS Lett 1997 Dec 22;420(1):25-7.

82. Tao W, Levine AJ. Nucleocytoplasmic shuttling of oncoprotein Hdm2 is required for Hdm2-mediated degradation of p53. Proc Natl Acad Sci U S A 1999 Mar 16;96(6):3077-80. 
83. Lu W, Pochampally R, Chen L, Traidej M, Wang Y, Chen J. Nuclear exclusion of p53 in a subset of tumors requires MDM2 function. Oncogene 2000 Jan 13;19(2):232-40.

84. Wu X, Bayle JH, Olson D, Levine AJ. The p53-mdm-2 autoregulatory feedback loop. Genes Dev 1993 Jul;7(7A):1126-32.

85. Lin J, Chen J, Elenbaas B, Levine AJ. Several hydrophobic amino acids in the p53 amino-terminal domain are required for transcriptional activation, binding to mdm-2 and the adenovirus 5 E1B 55-kD protein. Genes Dev 1994 May 15;8(10):1235-46.

86. Lu H, Lin J, Chen J, Levine AJ. The regulation of $p 53$-mediated transcription and the roles of hTAFII31 and mdm-2. Harvey Lect 1994;90:81-93.

87. Thut CJ, Goodrich JA, Tjian R. Repression of p53-mediated transcription by MDM2: a dual mechanism. Genes Dev 1997 Aug 1;11(15):1974-86.

88. Kussie PH, Gorina S, Marechal V, et al. Structure of the MDM2 oncoprotein bound to the p53 tumor suppressor transactivation domain. Science 1996 Nov 8;274(5289):948-53.

89. Kubbutat MH, Ludwig RL, Levine AJ, Vousden $\mathrm{KH}$. Analysis of the degradation function of Mdm2. Cell Growth Differ 1999 Feb;10(2):87-92.

90. Boyd SD, Tsai KY, Jacks T. An intact HDM2 RING-finger domain is required for nuclear exclusion of p53. Nat Cell Biol 2000 Sep;2(9):563-8.

91. Michael D, Oren M. The p53-Mdm2 module and the ubiquitin system. Semin Cancer Biol 2003 Feb;13(1):49-58.

92. Roth J, Dobbelstein M, Freedman DA, Shenk T, Levine AJ. Nucleocytoplasmic shuttling of the hdm2 oncoprotein regulates the levels of the p53 protein via a pathway used by the human immunodeficiency virus rev protein. Embo J 1998 Jan 15;17(2):554-64. 
93. Freedman DA, Levine AJ. Nuclear export is required for degradation of endogenous p53 by MDM2 and human papillomavirus E6. Mol Cell Biol 1998 Dec;18(12):7288-93.

94. Geyer RK, Yu ZK, Maki CG. The MDM2 RING-finger domain is required to promote p53 nuclear export. Nat Cell Biol 2000 Sep;2(9):569-73.

95. Yu ZK, Geyer RK, Maki CG. MDM2-dependent ubiquitination of nuclear and cytoplasmic P53. Oncogene 2000 Nov 30;19(51):5892-7.

96. Li M, Brooks CL, Wu-Baer F, Chen D, Baer R, Gu W. Mono- versus polyubiquitination: differential control of p53 fate by Mdm2. Science 2003 Dec 12;302(5652):1972-5.

97. Montes de Oca Luna R, Wagner DS, Lozano G. Rescue of early embryonic lethality in mdm2-deficient mice by deletion of $\mathrm{p} 53$. Nature 1995 Nov 9;378(6553):203-6.

98. Harris SL, Levine AJ. The p53 pathway: positive and negative feedback loops. Oncogene 2005 Apr 18;24(17):2899-908.

99. el-Deiry WS, Tokino T, Velculescu VE, et al. WAF1, a potential mediator of p53 tumor suppression. Cell 1993 Nov 19;75(4):817-25.

100. Xiong $\mathrm{Y}$, Hannon GJ, Zhang H, Casso D, Kobayashi R, Beach D. p21 is a universal inhibitor of cyclin kinases. Nature 1993 Dec 16;366(6456):701-4.

101. Deng C, Zhang P, Harper JW, Elledge SJ, Leder P. Mice lacking p21CIP1/WAF1 undergo normal development, but are defective in G1 checkpoint control. Cell 1995 Aug 25;82(4):675-84.

102. Taylor WR, Stark GR. Regulation of the G2/M transition by p53. Oncogene 2001 Apr 5;20(15):1803-15.

103. Shibue T, Taniguchi T. BH3-only proteins: integrated control point of apoptosis. Int J Cancer 2006 Nov 1;119(9):2036-43. 
104. Lowe SW, Lin AW. Apoptosis in cancer. Carcinogenesis 2000 Mar;21(3):485-95.

105. Chipuk JE, Green DR. Dissecting p53-dependent apoptosis. Cell Death Differ 2006 Jun;13(6):994-1002.

106. Yee KS, Vousden KH. Complicating the complexity of p53. Carcinogenesis 2005 Aug;26(8):1317-22.

107. Jeffers JR, Parganas E, Lee $\mathrm{Y}$, et al. Puma is an essential mediator of p53-dependent and -independent apoptotic pathways. Cancer Cell 2003 Oct;4(4):321-8.

108. Oda $\mathrm{E}$, Ohki $\mathrm{R}$, Murasawa $\mathrm{H}$, et al. Noxa, a BH3-only member of the $\mathrm{Bcl}-2$ family and candidate mediator of p53-induced apoptosis. Science 2000 May 12;288(5468):1053-8.

109. Nakano K, Vousden KH. PUMA, a novel proapoptotic gene, is induced by p53. Mol Cell 2001 Mar;7(3):683-94.

110. Deng X, Gao F, Flagg T, Anderson J, May WS. Bcl2's flexible loop domain regulates p53 binding and survival. Mol Cell Biol 2006 Jun;26(12):442134.

111. Li FP, Fraumeni JF, Jr. Soft-tissue sarcomas, breast cancer, and other neoplasms. A familial syndrome? Ann Intern Med 1969 Oct;71(4):747-52.

112. Li FP, Fraumeni JF, Jr., Mulvihill JJ, et al. A cancer family syndrome in twenty-four kindreds. Cancer Res 1988 Sep 15;48(18):5358-62.

113. Birch JM, Hartley AL, Tricker KJ, et al. Prevalence and diversity of constitutional mutations in the p53 gene among $21 \mathrm{Li}$-Fraumeni families. Cancer Res 1994 Mar 1;54(5):1298-304.

114. Lustbader ED, Williams WR, Bondy ML, Strom S, Strong LC. Segregation analysis of cancer in families of childhood soft-tissue-sarcoma patients. Am J Hum Genet 1992 Aug;51(2):344-56. 
115. Knudson AG, Jr. Mutation and cancer: statistical study of retinoblastoma. Proc Natl Acad Sci U S A 1971 Apr;68(4):820-3.

116. Varley JM, Evans DG, Birch JM. Li-Fraumeni syndrome--a molecular and clinical review. Br J Cancer 1997;76(1):1-14.

117. Srivastava S, Zou ZQ, Pirollo K, Blattner W, Chang EH. Germ-line transmission of a mutated p53 gene in a cancer-prone family with LiFraumeni syndrome. Nature 1990 Dec 20-27;348(6303):747-9.

118. Malkin D, Li FP, Strong LC, et al. Germ line p53 mutations in a familial syndrome of breast cancer, sarcomas, and other neoplasms. Science 1990 Nov 30;250(4985):1233-8.

119. Nigro JM, Baker SJ, Preisinger AC, et al. Mutations in the p53 gene occur in diverse human tumour types. Nature 1989 Dec 7;342(6250):705-8.

120. Mulligan LM, Matlashewski GJ, Scrable HJ, Cavenee WK. Mechanisms of p53 loss in human sarcomas. Proc Natl Acad Sci U S A 1990 Aug;87(15):5863-7.

121. Bartek J, Bartkova J, Vojtesek B, et al. Patterns of expression of the p53 tumour suppressor in human breast tissues and tumours in situ and in vitro. Int J Cancer 1990 Nov 15;46(5):839-44.

122. Baker SJ, Fearon ER, Nigro JM, et al. Chromosome 17 deletions and p53 gene mutations in colorectal carcinomas. Science $1989 \mathrm{Apr}$ 14;244(4901):217-21.

123. Menon AG, Anderson KM, Riccardi VM, et al. Chromosome 17p deletions and p53 gene mutations associated with the formation of malignant neurofibrosarcomas in von Recklinghausen neurofibromatosis. Proc Natl Acad Sci U S A 1990 Jul;87(14):5435-9.

124. Frebourg $\mathrm{T}$, Barbier N, Yan $\mathrm{YX}$, et al. Germ-line p53 mutations in 15 families with Li-Fraumeni syndrome. Am J Hum Genet 1995 Mar;56(3):608-15. 
125. Varley JM, McGown G, Thorncroft M, et al. Germ-line mutations of TP53 in Li-Fraumeni families: an extended study of 39 families. Cancer Res 1997 Aug 1;57(15):3245-52.

126. Varley JM, McGown G, Thorncroft M, et al. A previously undescribed mutation within the tetramerisation domain of TP53 in a family with LiFraumeni syndrome. Oncogene 1996 Jun 6;12(11):2437-42.

127. Lomax ME, Barnes DM, Gilchrist R, Picksley SM, Varley JM, Camplejohn RS. Two functional assays employed to detect an unusual mutation in the oligomerisation domain of p53 in a Li-Fraumeni like family. Oncogene 1997 Apr 17;14(15):1869-74.

128. Verselis SJ, Rheinwald JG, Fraumeni JF, Jr., Li FP. Novel p53 splice site mutations in three families with Li-Fraumeni syndrome. Oncogene 2000 Aug 31;19(37):4230-5.

129. Ponder B. Cancer. Gene losses in human tumours. Nature 1988 Sep 29;335(6189):400-2.

130. Gelehrter TD, Collins FS, Ginsburg D, editors. Principles of Medical Genetics. Second ed. Baltimore: Williams \& Wilkins; 1998.

131. Varley JM, Thorncroft M, McGown G, et al. A detailed study of loss of heterozygosity on chromosome 17 in tumours from Li-Fraumeni patients carrying a mutation to the TP53 gene. Oncogene 1997 Feb 20;14(7):86571.

132. Mesiano S, Jaffe RB. Developmental and functional biology of the primate fetal adrenal cortex. Endocr Rev 1997 Jun;18(3):378-403.

133. Michalkiewicz E, Sandrini R, Figueiredo B, et al. Clinical and outcome characteristics of children with adrenocortical tumors: a report from the International Pediatric Adrenocortical Tumor Registry. J Clin Oncol 2004 Mar 1;22(5):838-45.

134. Varley JM, McGown G, Thorncroft M, et al. Are there low-penetrance TP53 Alleles? evidence from childhood adrenocortical tumors. Am J Hum Genet 1999 Oct;65(4):995-1006. 
135. Ribeiro RC, Figueiredo B. Childhood adrenocortical tumours. Eur J Cancer 2004 May;40(8):1117-26.

136. Wilkin F, Gagne N, Paquette J, Oligny LL, Deal C. Pediatric adrenocortical tumors: molecular events leading to insulin-like growth factor II gene overexpression. J Clin Endocrinol Metab 2000 May;85(5):2048-56.

137. Rainey WE, Carr BR, Wang ZN, Parker CR, Jr. Gene profiling of human fetal and adult adrenals. J Endocrinol 2001 Nov;171(2):209-15.

138. Giordano TJ, Thomas DG, Kuick R, et al. Distinct transcriptional profiles of adrenocortical tumors uncovered by DNA microarray analysis. Am J Pathol 2003 Feb;162(2):521-31.

139. Boulle N, Logie A, Gicquel C, Perin L, Le Bouc Y. Increased levels of insulin-like growth factor II (IGF-II) and IGF-binding protein-2 are associated with malignancy in sporadic adrenocortical tumors. J Clin Endocrinol Metab 1998 May;83(5):1713-20.

140. Foulstone E, Prince S, Zaccheo O, et al. Insulin-like growth factor ligands, receptors, and binding proteins in cancer. J Pathol 2005 Jan;205(2):14553.

141. Robertson KD. DNA methylation and human disease. Nat Rev Genet 2005 Aug;6(8):597-610.

142. Eggenschwiler J, Ludwig T, Fisher P, Leighton PA, Tilghman SM, Efstratiadis A. Mouse mutant embryos overexpressing IGF-II exhibit phenotypic features of the Beckwith-Wiedemann and Simpson-GolabiBehmel syndromes. Genes Dev 1997 Dec 1;11(23):3128-42.

143. Weber MM, Fottner C, Schmidt P, et al. Postnatal overexpression of insulin-like growth factor II in transgenic mice is associated with adrenocortical hyperplasia and enhanced steroidogenesis. Endocrinology 1999 Apr;140(4):1537-43.

144. Figueiredo BC, Stratakis CA, Sandrini R, et al. Comparative genomic hybridization analysis of adrenocortical tumors of childhood. J Clin Endocrinol Metab 1999 Mar;84(3):1116-21. 
145. Ozisik G, Achermann JC, Jameson JL. The role of SF1 in adrenal and reproductive function: insight from naturally occurring mutations in humans. Mol Genet Metab 2002 Jun;76(2):85-91.

146. Luo X, Ikeda Y, Parker KL. A cell-specific nuclear receptor is essential for adrenal and gonadal development and sexual differentiation. Cell 1994 May 20;77(4):481-90.

147. Pianovski MA, Cavalli LR, Figueiredo BC, et al. SF-1 overexpression in childhood adrenocortical tumours. Eur J Cancer 2006 May;42(8):1040-3.

148. Barzon L, Chilosi M, Fallo F, et al. Molecular analysis of CDKN1C and TP53 in sporadic adrenal tumors. Eur J Endocrinol 2001 Aug;145(2):20712.

149. Wagner J, Portwine C, Rabin K, Leclerc JM, Narod SA, Malkin D. High frequency of germline p53 mutations in childhood adrenocortical cancer. J Natl Cancer Inst 1994 Nov 16;86(22):1707-10.

150. Chompret A, Brugieres L, Ronsin M, et al. P53 germline mutations in childhood cancers and cancer risk for carrier individuals. Br J Cancer 2000 Jun;82(12):1932-7.

151. DiGiammarino EL, Lee AS, Cadwell C, et al. A novel mechanism of tumorigenesis involving $\mathrm{pH}$-dependent destabilization of a mutant p53 tetramer. Nat Struct Biol 2002 Jan;9(1):12-6.

152. Figueiredo BC, Sandrini R, Zambetti GP, et al. Penetrance of adrenocortical tumours associated with the germline TP53 R337H mutation. J Med Genet 2006 Jan;43(1):91-6.

153. Achatz MI, Olivier M, Le Calvez F, et al. The TP53 mutation, R337H, is associated with Li-Fraumeni and Li-Fraumeni-like syndromes in Brazilian families. Cancer Lett 2007 Jan 8;245(1-2):96-102.

154. Ribeiro RC, Rodriguez-Galindo C, Figueiredo BC, et al. Germline TP53 $\mathrm{R} 337 \mathrm{H}$ mutation is not sufficient to establish Li-Fraumeni or Li-Fraumenilike syndrome. Cancer Lett 2007 Mar 18;247(2):353-5; author reply 6-8. 
155. Villunger A, Michalak EM, Coultas L, et al. p53- and drug-induced apoptotic responses mediated by $\mathrm{BH} 3$-only proteins puma and noxa. Science 2003 Nov 7;302(5647):1036-8.

156. Vogelstein B, Lane D, Levine AJ. Surfing the p53 network. Nature 2000 Nov 16;408(6810):307-10.

157. Sandrini R, Ribeiro RC, DeLacerda L. Childhood adrenocortical tumors. J Clin Endocrinol Metab $1997 \mathrm{Jul} ; 82(7): 2027-31$.

158. Kleihues $P$, Schauble B, zur Hausen A, Esteve J, Ohgaki H. Tumors associated with p53 germline mutations: a synopsis of 91 families. Am $\mathrm{J}$ Pathol 1997 Jan;150(1):1-13.

159. Figueiredo BC, Sandrini R, Zambetti GP, et al. Penetrance of Adrenocortical Tumors Associated with the Germline TP53 R337H Mutation. J Med Genet 2005 Jul 20.

160. Hollstein M, Shomer B, Greenblatt M, et al. Somatic point mutations in the p53 gene of human tumors and cell lines: updated compilation. Nucleic Acids Res 1996 Jan 1;24(1):141-6.

161. Graesmann A, Graesmann M. Microinjection and Organelle Transplantation Techniques: Methods and Applications. London: Academic Press; 1986.

162. Zambetti GP, Bargonetti J, Walker K, Prives C, Levine AJ. Wild-type p53 mediates positive regulation of gene expression through a specific DNA sequence element. Genes Dev 1992 Jul;6(7):1143-52.

163. Zambetti GP, Levine AJ. A comparison of the biological activities of wildtype and mutant p53. Faseb J 1993 Jul;7(10):855-65.

164. Cadwell C, Zambetti GP. The effects of wild-type p53 tumor suppressor activity and mutant p53 gain-of-function on cell growth. Gene 2001 Oct 17;277(1-2):15-30. 
165. Birch JM, Blair V, Kelsey AM, et al. Cancer phenotype correlates with constitutional TP53 genotype in families with the Li-Fraumeni syndrome. Oncogene 1998 Sep 3;17(9):1061-8.

166. Bougeard G, Limacher JM, Martin C, et al. Detection of 11 germline inactivating TP53 mutations and absence of TP63 and HCHK2 mutations in 17 French families with Li-Fraumeni or Li-Fraumeni-like syndrome. J Med Genet 2001 Apr;38(4):253-7.

167. Ory K, Legros Y, Auguin C, Soussi T. Analysis of the most representative tumour-derived p53 mutants reveals that changes in protein conformation are not correlated with loss of transactivation or inhibition of cell proliferation. Embo J 1994 Aug 1;13(15):3496-504.

168. Ryan KM, Vousden $\mathrm{KH}$. Characterization of structural p53 mutants which show selective defects in apoptosis but not cell cycle arrest. Mol Cell Biol 1998 Jul;18(7):3692-8.

169. Liu G, Parant JM, Lang G, et al. Chromosome stability, in the absence of apoptosis, is critical for suppression of tumorigenesis in Trp53 mutant mice. Nat Genet 2004 Jan;36(1):63-8.

170. Barnes DM, Hanby AM, Gillett CE, et al. Abnormal expression of wild type p53 protein in normal cells of a cancer family patient. Lancet 1992 Aug 1;340(8814):259-63.

171. Olive KP, Tuveson DA, Ruhe ZC, et al. Mutant p53 gain of function in two mouse models of Li-Fraumeni syndrome. Cell 2004 Dec 17;119(6):847-60.

172. Lang GA, Iwakuma T, Suh YA, et al. Gain of function of a p53 hot spot mutation in a mouse model of Li-Fraumeni syndrome. Cell $2004 \mathrm{Dec}$ $17 ; 119(6): 861-72$.

173. Parkin DM, Kramarova E, Draper GJ, et al., editors. International Incidence of Childhood Cancer, Vol. II, IARC Scientific Publication No. 144. Lyon: IARCPress; 1998.

174. Zancanella P, Pianovski MA, Oliveira BH, et al. Mitotane associated with cisplatin, etoposide, and doxorubicin in advanced childhood adrenocortical 
carcinoma: mitotane monitoring and tumor regression. J Pediatr Hematol Oncol 2006 Aug;28(8):513-24.

175. Else T, Hammer GD. Genetic analysis of adrenal absence: agenesis and aplasia. Trends Endocrinol Metab 2005 Dec;16(10):458-68.

176. Gicquel C, Bertherat J, Le Bouc Y, Bertagna X. Pathogenesis of adrenocortical incidentalomas and genetic syndromes associated with adrenocortical neoplasms. Endocrinol Metab Clin North Am 2000 Mar;29(1):1-13, vii.

177. Li M, Squire JA, Weksberg R. Molecular genetics of Wiedemann-Beckwith syndrome. Am J Med Genet 1998 Oct 2;79(4):253-9.

178. Longui CA, Lemos-Marini SH, Figueiredo B, et al. Inhibin alpha-subunit (INHA) gene and locus changes in paediatric adrenocortical tumours from TP53 R337H mutation heterozygote carriers. J Med Genet 2004 May;41(5):354-9.

179. Figueiredo BC, Cavalli LR, Pianovski MA, et al. Amplification of the steroidogenic factor 1 gene in childhood adrenocortical tumors. J Clin Endocrinol Metab 2005 Feb;90(2):615-9.

180. Gicquel C, Bertagna X, Le Bouc Y. Recent advances in the pathogenesis of adrenocortical tumours. Eur J Endocrinol 1995 Aug;133(2):133-44.

181. Livak KJ, Schmittgen TD. Analysis of relative gene expression data using real-time quantitative PCR and the 2(-Delta Delta C(T)) Method. Methods 2001 Dec;25(4):402-8.

182. Pounds S, Cheng C. Statistical development and evaluation of microarray gene expression data filters. J Comput Biol 2005 May;12(4):482-95.

183. Wilcoxon F. Individual comparisons by ranking methods. Biometrika 1949;1:80-3.

184. Pounds S, Cheng C. Robust estimation of the false discovery rate. Bioinformatics 2006 Aug 15;22(16):1979-87. 
185. Sheskin D. Handbook of Parametric and Nonparametric Statistical Procedures. Third ed. Boca Raton: Chapman \& Hall/CRC Press; 2003.

186. Peto R, Pike MC, Armitage $P$, et al. Design and analysis of randomized clinical trials requiring prolonged observation of each patient. II. analysis and examples. Br J Cancer 1977 Jan;35(1):1-39.

187. West AN, Neale GA, Pounds S, et al. Gene expression profiling of childhood adrenocortical tumors. Cancer Res 2007 Jan 15;67(2):600-8.

188. Bange J, Prechtl D, Cheburkin $Y$, et al. Cancer progression and tumor cell motility are associated with the FGFR4 Arg(388) allele. Cancer Res 2002 Feb 1;62(3):840-7.

189. de Fraipont F, El Atifi M, Cherradi N, et al. Gene expression profiling of human adrenocortical tumors using complementary deoxyribonucleic Acid microarrays identifies several candidate genes as markers of malignancy. J Clin Endocrinol Metab 2005 Mar;90(3):1819-29.

190. Martinerie C, Gicquel C, Louvel A, Laurent M, Schofield PN, Le Bouc Y. Altered expression of novH is associated with human adrenocortical tumorigenesis. J Clin Endocrinol Metab 2001 Aug;86(8):3929-40.

191. Simard J, Ricketts ML, Gingras S, Soucy P, Feltus FA, Melner MH. Molecular biology of the 3beta-hydroxysteroid dehydrogenase/delta5delta4 isomerase gene family. Endocr Rev 2005 Jun;26(4):525-82.

192. Bassett MH, Suzuki T, Sasano H, et al. The orphan nuclear receptor NGFIB regulates transcription of 3beta-hydroxysteroid dehydrogenase. implications for the control of adrenal functional zonation. J Biol Chem 2004 Sep 3;279(36):37622-30.

193. Arrighi I, Bloch-Faure M, Grahammer F, et al. Altered potassium balance and aldosterone secretion in a mouse model of human congenital long QT syndrome. Proc Natl Acad Sci U S A 2001 Jul 17;98(15):8792-7.

194. Marx C, Wolkersdorfer GW, Brown JW, Scherbaum WA, Bornstein SR. $\mathrm{MHC}$ class II expression--a new tool to assess dignity in adrenocortical tumours. J Clin Endocrinol Metab 1996 Dec;81(12):4488-91. 
195. Marx C, Bornstein SR, Wolkersdorfer GW, Peter M, Sippell WG, Scherbaum WA. Relevance of major histocompatibility complex class II expression as a hallmark for the cellular differentiation in the human adrenal cortex. J Clin Endocrinol Metab 1997 Sep;82(9):3136-40.

196. Gicquel C, Raffin-Sanson ML, Gaston V, et al. Structural and functional abnormalities at $11 \mathrm{p} 15$ are associated with the malignant phenotype in sporadic adrenocortical tumors: study on a series of 82 tumors. J Clin Endocrinol Metab 1997 Aug;82(8):2559-65.

197. Duguay SJ, Jin Y, Stein J, Duguay AN, Gardner P, Steiner DF. Posttranslational processing of the insulin-like growth factor-2 precursor. Analysis of O-glycosylation and endoproteolysis. J Biol Chem $1998 \mathrm{Jul}$ 17;273(29):18443-51.

198. Mesiano S, Mellon SH, Jaffe RB. Mitogenic action, regulation, and localization of insulin-like growth factors in the human fetal adrenal gland. J Clin Endocrinol Metab 1993 Apr;76(4):968-76.

199. Boulle N, Gicquel C, Logie A, Christol R, Feige JJ, Le Bouc Y. Fibroblast growth factor-2 inhibits the maturation of pro-insulin-like growth factor-II (Pro-IGF-II) and the expression of insulin-like growth factor binding protein-2 (IGFBP-2) in the human adrenocortical tumor cell line NClH295R. Endocrinology 2000 Sep;141(9):3127-36.

200. Hornsby PJ, Sturek M, Harris SE, Simonian MH. Serum and growth factor requirements for proliferation of human adrenocortical cells in culture: comparison with bovine adrenocortical cells. In Vitro 1983 Nov;19(11):863-9.

201. Crickard K, III CR, Jaffe RB. Control of proliferation of human fetal adrenal cells in vitro. J Clin Endocrinol Metab 1981 Oct;53(4):790-6.

202. Sell S. Cellular origin of cancer: dedifferentiation or stem cell maturation arrest? Environ Health Perspect 1993 Dec;101 Suppl 5:15-26.

203. Bell DW, Varley JM, Szydlo TE, et al. Heterozygous germ line hCHK2 mutations in Li-Fraumeni syndrome. Science $1999 \mathrm{Dec}$ 24;286(5449):2528-31. 
204. Chompret A, Abel A, Stoppa-Lyonnet D, et al. Sensitivity and predictive value of criteria for p53 germline mutation screening. J Med Genet 2001 Jan;38(1):43-7.

205. Varley J. TP53, hChk2, and the Li-Fraumeni syndrome. Methods Mol Biol 2003;222:117-29.

206. Peterson SK, Pentz RD, Blanco AM, et al. Evaluation of a decision aid for families considering p53 genetic counseling and testing. Genet Med 2006 Apr;8(4):226-33.

207. Malkin D. Predictive genetic testing for childhood cancer: taking the road less traveled by. J Pediatr Hematol Oncol 2004 Sep;26(9):546-8.

208. Campomenosi $\mathrm{P}$, Monti $\mathrm{P}$, Aprile A, et al. p53 mutants can often transactivate promoters containing a p21 but not Bax or PIG3 responsive elements. Oncogene 2001 Jun 14;20(27):3573-9.

209. Beckman G, Birgander R, Sjalander A, et al. Is p53 polymorphism maintained by natural selection? Hum Hered 1994 Sep-Oct;44(5):266-70.

210. Dumont $\mathrm{P}$, Leu JI, Della Pietra AC, 3rd, George DL, Murphy M. The codon 72 polymorphic variants of p53 have markedly different apoptotic potential. Nat Genet 2003 Mar;33(3):357-65.

211. Hu Z, Miao X, Ma H, et al. Dinucleotide polymorphism of $p 73$ gene is associated with a reduced risk of lung cancer in a Chinese population. Int J Cancer 2005 Apr 10;114(3):455-60.

212. Zhu ZZ, Cong WM, Liu SF, et al. A p53 polymorphism modifies the risk of hepatocellular carcinoma among non-carriers but not carriers of chronic hepatitis B virus infection. Cancer Lett 2005 Nov 8;229(1):77-83.

213. Tommiska J, Eerola $\mathrm{H}$, Heinonen $\mathrm{M}$, et al. Breast cancer patients with $\mathrm{p} 53$ Pro72 homozygous genotype have a poorer survival. Clin Cancer Res 2005 Jul 15;11(14):5098-103. 
214. Koushik A, Tranah GJ, Ma J, et al. p53 Arg72Pro polymorphism and risk of colorectal adenoma and cancer. Int J Cancer 2006 Oct 15;119(8):18638.

215. Mitra S, Misra C, Singh RK, Panda CK, Roychoudhury S. Association of specific genotype and haplotype of p53 gene with cervical cancer in India. J Clin Pathol 2005 Jan;58(1):26-31.

216. Granja F, Morari J, Morari EC, Correa LA, Assumpcao LV, Ward LS. Proline homozygosity in codon 72 of p53 is a factor of susceptibility for thyroid cancer. Cancer Lett 2004 Jul 16;210(2):151-7.

217. McGregor JM, Harwood CA, Brooks L, et al. Relationship between p53 codon 72 polymorphism and susceptibility to sunburn and skin cancer. $\mathrm{J}$ Invest Dermatol 2002 Jul;119(1):84-90.

218. Felley-Bosco E, Weston A, Cawley HM, Bennett WP, Harris CC. Functional studies of a germ-line polymorphism at codon 47 within the p53 gene. Am J Hum Genet 1993 Sep;53(3):752-9.

219. Kononen J, Bubendorf L, Kallioniemi A, et al. Tissue microarrays for highthroughput molecular profiling of tumor specimens. Nat Med 1998 Jul;4(7):844-7.

220. Russo G, Zegar C, Giordano A. Advantages and limitations of microarray technology in human cancer. Oncogene 2003 Sep 29;22(42):6497-507.

221. Golub TR, Slonim DK, Tamayo P, et al. Molecular classification of cancer: class discovery and class prediction by gene expression monitoring. Science 1999 Oct 15;286(5439):531-7.

222. Ross ME, Zhou X, Song G, et al. Classification of pediatric acute lymphoblastic leukemia by gene expression profiling. Blood 2003 Oct 15;102(8):2951-9.

223. Gruvberger S, Ringner M, Chen $\mathrm{Y}$, et al. Estrogen receptor status in breast cancer is associated with remarkably distinct gene expression patterns. Cancer Res 2001 Aug 15;61(16):5979-84. 
224. Hedenfalk I, Duggan D, Chen Y, et al. Gene-expression profiles in hereditary breast cancer. N Engl J Med 2001 Feb 22;344(8):539-48.

225. van 't Veer LJ, Dai H, van de Vijver MJ, et al. Gene expression profiling predicts clinical outcome of breast cancer. Nature 2002 Jan 31;415(6871):530-6.

226. Sorlie T, Perou CM, Tibshirani R, et al. Gene expression patterns of breast carcinomas distinguish tumor subclasses with clinical implications. Proc Natl Acad Sci U S A 2001 Sep 11;98(19):10869-74.

227. Robison JE, Perreard L, Bernard PS. State of the science: molecular classifications of breast cancer for clinical diagnostics. Clin Biochem 2004 Jul;37(7):572-8.

228. Reik W, Davies K, Dean W, Kelsey G, Constancia M. Imprinted genes and the coordination of fetal and postnatal growth in mammals. Novartis Found Symp 2001;237:19-31; discussion -42 .

229. Itoh N, Ornitz DM. Evolution of the Fgf and Fgfr gene families. Trends Genet 2004 Nov;20(11):563-9.

230. Wolkersdorfer GW, Marx C, Brown J, et al. Prevalence of HLA-DRB1 genotype and altered Fas/Fas ligand expression in adrenocortical carcinoma. J Clin Endocrinol Metab 2005 Mar;90(3):1768-74.

231. Ungefroren $H$, Voss $M$, Bernstorff $W V$, Schmid A, Kremer B, Kalthoff $H$. Immunological escape mechanisms in pancreatic carcinoma. Ann N Y Acad Sci 1999 Jun 30;880:243-51. 


\section{APPENDIX A: CHAPTER 2 SUPPLEMENTAL DATA}

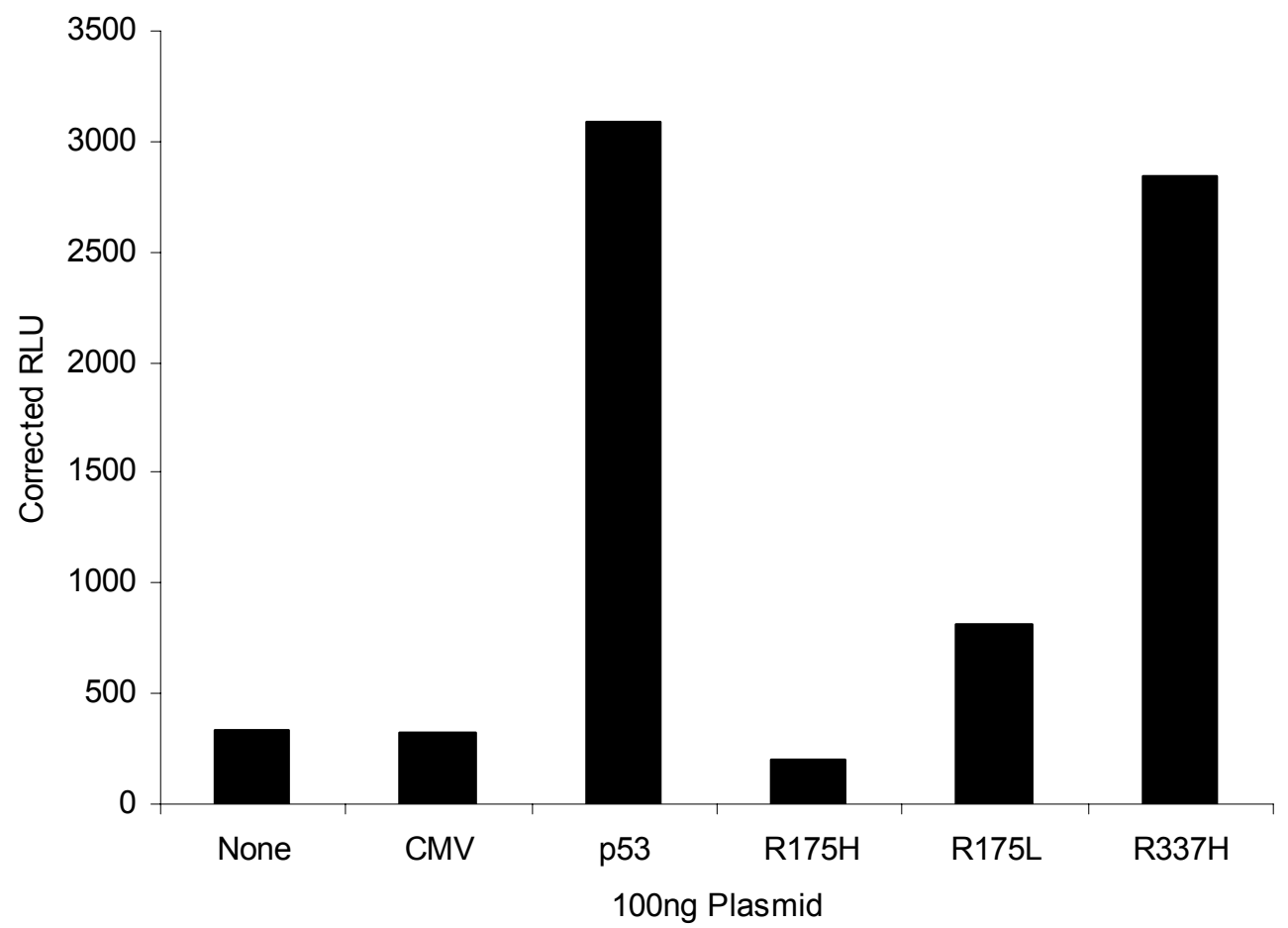

Figure A-1. Transactivation of the Wild-Type p53 Responsive PromoterLuciferase Reporter by WTp53 and Mutant p53 Proteins in 10(1) Cell Line. CMV p53 expression plasmids (100ng) were transfected in duplicate and reporter activity measured as described in the Materials and Methods (Section 2.2). 

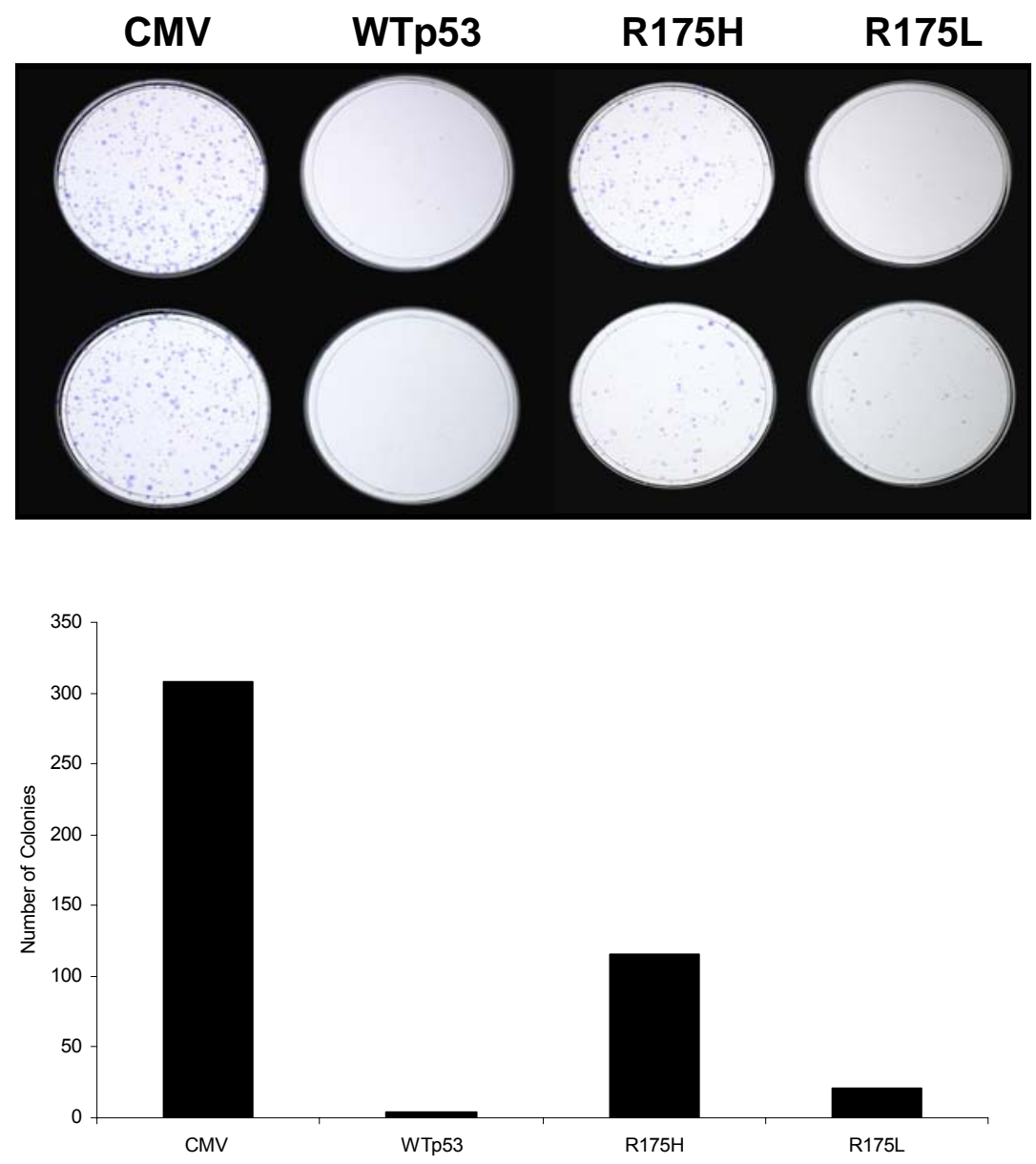

Figure A-2. p53 Colony Reduction Assay Using Increased Plasmid Dose. SaOS-2 cells were transfected in duplicate with $1 \mu \mathrm{g}$ CMV p53 expression plasmids and selected by neomycin (G418) resistance. Colonies were stained by Giemsa dye and photographed (upper panel) and subsequently counted (lower panel). 


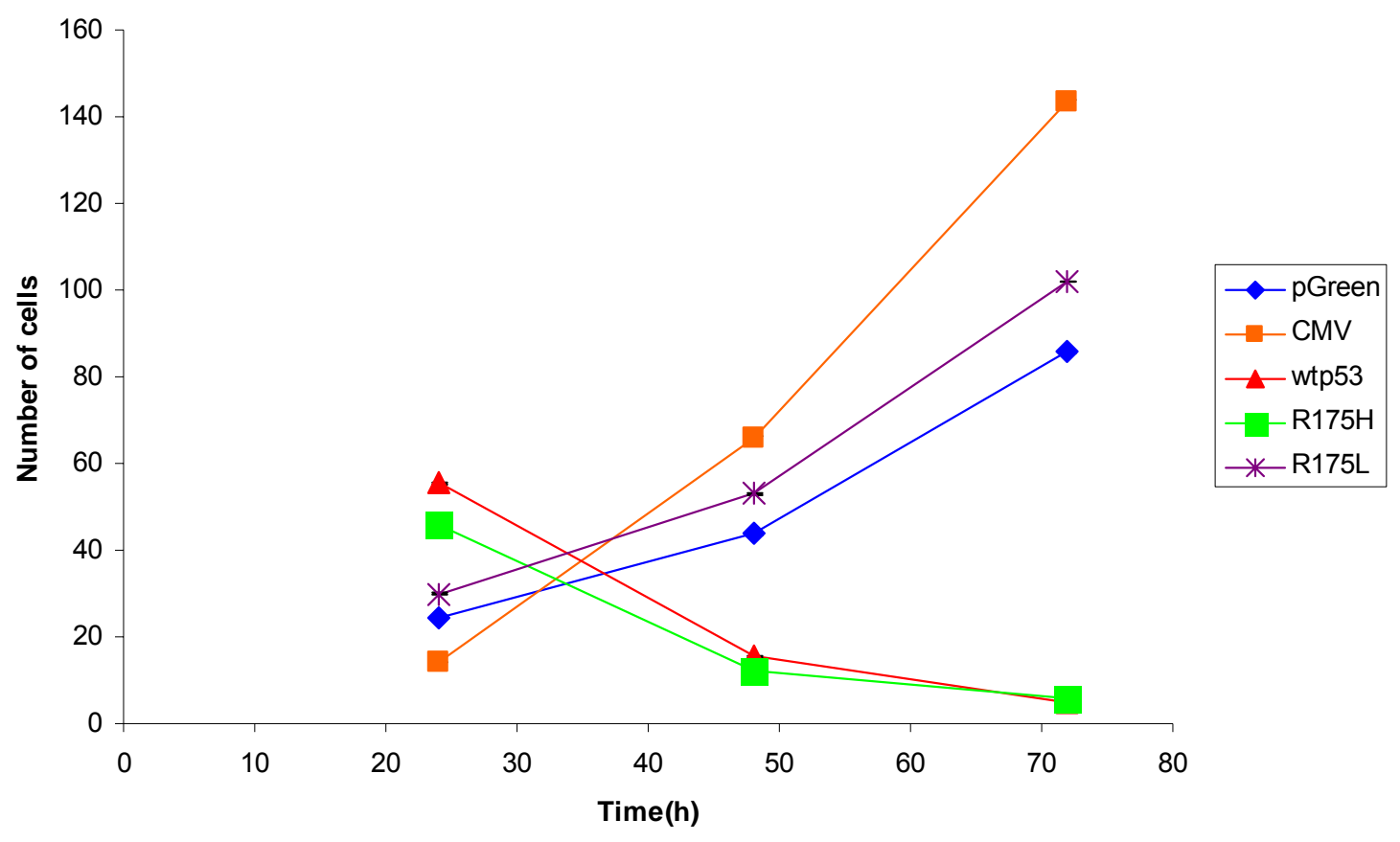

Figure A-3. Quantitation of p53 Apoptosis in H1299 Cell Line. H1299 cells were plated at $4 \times 10^{3}$ per $35 \mathrm{~mm}^{2}$ dish and co-microinjected with pGreenLantern (GFP) and CMV p53 expression plasmids and monitored for apoptosis as described in Materials and Methods. H1299 cells counted at 24, 48, and 72 hours. Representative of three independent experiments. 
APPENDIX B: CHAPTER 3 SUPPLEMENTAL DATA

Table B-1. qRT-PCR Primer Set Sequences and PCR Conditions.

\begin{tabular}{|c|c|c|c|c|}
\hline & Gene & Primer & Sequence & PCR Conditions \\
\hline \multicolumn{5}{|c|}{ Set 1} \\
\hline & IGF-II & Forward & 5'-CTTCTACTTCAGCAGGCCCG-3' & \multirow{4}{*}{$\begin{array}{l}95^{\circ} \mathrm{C}-3^{\prime}-1 \mathrm{x} \\
95^{\circ} \mathrm{C}-10^{\prime \prime}, 61.2^{\circ} \mathrm{C}-45^{\prime \prime}-40 \mathrm{x} \\
95^{\circ} \mathrm{C}-1^{\prime}, 55^{\circ} \mathrm{C}-1^{\prime}-1 \mathrm{x} \\
55^{\circ} \mathrm{C}-10^{\prime \prime}-80 \mathrm{x}\end{array}$} \\
\hline & & Reverse & 5'-TAGCACAGTACGTCTCCAGGA-3' & \\
\hline & NOV & Forward & 5'-CACGGCGGTAGAGGGAGATA-3' & \\
\hline & & Reverse & 5'-GGGTAAGGCCTCCCAGTGAA-3' & \\
\hline \multicolumn{5}{|c|}{ 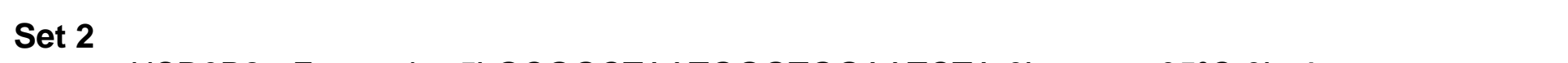 } \\
\hline & HSD3B2 & Forward & 5'-GCGGCTAATGGGTGGAATCTA-3' & \multirow{4}{*}{$\begin{array}{l}95^{\circ} \mathrm{C}-3^{\prime}-1 \mathrm{x} \\
95^{\circ} \mathrm{C}-10^{\prime \prime}, 64.3^{\circ} \mathrm{C}-45^{\prime \prime}-\mathbf{3 8 x} \\
95^{\circ} \mathrm{C}-1^{\prime}, 55^{\circ} \mathrm{C}-1^{\prime}-1 \mathrm{x} \\
55^{\circ} \mathrm{C}-10^{\prime \prime}-\mathbf{8 0 x}\end{array}$} \\
\hline & & Reverse & 5'-CATTGTTGTTCAGGGCCTCAT-3' & \\
\hline & NR4A1 & Forward & 5'-AAGCCACATTGTTGCCAAGACCTG-3' & \\
\hline & & Reverse & 5'-TGGTGTCCCATATTGGGCTTGGAT-3' & \\
\hline & NR4A2 & Forward & 5'-GGCTTCTTTAAGCGCACAGTGCAA-3' & \\
\hline & & Reverse & 5'-TGAAATCGGCAGTACTGACAGCGA-3' & \\
\hline & FGFR4 & Forward & 5'-TGATGGCCCAAATGTCAGGGTTCT-3' & \\
\hline & & Reverse & 5'-TTTAGCATAGCAGCTCTCCAGCCA-3' & \\
\hline
\end{tabular}


NOV

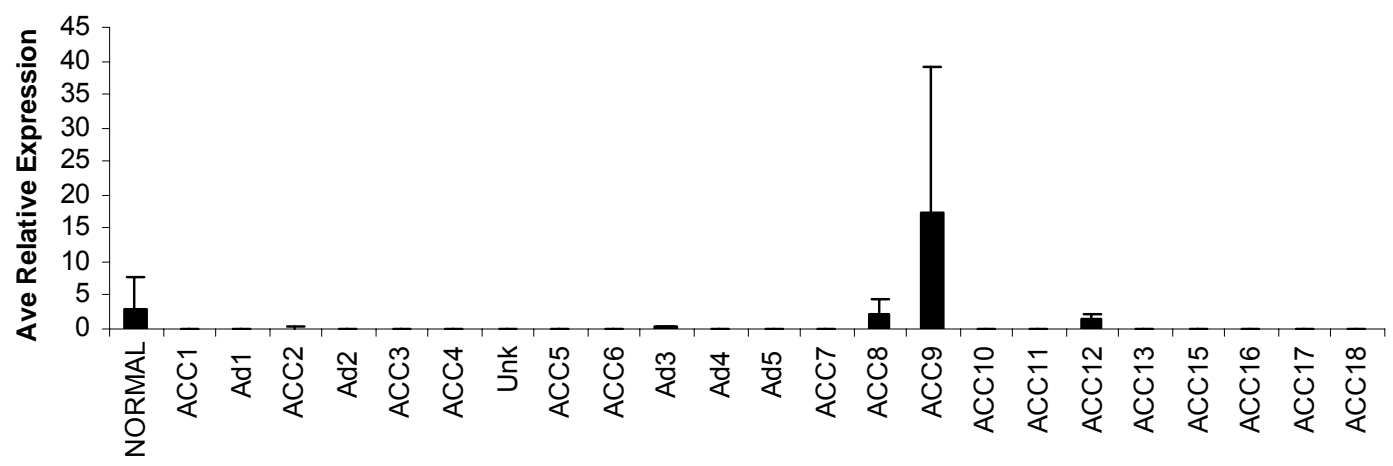

Figure B-1. NOV Gene Dysregulation in Pediatric Adrenocortical Cancer. NOV transcripts are markedly lower in adrenal tumors than in normal tissue. 


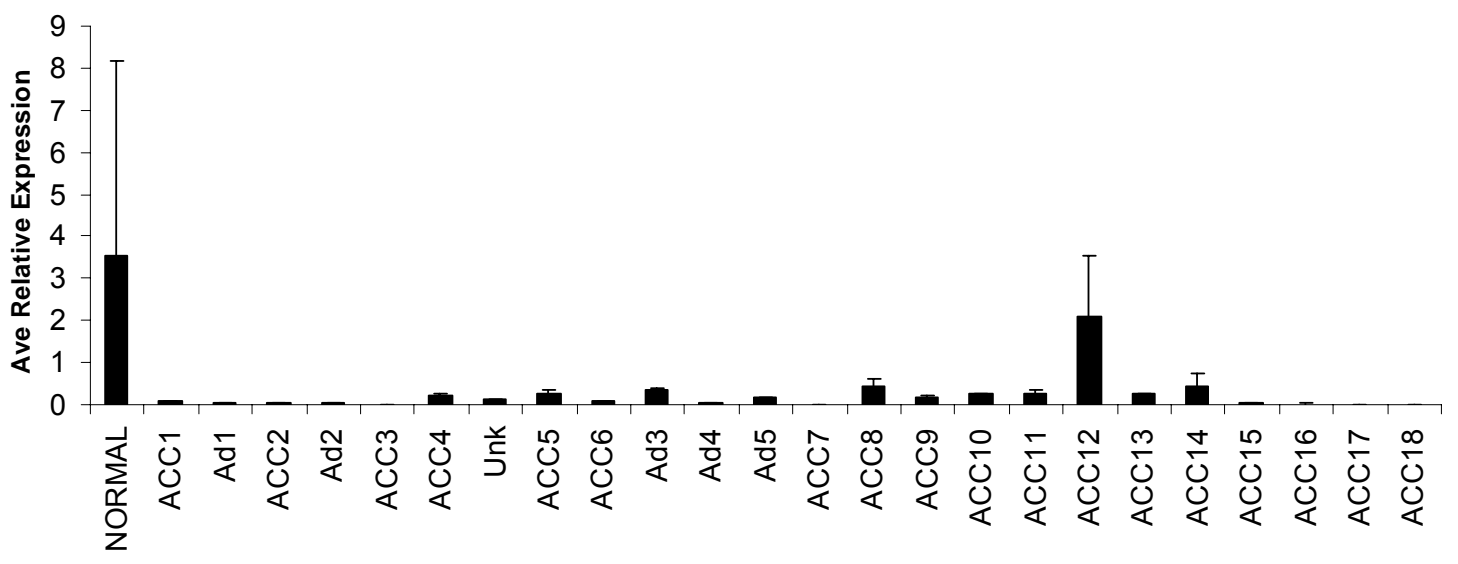

Figure B-2. Dysregulation of NR4A1 Gene Expression in Pediatric Adrenocortical Cancer. NR4A1 transcripts are markedly lower in adrenal tumors than in normal tissue. 
NR4A2

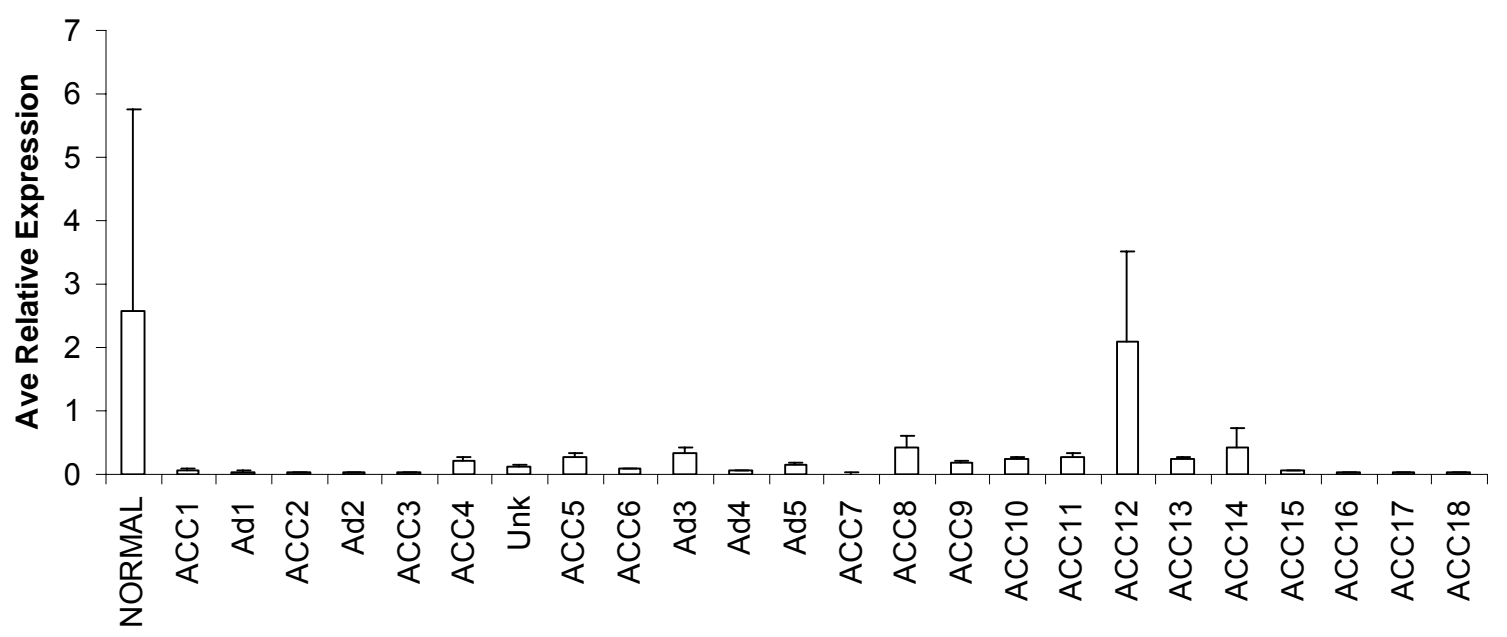

Figure B-3. NR4A2 Gene Dysregulation in Pediatric Adrenocortical Cancer. NR4A2 transcripts are markedly lower in adrenal tumors than in normal tissue. 


\section{VITA}

Alina Nico West was born on May 27, 1976 in Memphis, Tennessee. Nico received her Bachelor of Science degree in Biology and Psychology from the University of Memphis in Memphis, Tennessee in 1999. She joined the Interdisciplinary Sciences Program at the University of Tennessee Health Sciences Center in August 2001 and began her research project in the laboratory of Dr. Gerard Zambetti in June 2002. Nico has plans to graduate from the Interdisciplinary Sciences Program in December 2007. 